\title{
Performance of 1/3-Scale Model Precast Concrete Beam-Column Connections Subjected to Cyclic Inelastic Loads - Report No. 4
}

QC

100

.056

N0. 5436

1994

Building and Fire Research Laboratory

Gaithersburg, Maryland 20899

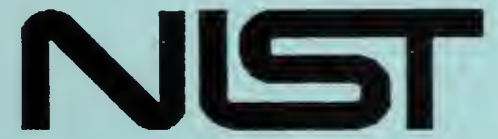

United States Department of Commerce Technology Administration

National Institute of Standards and Technology 



\section{Performance of 1/3-Scale Model Precast Concrete Beam-Column Connections Subjected to Cyclic Inelastic Loads - Report No. 4}

Geraldine S. Cheok

William C. Stone

June 1994

Building and Fire Research Laboratory

National Institute of Standards and Technology

Gaithersburg, MD 20899

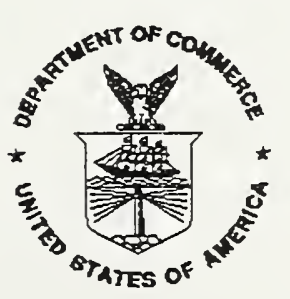

U.S. Department of Commerce

Ronald H. Brown, Secretary

Technology Administration

Mary L. Good, Under Secretary for Technology

National Institute of Standards and Technology

Arati Prabhakar, Director 



\begin{abstract}
Test results of four hybrid post-tensioned concrete beam-to-column connections are presented. These tests constitute Phase IV B of an experimental program on 1/3-scale model precast moment resisting connections being conducted at the National Institute of Standards and Technology (NIST). The objective of the test program is to develop guidelines for the design of moment resistant precast connections in regions of high seismicity.

The hybrid connections consist of mild steel used as energy dissipators and post-tensioning steel used to provide the required shear resistance. Variables examined were different amounts and type of mild steel. The amount of post-tensioning steel was kept constant. The specimens were subjected to reversed cyclic loading in accordance with a prescribed displacement history. The performances of the connections were evaluated based on comparisons of energy dissipation capacity, connection strength, and drift capacity with previous NIST tests (Phases I - IV A).
\end{abstract}

The results show that a hybrid precast connection can be designed so that it matches the performance of a monolithic connection in terms of energy dissipation, strength, and drift capacity.

KEYWORDS: Building Technology, beam-column, concrete, connections, cyclic loading, joint, precast, post-tensioning, story drift. 



\section{CONTENTS}

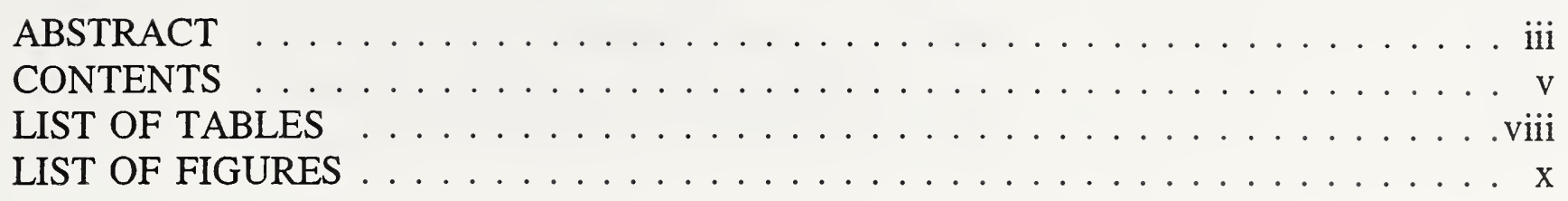

$1 . \mathrm{O}$ INTRODUCTION $\ldots \ldots \ldots \ldots \ldots \ldots \ldots \ldots \ldots \ldots$

2.0 PHASE IV SPECIMEN DESCRIPTION, DETAILS AND TEST PROCEDURE . . 3

2.1 Summary of Phase IV A Results . . . . . . . . . . . . . . 3

2.2 Phase IV B Specimens . . . . . . . . . . . . . . . . . 5

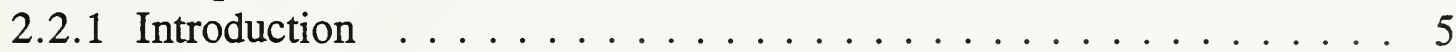

2.2.2 Specimen Details . . . . . . . . . . . . . . . 8

2.3 Post-tensioning and Grouting Procedures . . . . . . . . . . . . 13

2.4 Test Procedure . . . . . . . . . . . . . . . . . . . . . . . . 14

3.0 DISCUSSION OF TEST RESULTS . . . . . . . . . . . . . . . . . . . 17

3.1 Failure Mode . . . . . . . . . . . . . . . . . . . . 17

3.1.1 Specimen M-P-Z4 (2 - \#3, Grade 60 reinforcing bars,

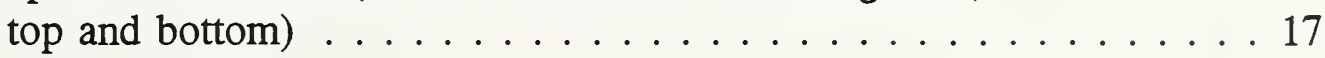

3.1.2 Specimen N-P-Z4 ( 2 - $9 \mathrm{~mm} \phi, 304$ stainless steel bars,

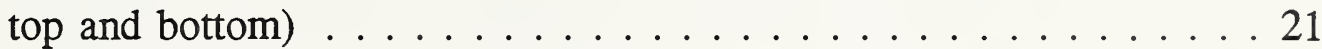

3.1.3 Specimen O-P-Z4 (3 - \#3, Grade 60, reinforcing bar,

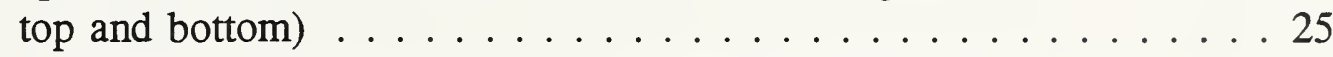

3.1.4 Specimen P-P-Z4 ( 3 - $9 \mathrm{~mm} \phi$, 304 stainless steel bars,

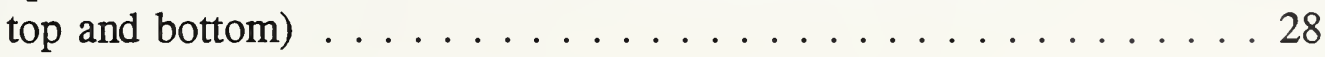

3.2 Story Drift . . . . . . . . . . . . . . . . . 32

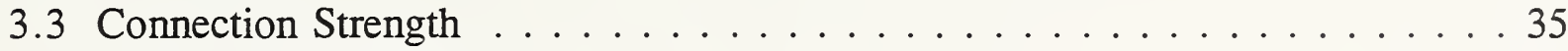

3.4 Energy Dissipation . . . . . . . . . . . . . . . 36

4.0 CONCLUSIONS AND FUTURE RESEARCH . . . . . . . . . . . . . . . . . 39

4.1 Summary and Conclusions . . . . . . . . . . . . . . . . 39

4.2 Code Implications . . . . . . . . . . . . . . . . . . . . . 39

4.2 Future Research . . . . . . . . . . . . . . . . . . . . . . 40

ACKNOWLEDGEMENTS . . . . . . . . . . . . . . . . . . . 41

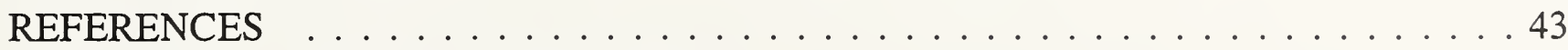

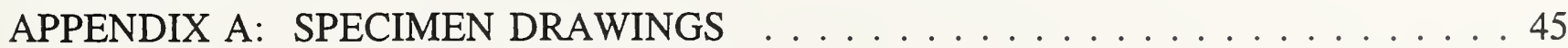

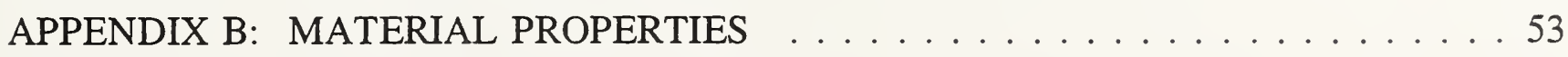

APPENDIX C: ORGANIZATIONAL CHART . . . . . . . . . . . . 59 



\section{LIST OF TABLES}

Table 2.1. Description of NIST Precast Connections . . . . . . . . . . . . . . . 4

Table 2.2. Strand Forces at Start of Test. . . . . . . . . . . . . . . . 13

Table 3.1. Peak Stresses and Residual Forces in PT Steel. . . . . . . . . . . . . . 21

Table 3.2. Connection Strengths and Story Drifts . . . . . . . . . . . . . . . 33

Table B.1. Compressive Strengths of Concrete and Grout. . . . . . . . . . . 53 



\section{LIST OF FIGURES}

Figure 2.1.

Figure 2.2.

Figure 2.3.

Figure 2.5.

Figure 2.6.

Figure 2.7.

Figure 2.7.

Figure 2.8 .

Figure 2.9.

Figure 2.10.

Figure 3.1.

Figure 3.2.

Figure 3.3.

Figure 3.4.

Figure 3.5 .

Figure 3.6.

Figure 3.7.

Figure 3.8 .

Figure 3.9.

Figure 3.10.

Figure 3.11.

Figure 3.12.

Figure 3.13.

Figure 3.14.

Figure 3.15.

Figure 3.16.

Figure 3.17.

Figure 3.18.

Figure 3.19.

Figure 3.20.

Figure 3.21.

Figure 3.22.

Figure 3.23.

Figure 3.24.

Figure 3.25.

Figure 3.26.

Figure 3.27.

Figure 3.28.

Figure 3.29.

Figure A1.

Figure A2.

Figure A3.

Figure A4.

Trough Beam Used in Phase IV B Specimens. . . . . . . . . . . . . 6

Bonding of PT Steel in Prototype Connections. . . . . . . . . . 7

Bonding of PT Steel in Model Connections. . . . . . . . . . . . . 8

Threads for 304 Stainless Steel Bars Used in N-P-Z4. . . . . . . . . . . 10

Threads for 304 Stainless Steel Bars Used in P-P-Z4 . . . . . . . . . . 11

Stainless Steel Bar for N-P-Z4 (bottom) and P-P-Z4 (top). . . . . . . . . 11

Welded Reinforcement Grid Ties for Beams and Columns. . . . . . . . 12

Boundary Conditions. . . . . . . . . . . . . . . . . . . . . 14

Basic Loading History for Phase IV B Specimens. . . . . . . . . . . . . 15

Load History for Specimen P-P-Z4. . . . . . . . . . . . . . 16

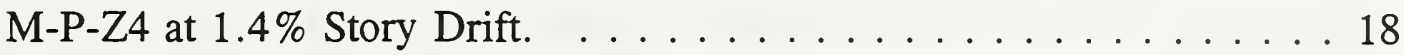

M-P-Z4 at failure, $3.4 \%$ Story Drift. . . . . . . . . . . . 18

Force in Prestressing Strand 1, M-P-Z4. . . . . . . . . . . . . . 19

Force in Prestressing Strand 2, M-P-Z4. . . . . . . . . . 20

Force in Prestressing Strand 3, M-P-Z4. . . . . . . . . . 20

N-P-Z4 at $1.4 \%$ Story Drift. . . . . . . . . . . . . 22

N-P-Z4 at Failure, $2.9 \%$ Story Drift. . . . . . . . . . 22

Force in Prestressing Strand 1, N-P-Z4. . . . . . . . . 23

Force in Prestressing Strand 2, N-P-Z4. . . . . . . . . . . . 24

Force in Prestressing Strand 3, N-P-Z4. . . . . . . . . . . 24

O-P-Z4 at $1.4 \%$ Story Drift. . . . . . . . . . . . . 25

O-P-Z4 at Failure, $3.4 \%$ Story Drift. . . . . . . . . . . 26

Force in Prestressing Strand 1, O-P-Z4. . . . . . . . . . 27

Force in Prestressing Strand 2, O-P-Z4. . . . . . . . . . 27

Force in Prestressing Strand 3, O-P-Z4 . . . . . . . . . . . 28

P-P-Z4 at $1.4 \%$ Story Drift. . . . . . . . . . . . . . . . . . . 29

P-P-Z4 at Failure, 2.9\% Story Drift. . . . . . . . . . . . . . . 29

Spalling of Concrete Cover, 2.9\% Story Drift, P-P-Z4. . . . . . . 30

Prestressing Force in Strand 1, P-P-Z4. . . . . . . . . . . . 31

Prestressing Force in Strand 2, P-P-Z4. . . . . . . . . . . . . 31

Prestressing Force in Strand 3, P-P-Z4 . . . . . . . . . . . 32

Hysteresis Curves for M-P-Z4. . . . . . . . . . . . . . . . 34

Hysteresis Curves for N-P-Z4. . . . . . . . . . . . . . . . . 34

Hysteresis Curves for O-P-Z4. . . . . . . . . . . . . . . . 34

Hysteresis Curves for P-P-Z4. . . . . . . . . . . . . . . . 34

Hysteresis Curves for A-M-Z4. . . . . . . . . . . . . . 35

Hysteresis Curves for B-M-Z4. . . . . . . . . . . . . . . . 35

Comparison of the Normalized Cyclic Energy for Phase IV B

Specimens. . . . . . . . . . . . . . . . . . . . 36

Cyclic Energy Dissipation for P-P-Z4 . . . . . . . . . . . . . . 37

Basic Details for Specimens I-P-Z4 and K-P-Z4 (Phase IV A). . . . . 47

Basic Details for Specimen J-P-Z4 (Phase IV A). . . . . . . . . . . 47

Basic Details for Specimen L-P-Z4 C (Phase IV A). . . . . . . . . 48

Elevation View of Beams, M-P-Z4 to P-P-Z4 (Phase IV B). . . . . . 49 
Figure A5. Beam Cross Sections, M-P-Z4 to P-P-Z4 (Phase IV B). . . . . . . 50

Figure A6. Top and Elevation Views of Column, M-P-Z4 to P-P-Z4 (Phase IV B). . . . . . . . . . . . . . . . . . 51

Figure A7. Column Cross Section, M-P-Z4 to P-P-Z4 (Phase IV B). . . . . . 52

Figure B1. \#3, Grade 60, Reinforcing Bar Used as Mild Steel in M-P-Z4 . . . . . 53

Figure B2. $\quad 304$ Stainless Steel Bar Used as Mild Steel in N-P-Z4. . . . . . . . . . 54

Figure B3. \#3, Grade 60, Reinforcing Bar Used as Mild Steel in O-P-Z4. . . . . . 54

Figure B4. $\quad 304$ Stainless Steel Bar Used as Mild Steel in P-P-Z4. . . . . . . . . . 55

Figure B5. Prestressing Tendon, $13 \mathrm{~mm} \phi$, Grade $270 . \ldots \ldots \ldots \ldots$

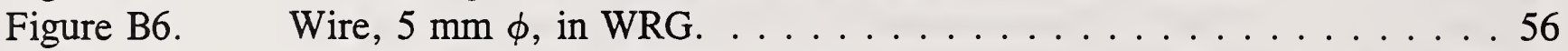

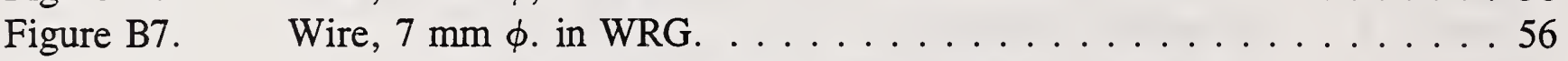

Figure B8. \#3, Grade 60, Reinforcing Bars Used in Beams, M-P-Z4 to

P-P-Z4 . . . . . . . . . . . . . . . . . . . . . . . . . . . 57

Figure B9. \#6, Grade 60, Reinforcing Bars Used in Columns, M-P-Z4 to

P-P-Z4 . . . . . . . . . . . . . . . . . . . . . 57 


\section{O INTRODUCTION}

Precast concrete frame construction is not presently used extensively in seismic regions of the USA. The UBC [ICBO, 1991] permits only certain specific building systems to be used and a precast frame is not one of them. The reason is that extensive research on cast-in-place frames has led to the development of reinforcement details that provide suitable ductility, and these details are now prescribed in the UBC. In most cases, such detailing cannot be easily achieved in a purely precast system. The result is that most precast structures can be made to satisfy the UBC only under the guise of an "undefined structural system" [Sec. 2333 (f) 6] which must " ... be shown by technical and test data which establish the dynamic characteristics and demonstrate the lateral force resistance and energy absorption capacity to be equivalent to systems listed in Table No. 23-O for equivalent $R_{w}$ values" [Section 2333 (i) 2]. This requirement makes approval of a precast frame very difficult. In addition, another UBC requirement calls for "reinforcement resisting earthquake-induced" forces to conform to ASTM A 706 and A 615 Grades 40 and 60 specifications which excludes prestressing steel as well as other types of energy dissipating alloys. Since the advantages of precasting and prestressing are interlinked, this provision on prestressing inhibits the use of precast concrete.

Therefore, an experimental program to examine the behavior of $1 / 3$-scale model precast concrete beam-column connections subjected to cyclic inelastic loads was initiated at the National Institute of Standards and Technology in 1987. The objective of the program was to develop recommended guidelines for the design of an economical precast moment resisting beam-tocolumn connection for use in regions of high seismic risk. The basic concept used for the precast connections was the utilization of post-tensioning steel to connect the precast elements and to provide the required shear resistance to the applied loads.

The test program is divided into four phases. Phase I [Cheok and Lew, 1990] was the exploratory phase in which four monolithic specimens were tested. Two of these specimens were designed to UBC [ICBO, 1985] seismic Zone 2 specifications and two to Zone 4 specifications. The results from these tests serve as a reference level for the precast tests. In addition to the monolithic tests, two precast connections were tested. These specimens were designed similarly to the monolithic Zone 4 specimens. The objective of this phase was to determine the viability of the concept. Based on the results of Phase I, six precast specimens were tested in Phase II [Cheok and Lew, 1991]. The objective of this phase was to improve the cyclic energy dissipation characteristics of the precast specimens. The location of the posttensioning steel and the type of post-tensioning steel were investigated. Because of stiffness degradation observed in the earlier precast specimens during the latter stages of the tests, the use of partially bonded post-tensioning steel was studied in Phase III [Cheok and Lew, 1993]. Two precast specimens were tested in this phase.

Hybrid precast connections were studied in Phase IV. The connections are termed hybrid because they contained both mild or low strength steel and prestressing (PT) or high strength steel. The basic premise for this concept was that the mild steel served as an energy dissipator while the friction force developed between the beam and the column by the post-tensioning force provided the necessary shear resistance. Concern was raised that the shear resistance provided by this arrangement would not be sufficient to resist the applied shear loads in addition to gravity 
loads. To address this concern, simulated gravity loads were applied to the beams for the Phase IV tests.

Phase IV was divided into two sub-phases, A and B. In Phase IV A [Cheok, Stone, Lew, 1993], six tests were conducted on three archetype designs. The objectives of this sub-phase were to test the hybrid concept and to determine the most promising archetype design. The results from this phase were used to determine the specimen details for Phase IV B. One of the specimens in Phase IV A, which incorporated replaceable mild and PT steels, was tested three times. In Phase IV B, four "production" type tests were conducted. The term production is used as the precast beams and columns were fabricated by a precaster. The connections were then assembled and tested at NIST. The primary variable in this sub-phase was the amount and type of mild steel. The PT steel was located at the centroid of the beam. This location was shown in Phases I to IV A to produce the largest drift capacity prior to yielding of the PT steel.

A steering committee was formed to provide technical guidance for Phases I-III. The members of this committee include Mr. Dan Jenny (formerly with the Precast/Prestressed Concrete Institute, PCI), Dr. Robert Englekirk (Englekirk and Sabol, Inc.), Dr. S. K. Ghosh (Portland Cement Association), Mr. Paul Johal(PCI), and Dr. Nigel Priestley (UC at San Diego). Partial funding for the Phase IV tests was made available from ConREF (Concrete Research and Education Foundation) of the American Concrete Institute. Also, an ACI oversight committee was formed (see organizational chart in Appendix C on page 59) to provide technical guidance.

This report provides a description of the Phase IV B specimens and a comparison of the results from this phase to the results from Phases I - IV A. This is the fourth report in a series describing NIST work on precast moment resisting frames. Detailed results from Phases I, II, III and IV A may be found in NIST reports Cheok and Lew [1990, 1991], Cheok, Stone, and Lew [1993], and in papers by Cheok, Stone, and Lew [1992], and by Cheok and Lew [1993]. 


\subsection{PHASE IV SPECIMEN DESCRIPTION, DETAILS AND TEST PROCEDURE}

\subsection{Summary of Phase IV A Results}

The basic concept of the Phase IV specimens was to use mild steel as energy dissipators and to use prestressing (PT) steel to provide the necessary shear resistance. Typically, the mild steel consisted of Grade $60\left(f_{y}=414 \mathrm{MPa}\right)$ deformed reinforcing bars, and the PT steel consisted of high strength bars $\left(f_{p u}=1034 \mathrm{MPa}\right)$ or prestressing strands $\left(f_{\mathrm{pu}}=1862 \mathrm{MPa}\right)$. To maintain the clamping force, the PT steel was designed to remain in the elastic range.

Two methods were used in the Phase IV A specimens to delay yielding of the PT steel. One was to place the PT steel in the middle of the beam where it would experience less strain and to fully grout it (I-P-Z4 and K-P-Z4). The other was to have unbonded PT steel located at the top and bottom of the beam (J-P-Z4). In both cases the mild steel was located at the top and bottom of the beam and was fully bonded. Specimen J-P-Z4 had one third more mild steel than did specimen K-P-Z4. A third specimen, L-P-Z4, was tested three times. The specimen in the first two tests, L-P-Z4 A and L-P-Z4 B, contained only unbonded PT steel. These tests were conducted to determine the type of PT steel -- high strength bar or strand -- to be used in the third test. The specimen in the third test, L-P-Z4 C, consisted of unbonded mild steel and PT steel located at the top and bottom of the beam. The intent of this type of system was that it represented a repairable system whereby both the mild and PT steels could be replaced after being damaged. Basic connection details for specimens I-P-Z4 to L-P-Z4 are given in Appendix A, Figs. A1 to A3.

Premature bond failure of the mild steel in specimen I-P-Z4 at a story drift of approximately $1.7 \%$ rendered the results for this specimen inconclusive. As a result, specimen K-P-Z4 was constructed similarly to specimen I-P-Z4 and tested. Failure of specimens K-P-Z4 and J-P-Z4 resulted when the mild steel bars fractured. The story drifts at failure for specimens K-P-Z4 and J-P-Z4 were $3.1 \%$ and $3.6 \%$, respectively. Comparisons with the monolithic Zone 4 specimens show comparable connection strength and ductility for specimens K-P-Z4 and J-P-Z4. Similar cyclic energy dissipation to approximately $2 \%$ story drift was observed between these two precast specimens and the monolithic specimens.

Specimen L-P-Z4 C, the replaceable system, failed at a story drift of $2.0 \%$. This specimen failed prematurely. A detailed explanation of this can be found in Cheok, Stone, and Lew [1993]. In brief, failure resulted from a compromise in the detailing due to problems with steel congestion from scaling the prototype connection by a factor of 3 . It is considered unlikely that this type of premature failure would occur in a prototype connection. Removal of both the mild steel and the post-tensioning steel after testing was accomplished with little difficulty; thus proving the feasibility of the design. The cost of such a replaceable connection, however, may prohibit its use in practice.

A summary of all the beam-column connections tested at NIST is given in Table 2.1. 
Table 2.1. Description of NIST Precast Connections

\begin{tabular}{|c|c|c|c|c|c|c|c|c|c|}
\hline \multirow{2}{*}{$\begin{array}{l}\text { Test } \\
\text { Phase }\end{array}$} & \multirow{2}{*}{$\begin{array}{l}\text { Specimen } \\
\text { Names }\end{array}$} & \multirow{2}{*}{$\begin{array}{l}\text { Seismic } \\
\text { Zone }\end{array}$} & \multirow{2}{*}{ Type $^{a}$} & \multicolumn{2}{|c|}{ PT Steel } & \multirow{2}{*}{$\begin{array}{l}\text { PT Steel } \\
\text { dist. } \\
\text { from } \\
\text { extreme } \\
\text { fiber, } d_{p} \\
(\mathrm{~mm}) \\
\end{array}$} & \multirow{2}{*}{$\begin{array}{c}\text { Length of } \\
\text { debonded } \\
\text { PT Steel } \\
(\mathrm{mm})\end{array}$} & \multicolumn{2}{|c|}{ Mild Steel } \\
\hline & & & & Type $^{b}$ & Bond $^{c}$ & & & $\begin{array}{c}\text { Area } \\
\left(\mathrm{mm}^{2}\right)\end{array}$ & Bond $^{d}$ \\
\hline I & $\begin{array}{l}\text { A-M-Z2 } \\
\text { B-M-Z2 }\end{array}$ & 2 & M & --- & --- & --- & --- & 568 & $\mathrm{~F}$ \\
\hline I & $\begin{array}{l}\text { A-M-Z4 } \\
\text { B-M-Z4 }\end{array}$ & 4 & M & --- & --- & --- & --- & 613 & $\mathrm{~F}$ \\
\hline I & $\begin{array}{l}\text { A-P-Z4 } \\
\text { B-P-Z4 }\end{array}$ & 4 & $P$ & B & $\mathrm{F}$ & 89 & --- & --- & --- \\
\hline II & $\begin{array}{l}\text { A-P-Z2 } \\
\text { B-P-Z2 }\end{array}$ & 2 & $P$ & $S$ & $\mathrm{~F}$ & 63 & --- & --- & --- \\
\hline II & $\begin{array}{l}\text { C-P-Z4 } \\
\text { D-P-Z4 }\end{array}$ & 4 & $P$ & B & $\mathrm{F}$ & 135 & --- & --- & --- \\
\hline II & $\begin{array}{l}\text { E-P-Z4 } \\
\text { F-P-Z4 }\end{array}$ & 4 & $P$ & $S$ & $\mathrm{~F}$ & 102 & --- & --- & --- \\
\hline III & $\begin{array}{l}\text { G-P-Z4 } \\
\text { H-P-Z4 }\end{array}$ & 4 & $\mathrm{P}$ & $S$ & $\mathrm{P}$ & 102 & 1219 & --- & --- \\
\hline IV A & $\begin{array}{c}\text { I-P-Z4 } \\
\text { K-P-Z4 }\end{array}$ & 4 & $p$ & $S$ & $\mathrm{~F}$ & 254 & --- & 142 & $\mathrm{~F}$ \\
\hline IV A & J-P-Z4 & 4 & $P$ & B & $\mathrm{U}$ & 51 & 914 & 213 & $\mathrm{~F}$ \\
\hline IV A & L-P-Z4 A & 4 & $P$ & $S$ & $\mathrm{U}$ & 40 & 914 & $-\cdots$ & --- \\
\hline IV A & L-P-Z4 B & 4 & $\mathrm{P}$ & B & $\mathrm{U}$ & 40 & 914 & --- & --- \\
\hline IV A & L-P-Z4 C & 4 & $\mathrm{P}$ & S & $\mathrm{U}$ & 40 & 914 & 186 & $\mathrm{U}$ \\
\hline IV B & M-P-Z4 & 4 & $\mathrm{P}$ & S & $\mathrm{P}$ & 203 & 1511 & 142 & $\mathrm{P}$ \\
\hline IV B & N-P-Z4 & 4 & $P$ & $S$ & $\mathrm{P}$ & 203 & 1511 & 131 & $P$ \\
\hline IV B & O-P-Z4 & 4 & $P$ & $S$ & $P$ & 203 & 1511 & 213 & $\mathrm{P}$ \\
\hline IV B & P-P-Z4 & 4 & $P$ & $S$ & $P$ & 203 & 1511 & 197 & $\mathrm{~F}$ \\
\hline
\end{tabular}

a $\quad \mathrm{M}=$ Monolithic; $\mathrm{P}=$ Precast

b $\quad$ B $=$ Post-tensioning bars; $S=$ Prestressing strands

c $\quad F=$ Fully grouted; $P=$ Partially grouted; $U=$ Unbonded 


\subsection{Phase IV B Specimens}

\subsubsection{Introduction}

Four beam-column connections were tested in Phase IV B. The design forces used to design the precast connection were based on those used for a monolithic connection. The prototype structure was a 12-story office structure with a story height equal to $3.96 \mathrm{~m}$. It was designed based on the following values: $R_{w}=12, Z=4, I=1, S=1, C_{t}=0.030$.

The precast beams and columns were fabricated by a major U.S. precast company using standard practices at their plant in California and shipped to NIST where they were assembled and tested. The objective of this phase of the test program was to determine the optimum combination of mild and PT steels and to examine the use of an alternate type of mild steel as a means of improving the energy dissipation characteristics of the connection.

In Phase IV A, the beams had a nominal moment capacity of $2440 \mathrm{kN}-\mathrm{m}\left(\phi=0.9, \mathrm{f}_{\mathrm{y}}=\right.$ $414 \mathrm{MPa})$ and a maximum moment capacity of $3241 \mathrm{kN}-\mathrm{m}\left(\phi=1.0, \mathrm{f}_{\mathrm{y}}=1.25 * 414 \mathrm{MPa}=\right.$ $517 \mathrm{MPa}$ ). Since one of the variable in the Phase IV B specimens was the amount of mild steel, the nominal and maximum moment capacities served as lower and upper bounds, respectively, in the design of the beams.

The intent at the beginning of Phase IV B was to proportion the mild and PT steels so that the ratios of the moment contribution from the mild steel to that from the PT steel would be $10 \%$, $20 \%$ and $30 \%$, respectively. The mild steel in these cases would consist of Grade $60\left(f_{y}=414\right.$ $\mathrm{MPa}$ ) reinforcing bars. The mild steel in the fourth specimen would consist of 304 stainless steel bars with the moment contribution ratio of the mild steel to the PT steel equal to $20 \%$.

However, due to the available sizes of the reinforcing bars and the PT strands, it was not possible to obtain the exact ratios of $10 \%, 20 \%$, and $30 \%$. Several combinations of varying amounts of mild and PT steels were tried. The final ratios used in the specimens were $35 \%$ and $47 \%$. These ratios corresponded to two and three \#3 bars located at the top and bottom of the beams, respectively, with $3-13 \mathrm{~mm}$ Grade 270 strands ( $f_{p u}=1862 \mathrm{MPa}$ ). It was decided to design the two remaining specimens with similar moment contribution ratios with the difference being replacement of the \#3, Grade $60\left(f_{y}=414 \mathrm{MPa}\right)$ bars with 304 stainless steel bars meeting ASTM A240-87 [ASTM, 1988] specifications. A specimen with a lower moment contribution ratio $(20 \%-25 \%)$ would have resulted in one \#3 bar top and bottom, and based on the Phase IV A results, this connection detail would have low energy dissipation characteristics.

The reason for using 304 stainless steel bars as the energy dissipators was based on the Phase IV A results. It was felt that improved energy dissipation characteristics at higher drift levels ( $>2.0 \%$ ) of the Phase IV A specimens could be possible if failure (fracture of mild steel) of these specimens was delayed. As 304 stainless steel has a total strain elongation capacity of approximately $50 \%$, as compared to about $20 \%$ for the Grade 60 reinforcing bars, this steel was believed to be a good candidate for use in the Phase IV B specimens.

Results from the Phase IV A tests indicated that the use of unbonded high strength bars located at the top and bottom of the beam yielded at approximately $1.7 \%$ story drift. Therefore, it was 
felt that the use of prestressing strands located at the centroid of the beam would increase the chances of PT steel remaining in the elastic range at higher story drifts. Also, the use of central post-tensioning that runs the full length of the building reduces the number of anchorages and the amount of labor, thereby reducing the cost.

Placement of the PT steel at the centroid of the beam eliminates the need for dogbones (the 51 and $68 \mathrm{~mm}$ extensions of the beams at the column face as seen in Figs. A1 - A3). The idea of using a trough which runs down the middle of the beam at top and bottom was proposed and decided upon (Fig. 2.1). During construction, the mild steel bars would be dropped into the trough and inserted through the ducts in the beams and columns after which they would be grouted in place. This trough beam with the "uniform" rectangular cross section makes for easier construction and is more acceptable architecturally.

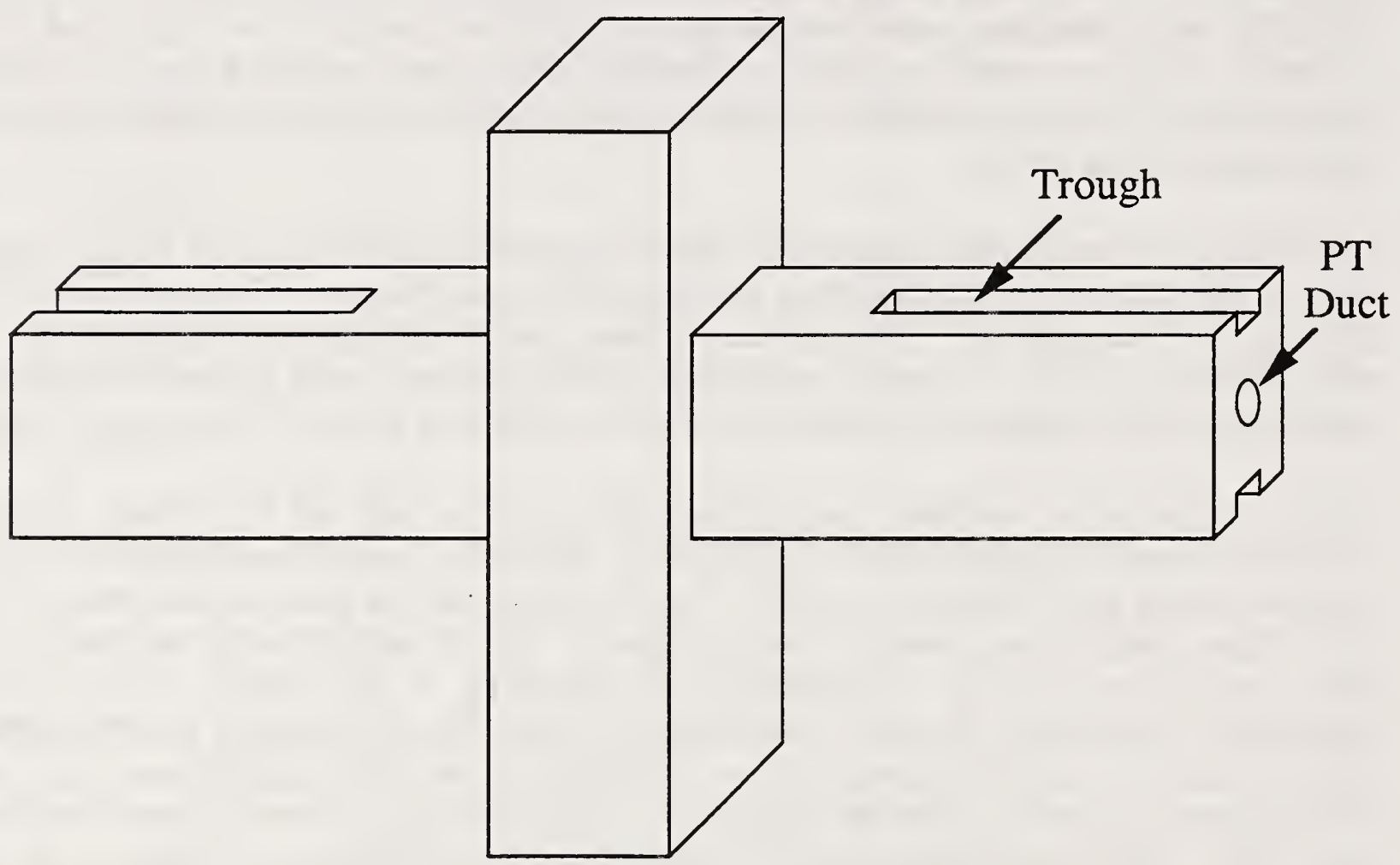

Figure 2.1. Trough Beam Used in Phase IV B Specimens.

The issue of whether to grout or not to grout the post-tensioning steel required a compromise. The advantages of using fully bonded tendons are corrosion protection and redundancy in the anchorage if the primary anchorage failed. However, fully bonded tendons run the risk of losing their initial prestress by localized yielding of the tendons at the beam-column interface, and therefore, the required clamping force. Unbonding the tendons provides the greatest potential 
that they remain in the elastic range which means that the connection would experience no permanent drift. Therefore, it was decided that the tendons would be partially bonded, that is, the tendons would be unbonded through the column and for a distance on either side of the column and would be bonded at mid-span of each bay as shown in Fig. 2.2. The length of this unbonded distance in the beam depends on the required development length for the tendons. This arrangement would address the concern for progressive collapse for an unbonded PT system.

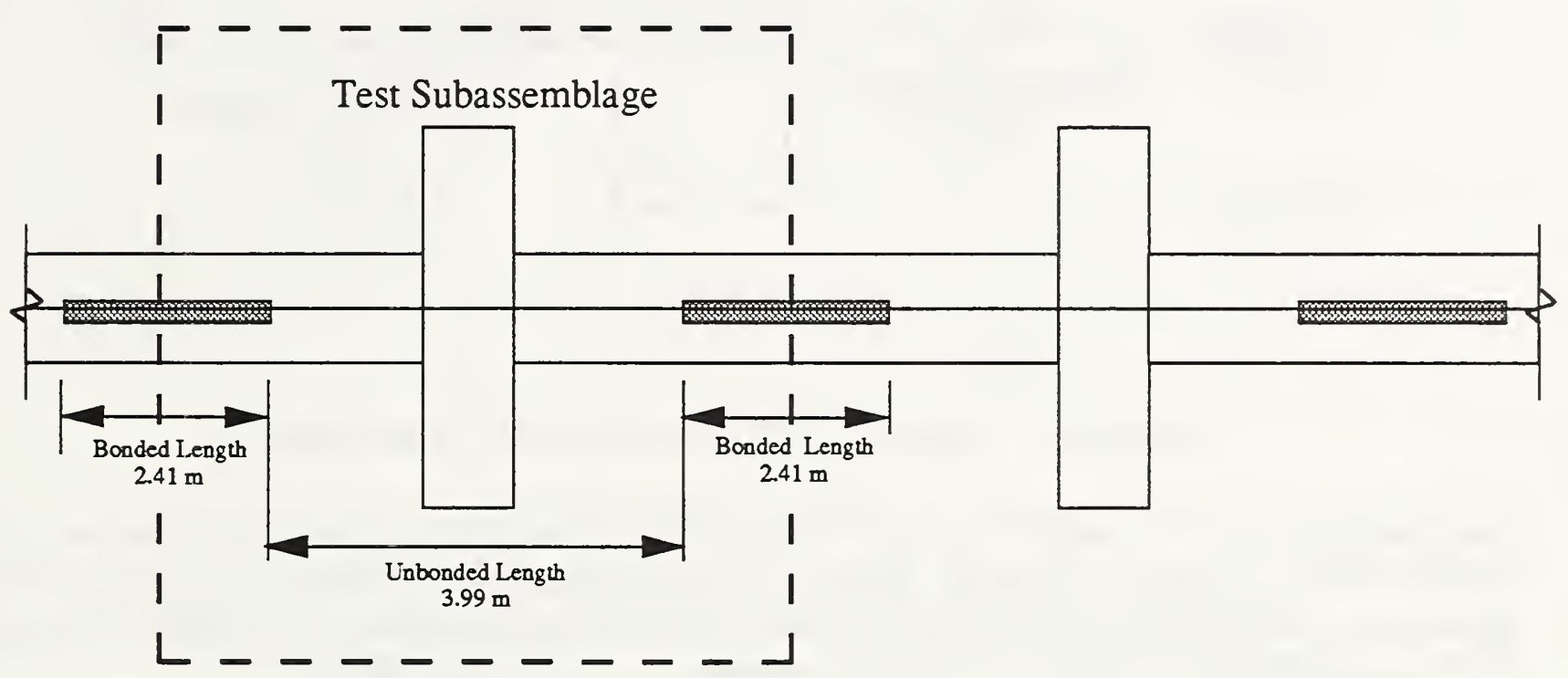

Figure 2.2. Bonding of PT Steel in Prototype Connections.

It was felt that it would be advantageous to be able to monitor the loads in the PT steel throughout the tests. Monitoring of the loads in the PT steel would give an indication of when yielding occurred and of the load losses in the PT steel due to yielding and to beam shortening. The most obvious method of monitoring the loads was strain measurements on the PT steel. However, given the scenario for bonding the PT steel shown in Fig. 2.2, this would have been difficult as the chances were poor for strain gages attached to the PT steel to survive the posttensioning process and the high strain levels at large drift levels. Therefore, it was decided to grout the PT steel as shown in Fig. 2.3 and to install load cells on each tendon on the unbonded side. The total bonded length of the PT steel was the same as shown in Fig. 2.2. 


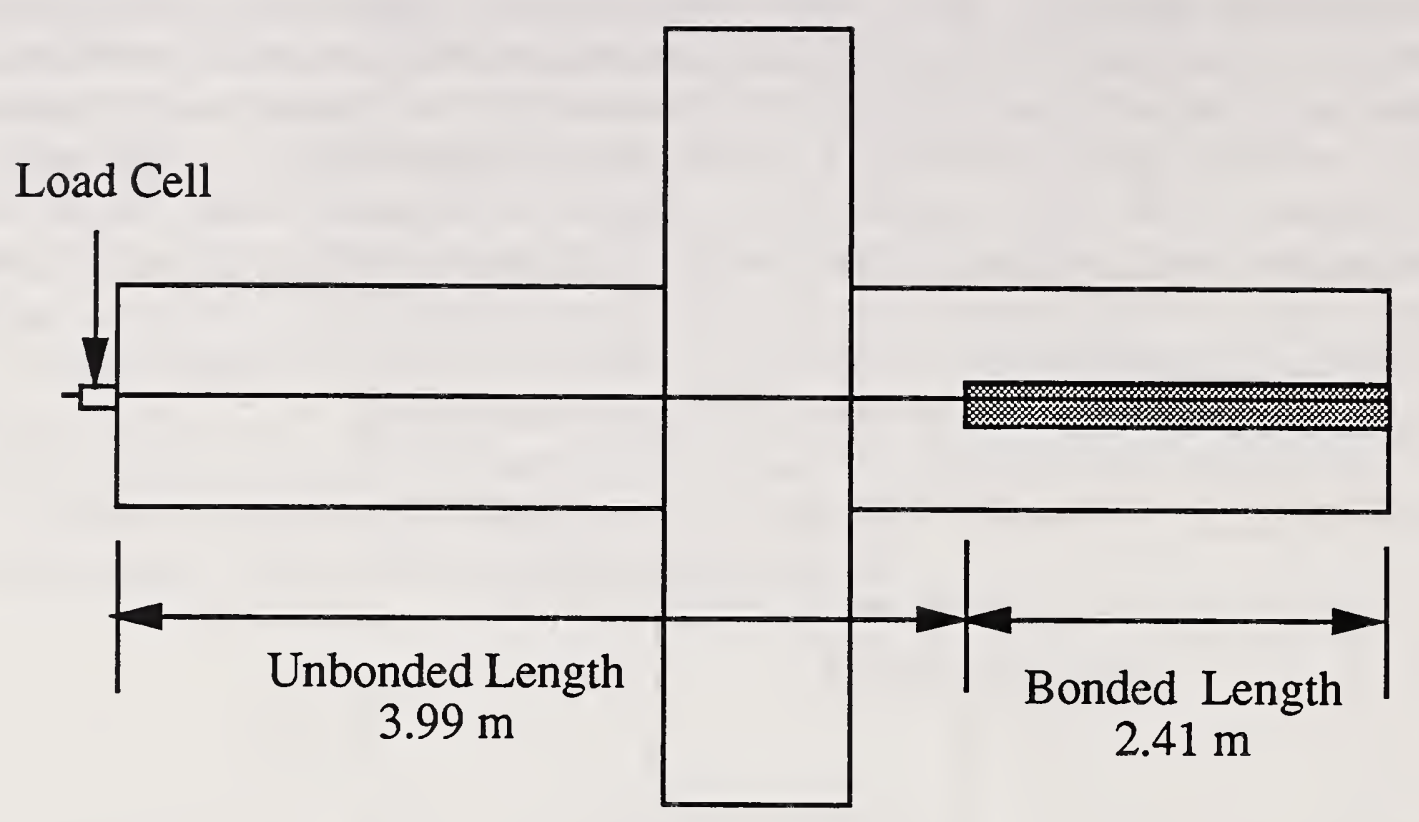

Figure 2.3. Bonding of PT Steel in Model Connections.

Steel angles were also included at the corners of the beams at the column interface as it was shown that the beams in J-P-Z4 suffered less damage in these regions than did those in specimens I-P-Z4 and K-P-Z4 which did not utilize reinforcing angles. Prevention of concrete crushing at the beam corners is especially necessary at higher drift levels.

In summary, the Phase IV B connections were to have central post-tensioning that was partially bonded. The PT steel would consist of prestressing strands and steel angles would be included at the corners of the beams at the column face. Two types of mild steel were to be used regular Grade $60\left(f_{p y}=414 \mathrm{MPa}\right)$ reinforcing bars and bars made from 304 stainless steel $\left(\mathrm{f}_{\mathrm{py}}=414 \mathrm{MPa}\right)$.

\subsubsection{Specimen Details}

All four specimens, M-P-Z4 to P-P-Z4, had the same design details. The beam and column details are given in Appendix A, Figs. A7 - A10. All of the specimens were post-tensioned with 3 - $13 \mathrm{~mm}$, Grade $270\left(\mathrm{f}_{\mathrm{pu}}=1862 \mathrm{MPa}\right)$ prestressing strands [ASTM A 416-87a, (ASTM, 1988)] located at the beam centroid. The initial stresses in the prestressing strands were approximately equal to $827 \mathrm{MPa}$ or $0.44 \mathrm{f}_{\mathrm{pu}}\left(\mathrm{f}_{\mathrm{pu}}=1862 \mathrm{MPa}\right)$.

The Phase IV B specimens varied only in the amount and type of mild steel. The mild steel in specimens M-P-Z4 and O-P-Z4 consisted of 2 - \#3 (top and bottom) and 3 - \#3 (top and bottom) reinforcing bars, respectively. The mild steel in specimens N-P-Z4 and P-P-Z4 consisted of 2 $9 \mathrm{~mm} \phi$ and $3-9 \mathrm{~mm} \phi 304$ stainless steel bars, respectively. The main reinforcement details for the Phase IV B specimens are shown in Fig. 2.4. The height and width of the beams in 
Phase IV B differed from those in Phase IV A due to the elimination of the dogbones in the Phase IV B specimens.

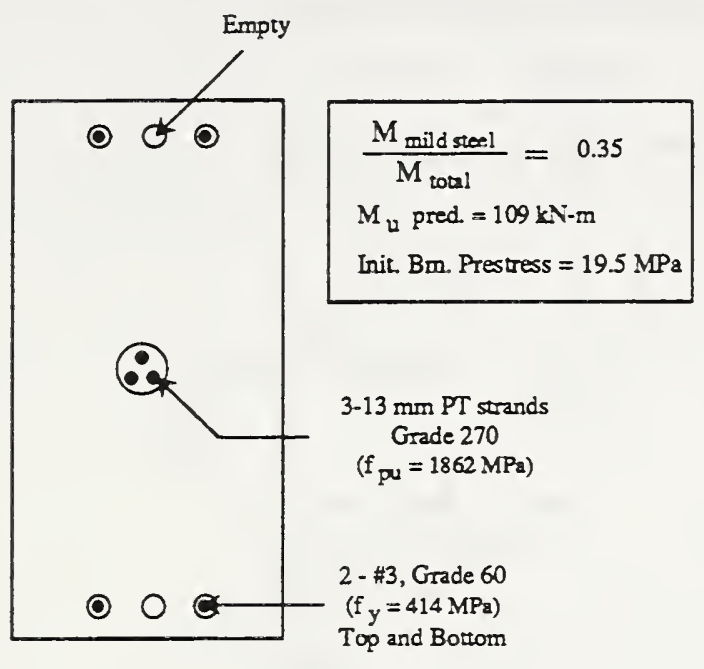

M-P-Z4

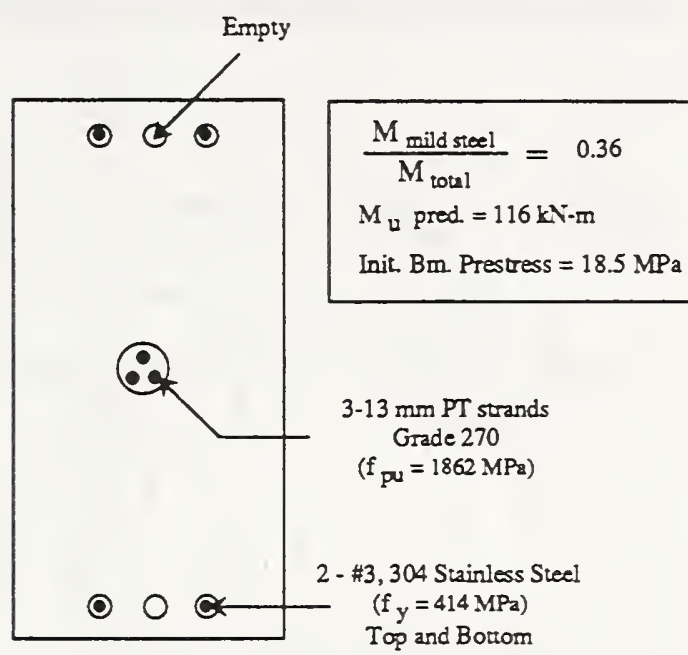

N-P-Z4

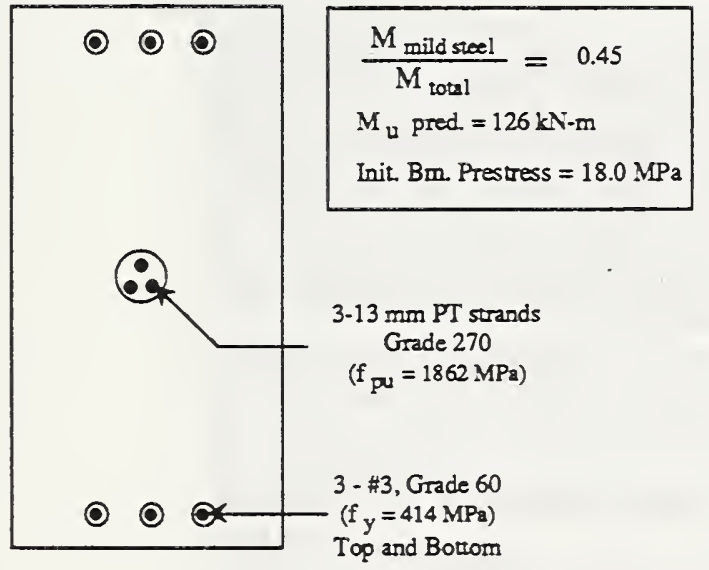

O-P-Z4

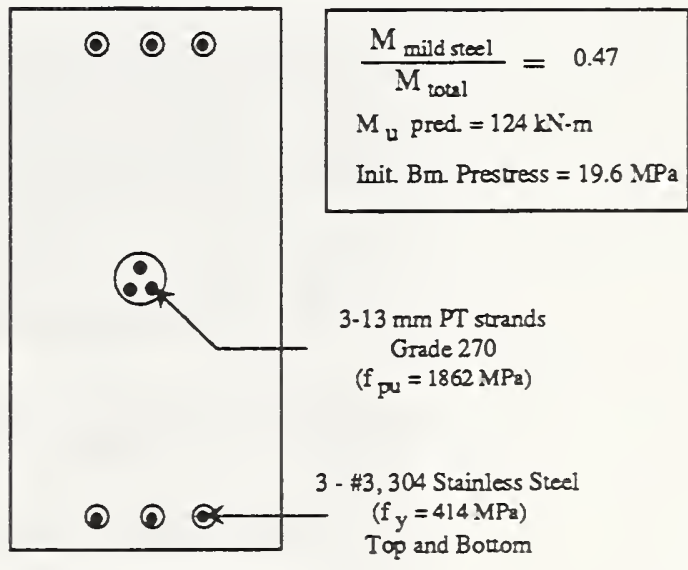

P-P-Z4

Figure 2.4. Phase IV B Main Reinforcement Steel.

The stainless steel bars were machined from $11 \mathrm{~mm} \phi(\mathrm{N}-\mathrm{P}-\mathrm{Z} 4)$ and $13 \mathrm{~mm} \phi$ (P-P-Z4) round stock. The threads in the stainless steel bars are shown in Figs. $2.5-2.7$. The threads shown 
in Fig. 2.5 were used for the bars in specimen N-P-Z4 and those shown in Fig. 2.6 were used for specimen P-P-Z4. The thread pattern shown in Fig. 2.6 proved to be more effective. Figure 2.7 shows a comparison of the stainless steel bars with the different threads. The reason for the different threads and size of the stainless steel bars was that the stainless steel bars debonded during the test of specimen N-P-Z4. This is discussed in Section 3.1.2.

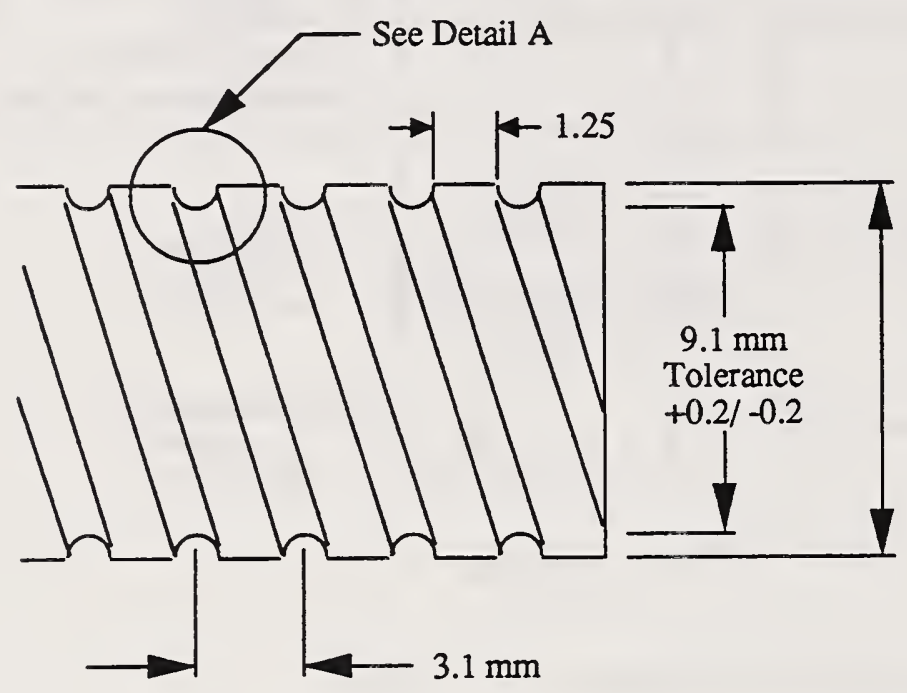

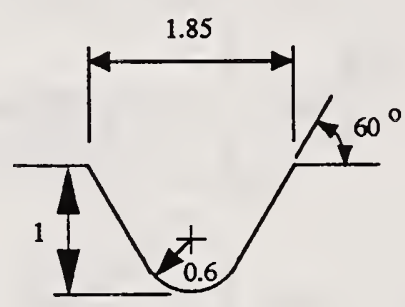

Detail A

All dimensions in $\mathrm{mm}$

Figure 2.5. Threads for 304 Stainless Steel Bars Used in N-P-Z4. 

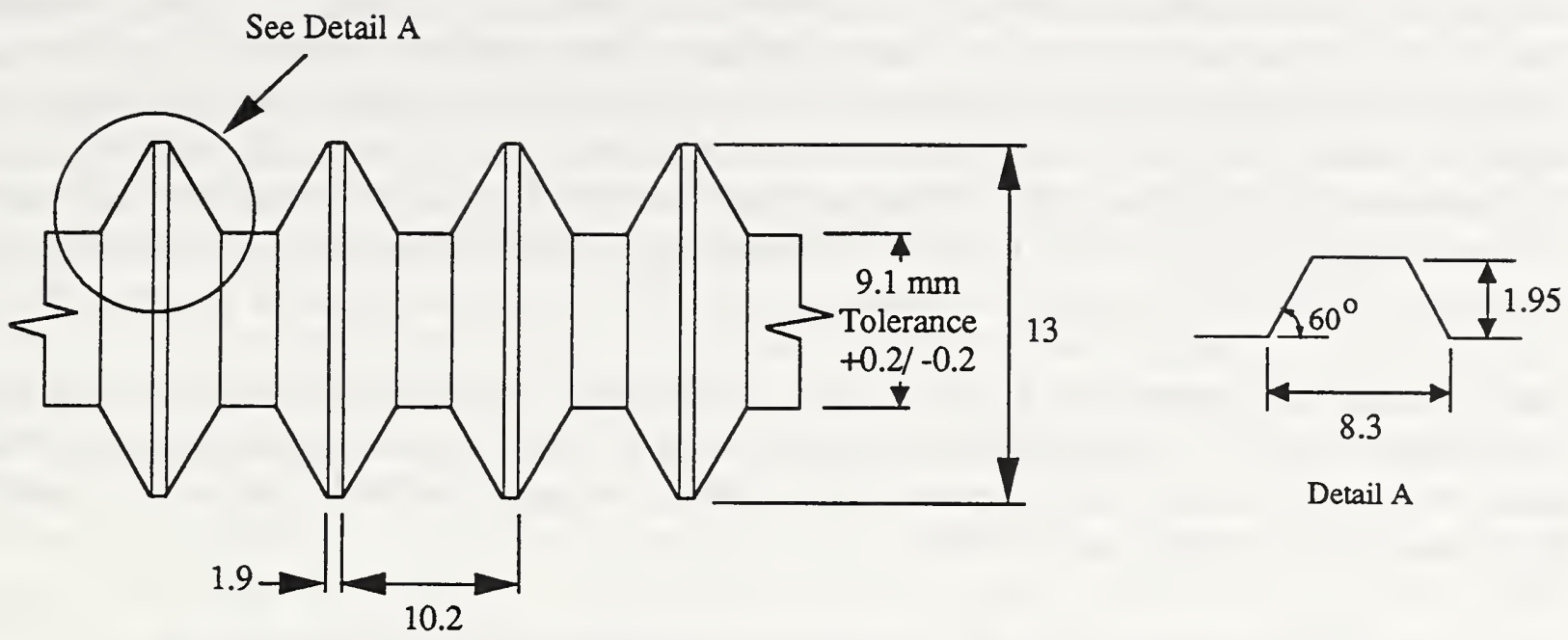

Detail A

Figure 2.6. Threads for 304 Stainless Steel Bars Used in P-P-Z4.

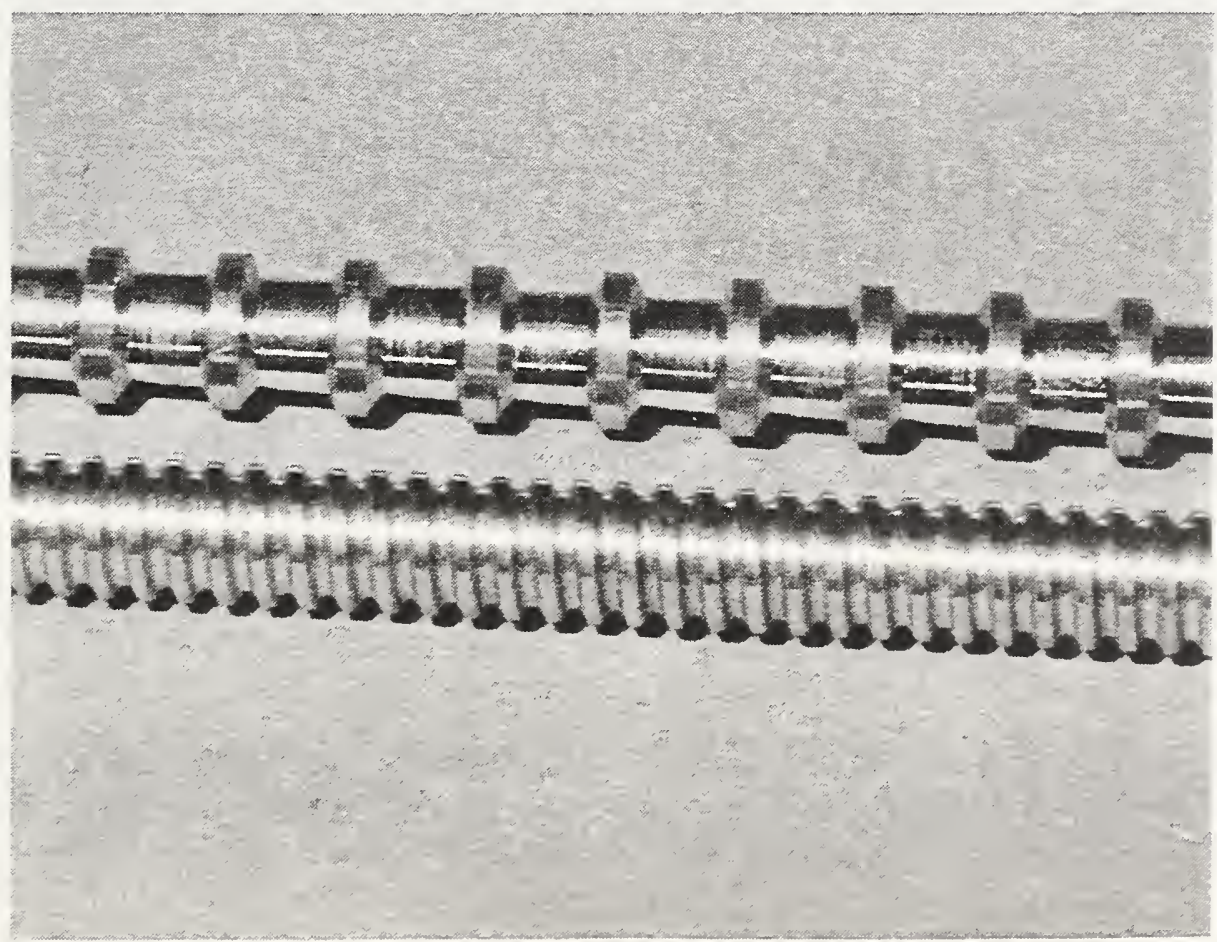

Figure 2.7. Stainless Steel Bar for N-P-Z4 (bottom) and P-P-Z4 (top). 
Failure of the Phase IV A specimens resulted from the fracture of the mild steel bars. Therefore, it was decided to debond the mild steel bars for a length equal to $25 \mathrm{~mm}$ on either side of the beam-column interface. From the observations made in Phase IV A tests, it appeared that the fully bonded mild steel bars debonded for a short distance on either side of the beamcolumn interface at higher drift levels. The intentional debonding of the mild steel would therefore not diminish the energy dissipation characteristics of the connection and would delay the fracture of the mild steel bars. However, the machined stainless steel bars in specimen P-P$\mathrm{Z} 4$ were fully bonded to maximize the total development length of the bars. This was to ensure against bond failure of the mild steel during the test of P-P-Z4 as occurred in specimen N-P-Z4 .

The stirrups in the beams and the ties in the column were welded reinforcement grids (WRG) as shown in Fig. 2.7. The WRG was custom made to fit the necessary requirements for the specimens and were made from smooth wire. WRG was used due to the congestion caused by the hooks in the stirrups and cross-ties.

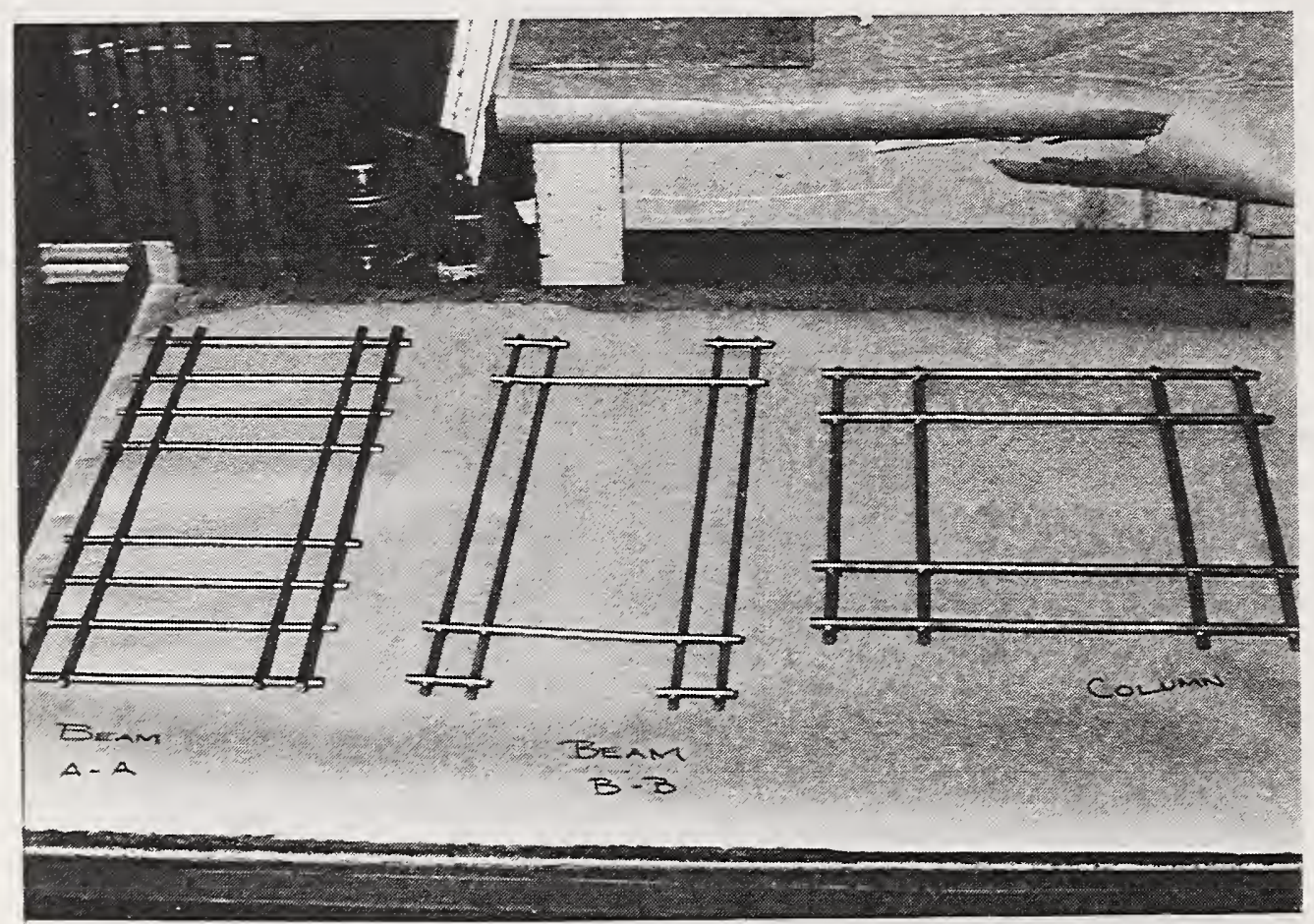

Figure 2.7. Welded Reinforcement Grid Ties for Beams and Columns.

The design concrete strength was $41.37 \mathrm{MPa}$. The reinforcing steel in beams and columns was Grade $60\left(f_{p y}=414 \mathrm{MPa}\right)$. The actual material properties are given in Appendix B on page 53 . 


\subsection{Post-tensioning and Grouting Procedures}

As shown in Fig. 2.3, the PT steel was to be bonded for only a portion of its length. A rubber stopper was used to prevent the grout from flowing into the unbonded section of the PT steel. The tapered stopper, slightly larger than the duct, had holes cut out to let the strands through and was located by measuring the calculated distance from the stopper to the end of the beam. As an added precaution, the strands were greased and sheathed beyond the stopper in the region of the strands which was intended to be unbonded.

When post-tensioning the specimens, the prestressing strands were pulled to an initial stress equal to $0.8 \mathrm{f}_{\mathrm{pu}}$ to seat the chucks. This lessened the load losses in the strands caused by seating of the chucks during the tests at high drift levels. The loads in the strands were then released and the strands were stretched to approximately $0.7 \mathrm{f}_{\mathrm{pu}}$ at which point shims were placed under the chucks as necessary. The sizes of the shims were adjusted so that the final stresses in the strands were equal to $0.44 \mathrm{f}_{\mathrm{pu}}$. This initial stress was lower than that in previous NIST specimens and was decided upon because this would allow the specimens to undergo higher drift levels before yielding the PT steel. The forces in the strands at the start of each connection test are given in Table 2.2.

Table 2.2. Strand Forces at Start of Test.

\begin{tabular}{||c|c|c|c|}
\hline SPECIMEN & STRAND 1 (kN) & STRAND 2 (kN) & STRAND 3 (kN) \\
\hline M-P-Z4 & $84\left(0.46 \mathrm{f}_{\mathrm{pu}}\right)$ & $79\left(0.42 \mathrm{f}_{\mathrm{pu}}\right)$ & $84\left(0.46 \mathrm{f}_{\mathrm{pu}}\right)$ \\
N-P-Z4 & $78\left(0.43 \mathrm{f}_{\mathrm{pu}}\right)$ & $76\left(0.42 \mathrm{f}_{\mathrm{pu}}\right)$ & $77\left(0.42 \mathrm{f}_{\mathrm{pu}}\right)$ \\
O-P-Z4 & $75\left(0.41 \mathrm{f}_{\mathrm{pu}}\right)$ & $77\left(0.42 \mathrm{f}_{\mathrm{pu}}\right)$ & $75\left(0.41 \mathrm{f}_{\mathrm{pu}}\right)$ \\
P-P-Z4 & $84\left(0.46 \mathrm{f}_{\mathrm{pu}}\right)$ & $81\left(0.44 \mathrm{f}_{\mathrm{pu}}\right)$ & $82\left(0.45 \mathrm{f}_{\mathrm{pu}}\right)$ \\
\hline
\end{tabular}

As with the specimens in Phase IV A, the ducts used in the Phase IV B specimens for the mild steel were made of $13 \mathrm{~mm}$ ID electrical conduit. These conduits were removed by unwinding after the beams were cast. This allowed greater clearance and easier grouting of the mild steel. A cable grout was used to grout the mild steel bars and the PT steel.

The construction joint was made of a fiber reinforced grout. The width of the construction joint was $8.5 \mathrm{~mm}$. The fibers used were $13 \mathrm{~mm}$ long and were made of nylon. The amount of fibers used was $8.7 \mathrm{~kg} / \mathrm{m}^{3}$ of grout. Prior to grouting the construction joint, the surfaces of the beams and columns were roughened to an amplitude of approximately $6 \mathrm{~mm}$ and these surfaces were wetted down for several hours prior to grouting. The grout used was a commercially available non-shrink sanded grout. The strengths of this grout and the cable grout are given in Appendix B. 


\subsection{Test Procedure}

The boundary conditions for the connections are shown in Fig. 2.8. Boundary conditions for the test specimens were as follows: pinned at the column bottom and roller supported at the column top and beam ends.

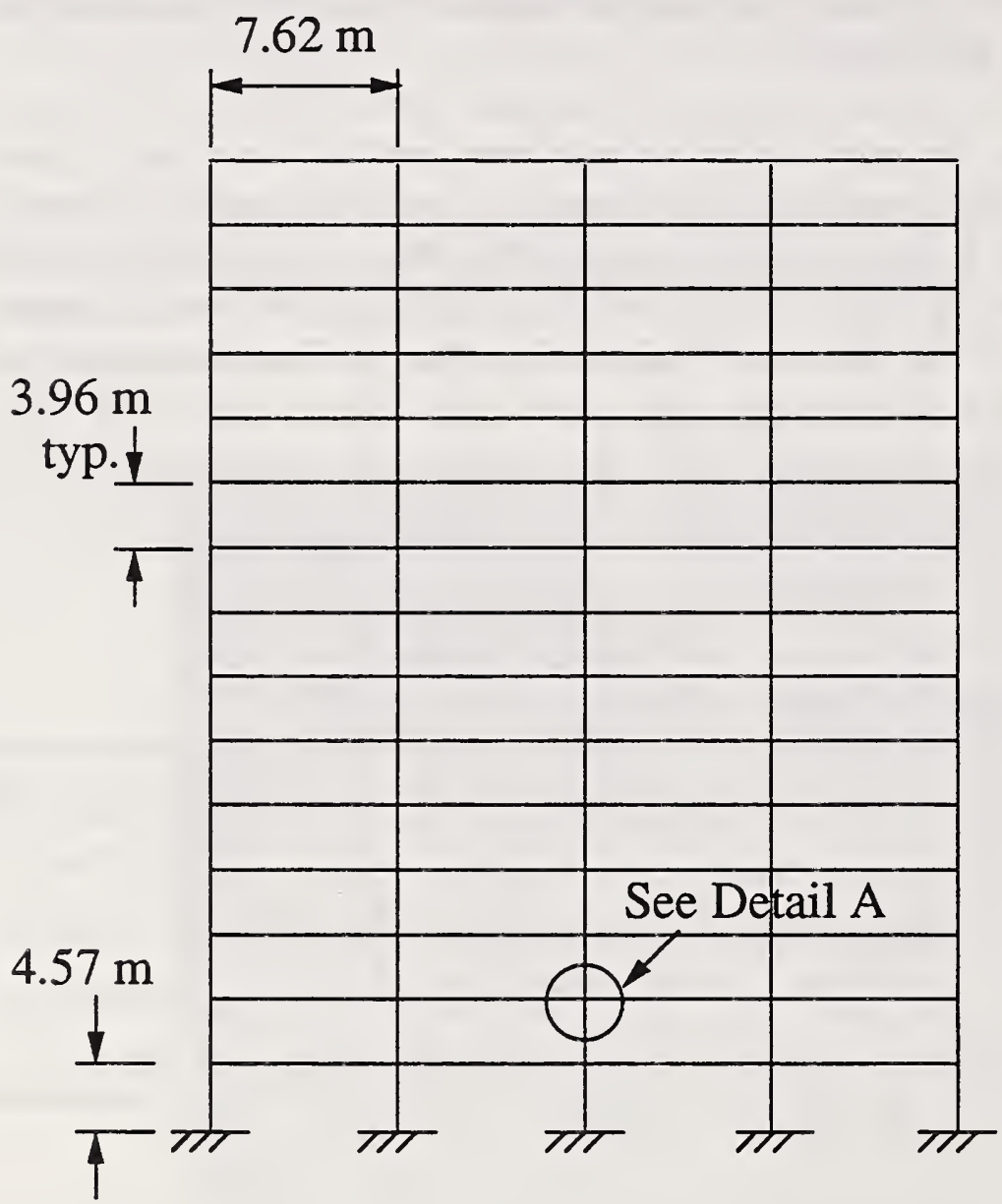

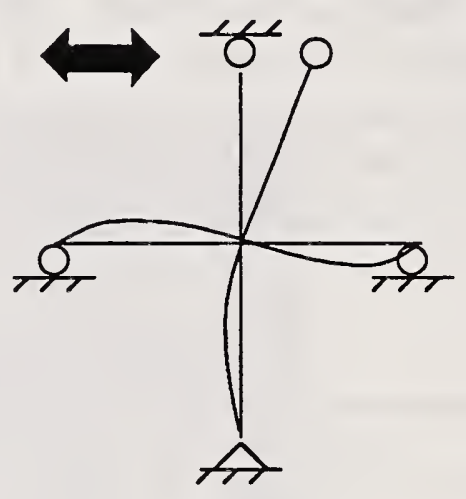

Detail A

Figure 2.8. Boundary Conditions.

As discussed in Cheok and Stone [1993], the loading history for the Phase IV B specimens was based on story drift and is the one recommended for use in the PREcast Seismic Structural Systems (PRESSS) Program [Priestley, 1992]. The basic loading history is three cycles at a particular drift level followed by an elastic cycle as shown in Fig. 2.9. In the elastic cycle, the connection was loaded to approximately $30 \%$ of the peak load in the previous three cycles. 


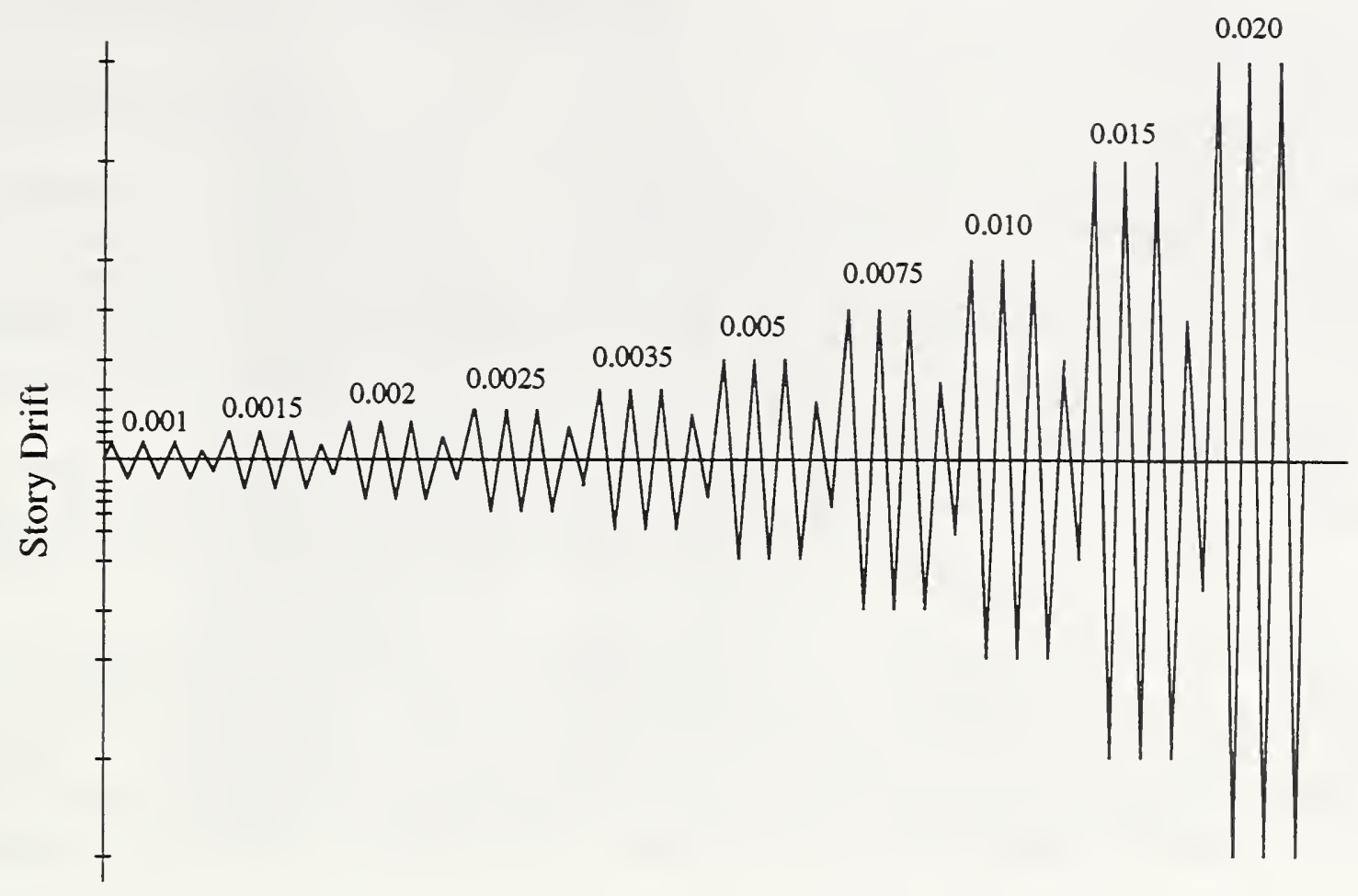

Figure 2.9. Basic Loading History for Phase IV B Specimens.

The loading history for specimen P-P-Z4 was similar to that shown in Fig. 2.9 to $3.0 \%$ story drift. However, after this drift level, the specimen was cycled three times at $1.0 \%, 1.5 \%$, $2.0 \%, 3.0 \%$ and $3.5 \%$ with an elastic cycle in between each drift level (Fig. 2.10). This was done in an effort to determine the performance of the connection in an "aftershock". 


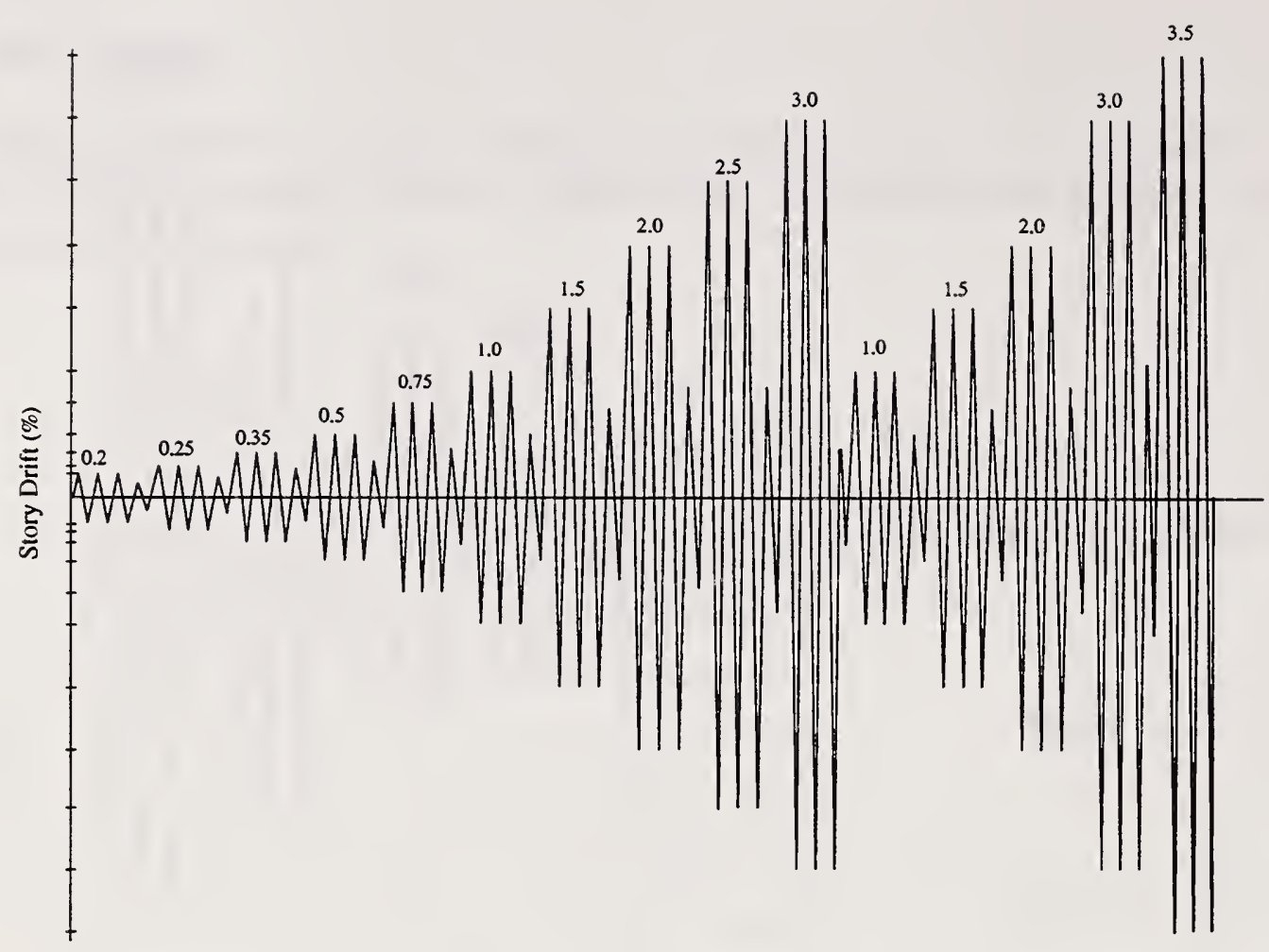

Figure 2.10. Load History for Specimen P-P-Z4.

Concentrated loads simulating gravity loads on the beams were applied to all Phase IV specimens. A load of approximately $20 \mathrm{kN}$ was applied to each beam at approximately $89 \mathrm{~mm}$ from the column face. The load was equivalent to a uniform dead load of $5.3 \mathrm{kPa}$ and a live load of $2.4 \mathrm{kPa}$. The simulated gravity loads on the beams were maintained constant throughout the tests. 


\subsection{DISCUSSION OF TEST RESULTS}

\subsection{Failure Mode}

In general, the crack widths in all the specimens, both beams and columns, were very small $(<1 \mathrm{~mm})$ throughout the tests and these cracks closed at zero displacement. Because of this, the strains in the beam ties were very low and were approximately $10 \%$ to $15 \%$ of yield. Also, closures of the openings between the beam and column at zero displacement were observed, even at story drifts of $3.0 \%-3.5 \%$.

As the PT steel was bonded in one beam and unbonded through the other, there existed a possibility that the crack pattern might differ in the two beams. However, no discernable difference in the crack patterns in the two beams of a specimen was observed.

In all specimens, crushing of the beams began at a story drift of $0.75 \%$. The beam corners at the column face sustained some crushing at the ends of the angle leg and some crushing inside the angle. Although significant crushing of the fiber reinforced grout occurred in the later stages of the tests, the grout was held together by the fibers. As with the Phase IV A specimens, no vertical slip of the beam relative to the column was observed during the tests.

\subsubsection{Specimen M-P-Z4 (2 - \#3, Grade 60 reinforcing bars, top and bottom)}

Fracture of mild steel bars resulted in the failure of specimen M-P-Z4. Two of the bar fractures occurred during the cycles to $2.9 \%$ story drift and one occurred at the cycle to $3.4 \%$ story drift. The connection at $1.4 \%$ and $3.4 \%$ (failure) story drifts are shown in Figs. 3.1 and 3.2. The maximum opening between the beam and column at $3.4 \%$ story drift was $13 \mathrm{~mm}$. 


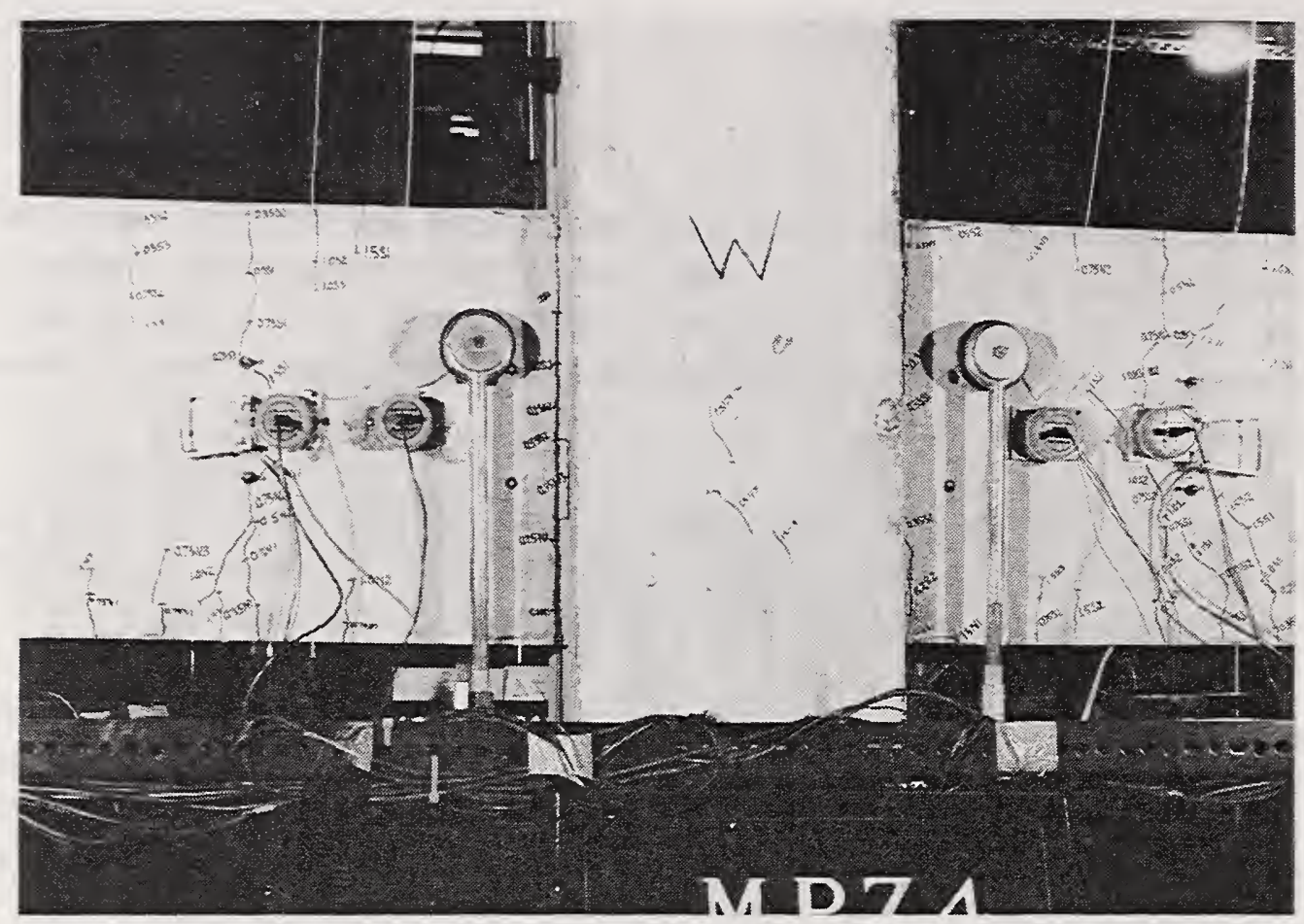

Figure 3.1. M-P-Z4 at $1.4 \%$ Story Drift.

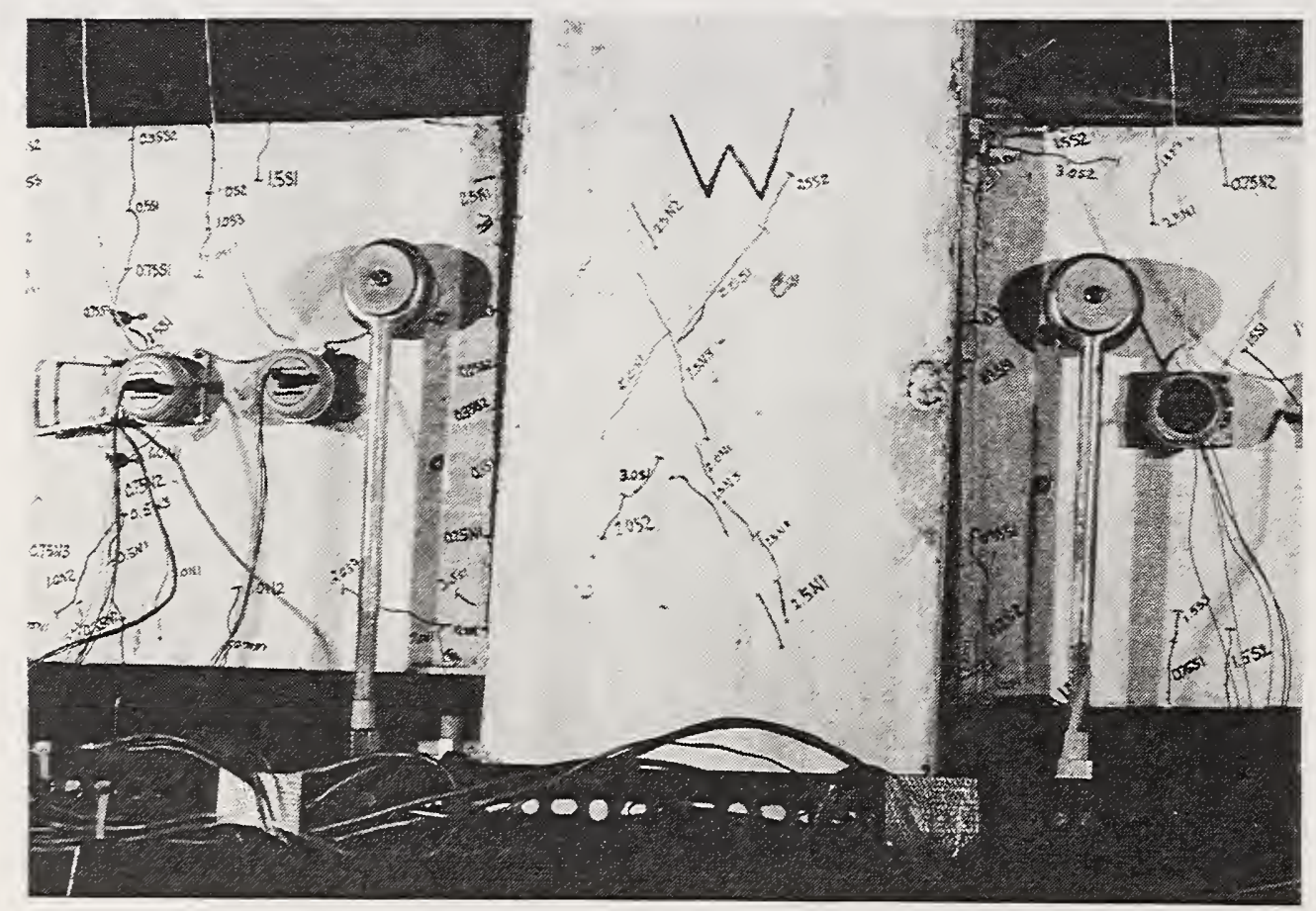

Figure 3.2. M-P-Z4 at failure, $3.4 \%$ Story Drift. 
The forces in each of the PT strands are shown in Figs. 3.3 to 3.5. The peak stresses and stresses at the end of each test are given in Table 3.1. As seen in Table 3.1, the average peak stress in the PT steel was $0.85 \mathrm{f}_{\mathrm{pu}}$ for M-P-Z4 which indicates that the PT steel did not yield $\left(\mathrm{f}_{\mathrm{py}}\right.$ $=0.93 \mathrm{f}_{\mathrm{pu}}$ ) and that it remained in the elastic range throughout the test. A further indication of this is shown by comparing the stresses in the PT steel at the beginning and at the end of the test. The average stress in the PT steel at the end of the test was $0.39 \mathrm{f}_{\mathrm{pu}}$ which means that the average total loss $\left(f_{p \text { ini }}-f_{p \text { end }}\right)$ in the PT steel was $0.06 f_{p u}$. Therefore, the clamping force required to resist the gravity loads was maintained throughout the test to failure.

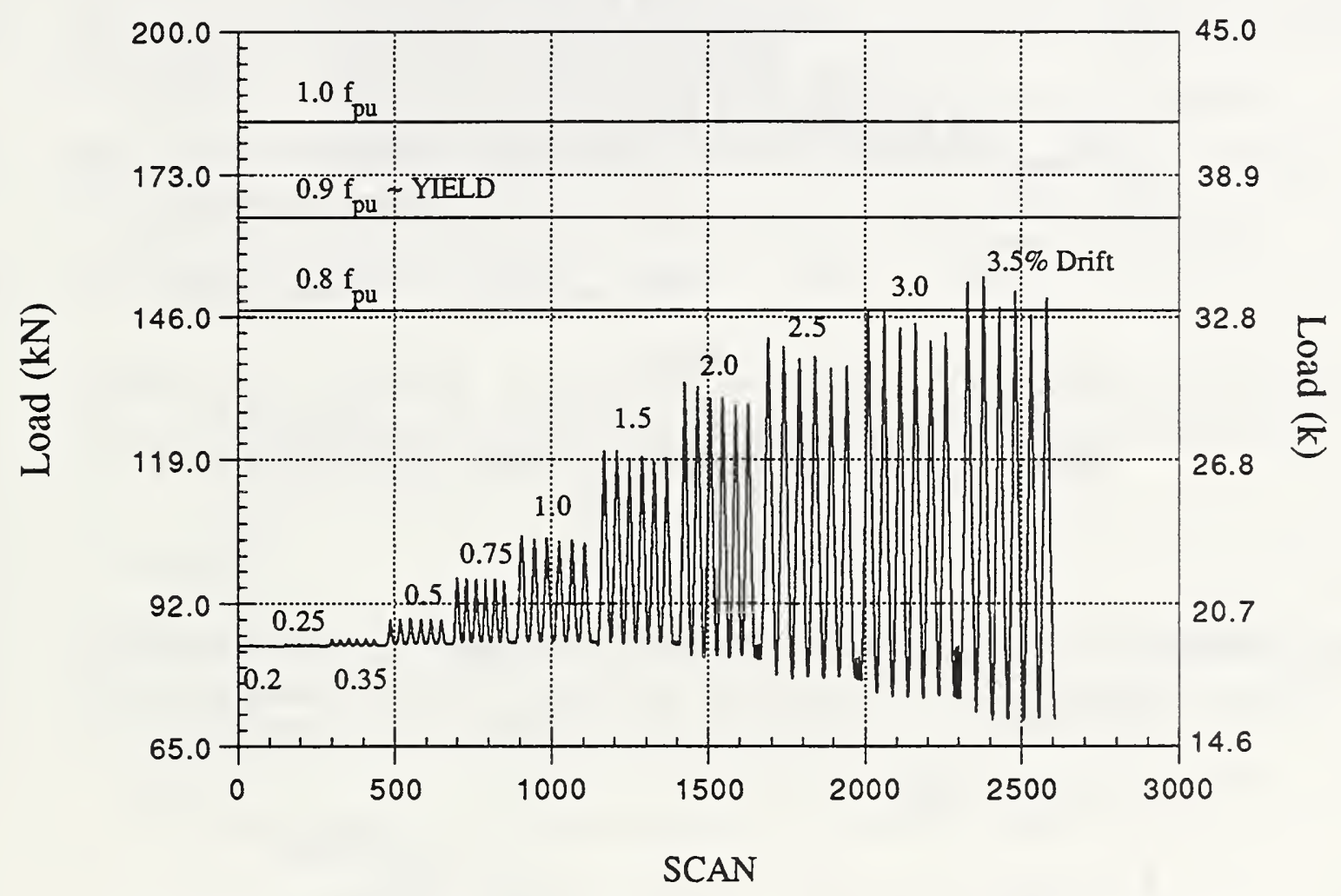

Figure 3.3. Force in Prestressing Strand 1, M-P-Z4. 


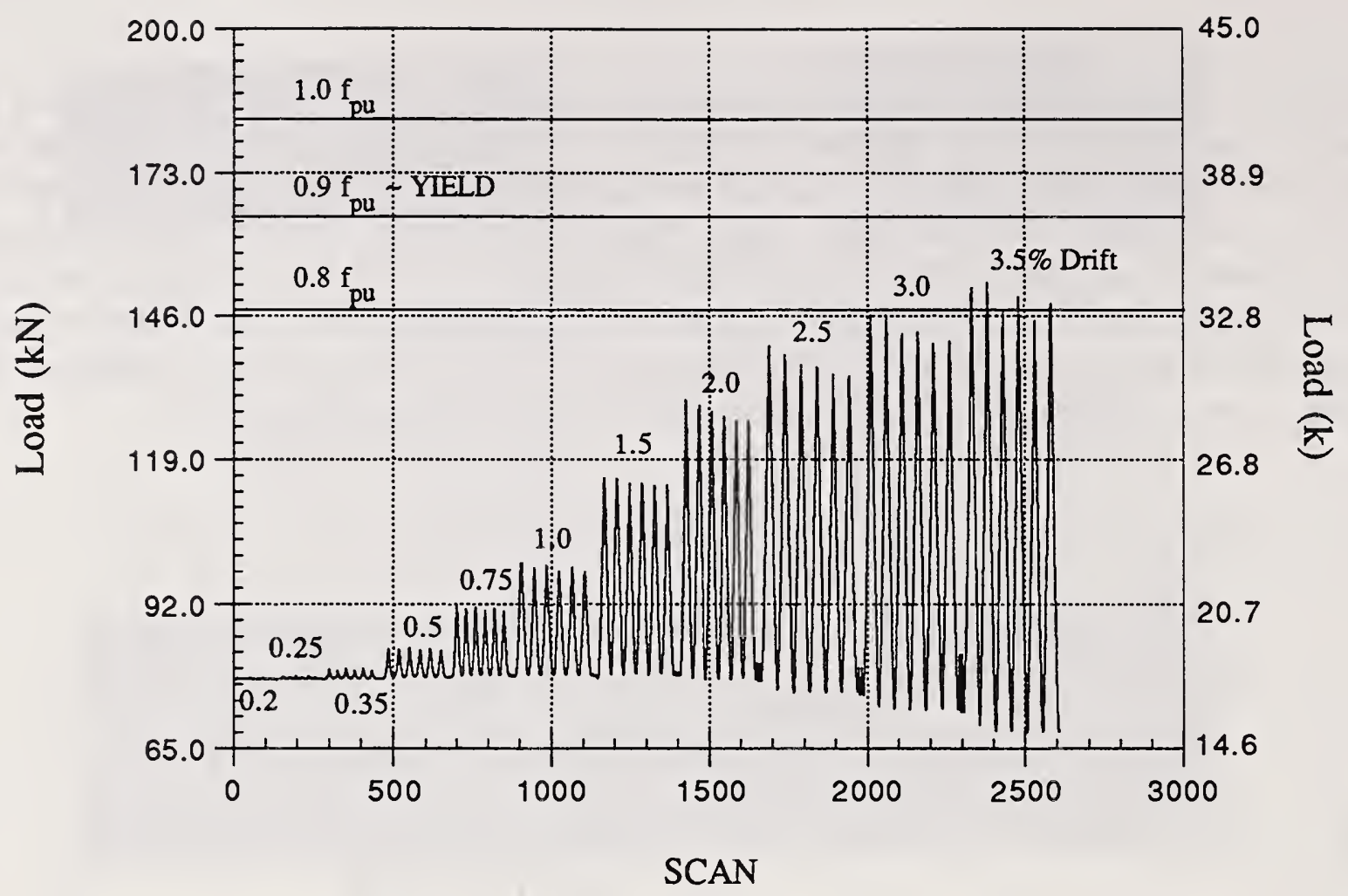

Figure 3.4. Force in Prestressing Strand 2, M-P-Z4.

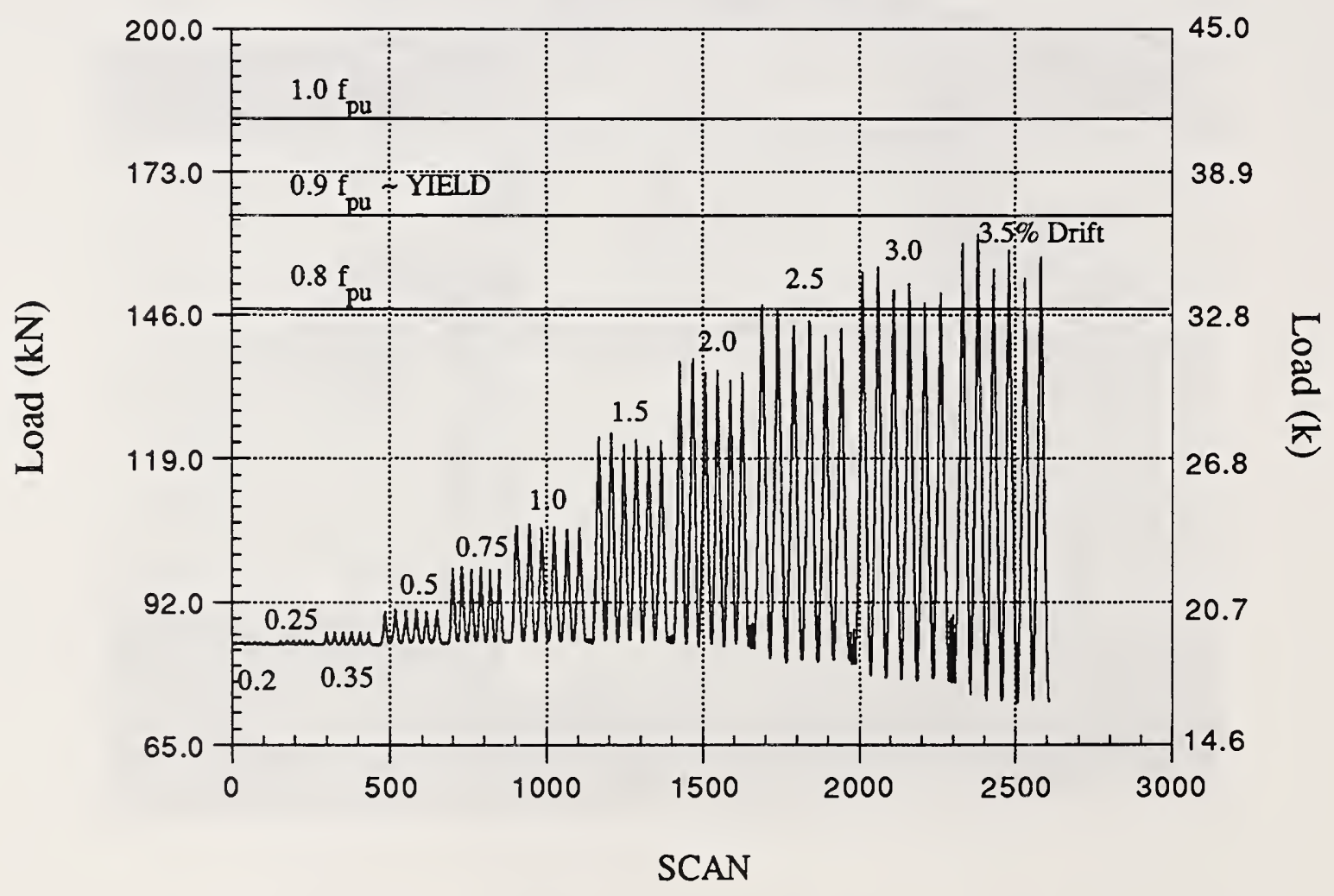

Figure 3.5. Force in Prestressing Strand 3, M-P-Z4. 


\section{ERATA SHEET \\ NISTIR 5436}

1). Fig. 2.3, Page 8 - The grouting scheme is for the model but the dimensions are for the prototype.

2). Fig. 2.4, Page 9 - The init. beam prestresses are 2.98, 2.83, 2.76, and 3.0 $\mathrm{MPa}$ for specimens M-P-Z4, N-P-Z4, O-P-Z4, and P-P-Z4, respectively.

3). Fig. 2.6, Detail A, Page 11 - The dimension $8.3 \mathrm{~mm}$ should be $4.15 \mathrm{~mm}$.

4). Page 13. Last paragraph. The amount of fibers used was $1.78 \mathrm{~kg} / \mathrm{m}^{3}\left(3 \mathrm{lb} / \mathrm{yd}^{3}\right)$ not $8.7 \mathrm{~kg} / \mathrm{m}^{3}$.

5). Fig. 3.28, Page 36 - The title for the Y-axis should read [Cyclic Energy Dissipated/(Pred. Mom. * Story Drift)].

6). References, Page 43 - The reference:

Cheok, G. C., Stone W. C. and Lew, H. S (1993), "Performance of 1/3-Scale Model Precast Concrete Beam-Column Connections Subjected to Cyclic Inelastic Loads - Report No. 3," NISTIR 5246, NIST, Gaithersburg, MD, August, 1993.

should read:

Cheok, G. C. and Stone W. C. (1993), "Performance of 1/3-Scale Model Precast Concrete Beam-Column Connections Subjected to Cyclic Inelastic Loads - Report No. 3," NISTIR 5246, NIST, Gaithersburg, MD, August, 1993. 

Table 3.1. Peak Stresses and Residual Forces in PT Steel.

\begin{tabular}{|c|c|c|c|c|c|c|}
\hline \multirow{2}{*}{ Specimen } & \multirow{2}{*}{$\begin{array}{l}\text { Avg. peak } \\
\text { stress }^{2} \text { in } \\
\text { Strands }\end{array}$} & \multicolumn{2}{|c|}{ \% Story Drift @ } & \multirow{2}{*}{$\begin{array}{l}\text { Stress }^{\mathrm{b}} \text { in } \\
\text { strand } 1 @ \\
\text { end of test }\end{array}$} & \multirow{2}{*}{$\begin{array}{l}\text { Stress }^{\mathrm{b}} \text { in } \\
\text { strand } 2 @ \\
\text { end of test }\end{array}$} & \multirow{2}{*}{$\begin{array}{l}\text { Stress }^{b} \text { in } \\
\text { strand } 3 @ \\
\text { end of test }\end{array}$} \\
\hline & & Peak Stress & Failure & & & \\
\hline M-P-Z4 & $0.85 \mathrm{f}_{\mathrm{pu}}$ & 3.4 & 3.4 & $0.38 \mathrm{f}_{\mathrm{pu}}$ & $0.37 \mathrm{f}_{\mathrm{pu}}$ & $0.40 \mathrm{f}_{\mathrm{pu}}$ \\
\hline N-P-Z4 & 0.94 & 5.9 & $2.9^{c}$ & 0.13 & 0.11 & 0.10 \\
\hline O-P-Z4 & 0.88 & 3.9 & 3.4 & 0.39 & 0.40 & 0.38 \\
\hline P-P-Z4 & 0.84 & 3.4 & $2.9^{\mathrm{d}}$ & 0.53 & 0.51 & 0.53 \\
\hline
\end{tabular}

a Stress is the average of values for the 3 prestressing strands.

b The stresses at the end of the tests were equal to the minimum values for all specimens except specimen P-P-Z4. The minimum stresses in strands 1,2 , and 3 were $0.44,0.42,0.44 \mathrm{f}_{\mathrm{pu}}$, respectively, for specimen P-P-Z4. These minimum values were obtained at $1.0 \%$ story drift in the aftershock.

c Specimen experienced bond failure of mild steel.

d This value is that for the specimen in the aftershock, i.e., the specimen did not fail when it was subjected to the first 3 cycles at this drift level.

\subsubsection{Specimen N-P-Z4 (2 - $9 \mathrm{~mm} \phi, 304$ stainless steel bars, top and bottom)}

Specimen N-P-Z4 failed prematurely due to bond failure of the stainless steel bars. Bond failure of one of the stainless steel bars occurred at approximately $2.0 \%$ story drift. Bond failure occurred at approximately $2.5 \%, 3.0 \%$, and $6.0 \%$ (second cycle) for the remaining stainless steel bars. The bar which debonded at $6.0 \%$ story drift had yielded in the first cycle at $6.0 \%$ before debonding. The opening between the beam and column at $5.9 \%$ story drift was $23 \mathrm{~mm}$. Figures 3.6 and 3.7 show the specimen at story drifts of $1.4 \%$ and $2.9 \%$ (failure). 


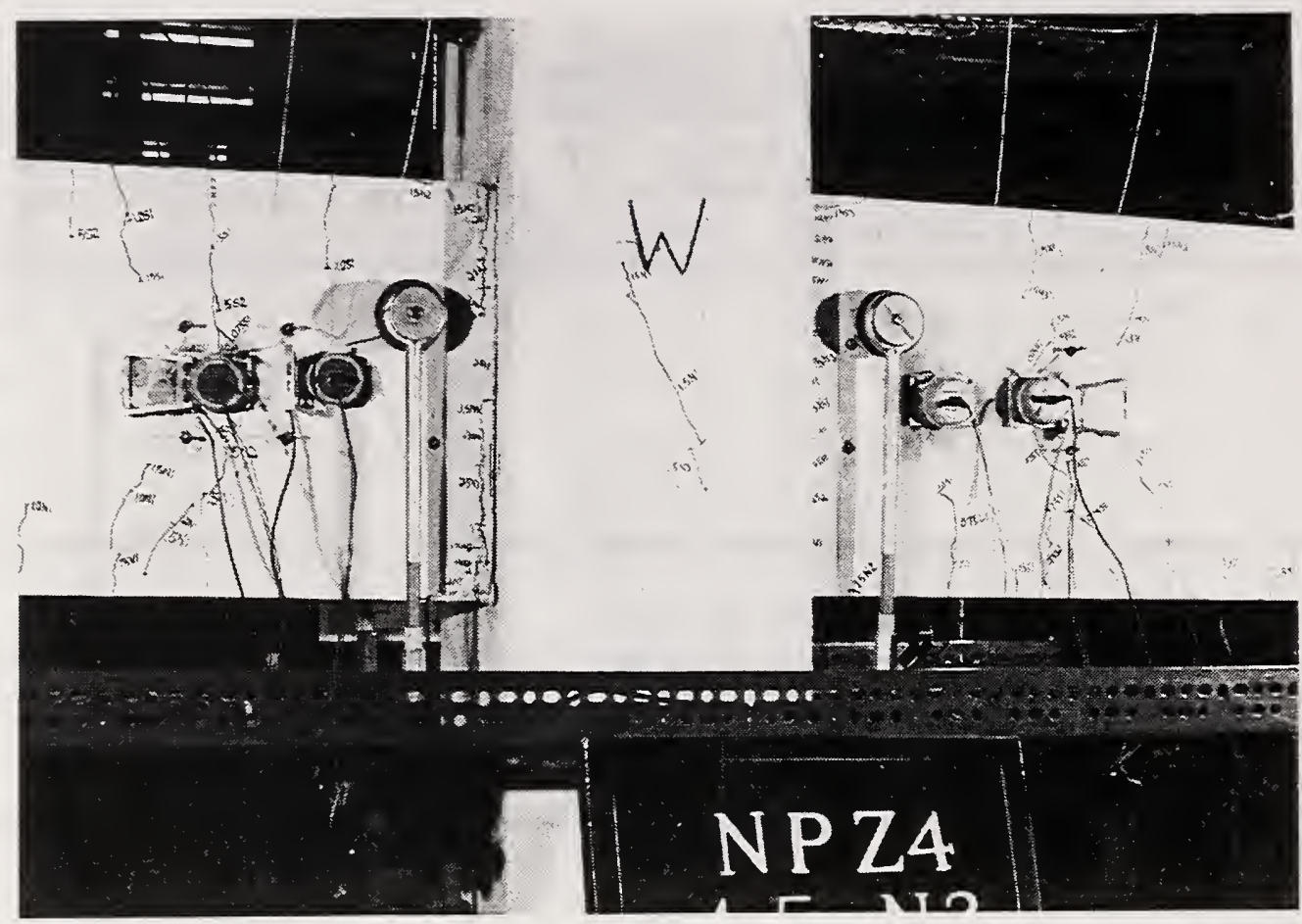

Figure 3.6. N-P-Z4 at $1.4 \%$ Story Drift.

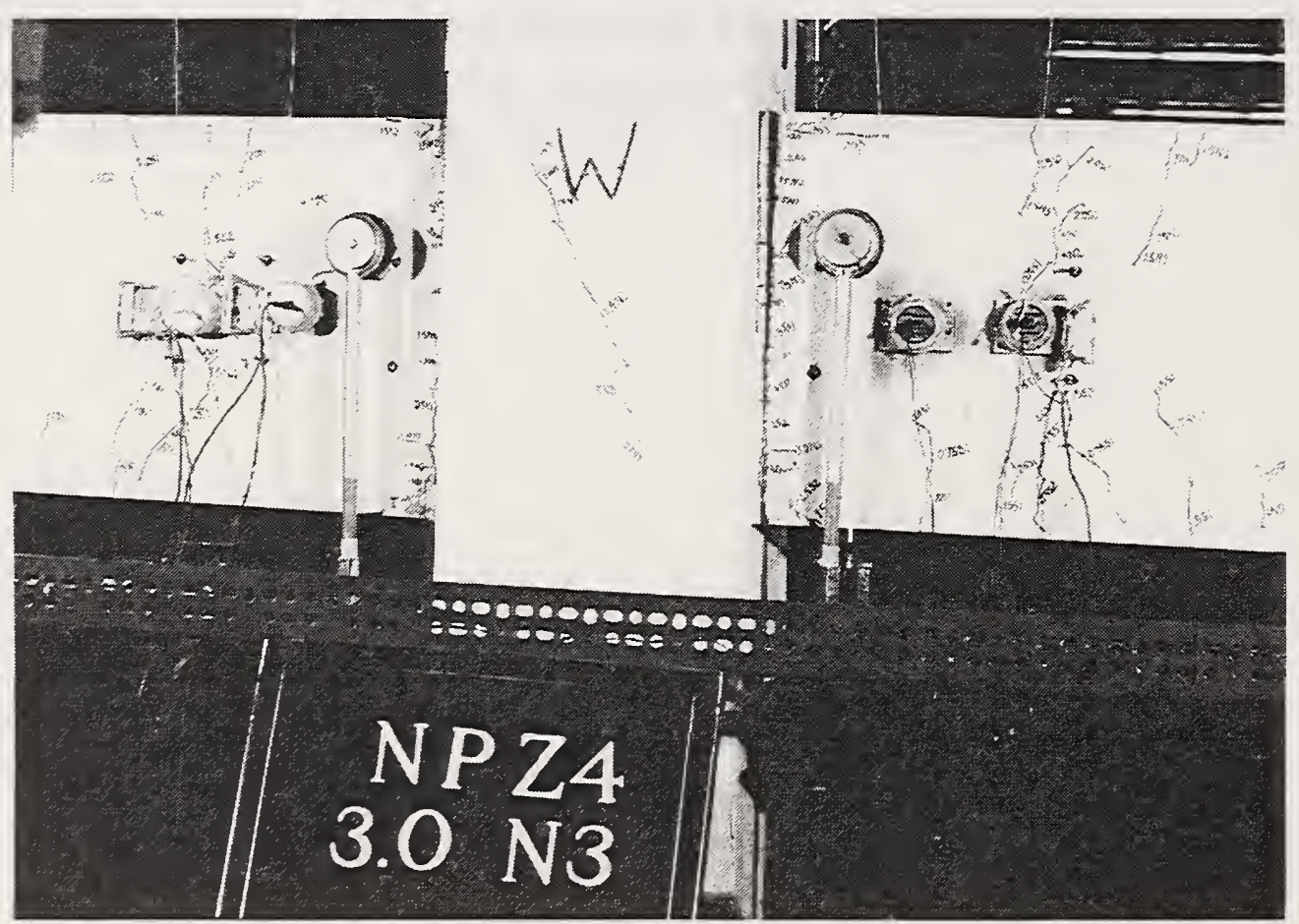

Figure 3.7. N-P-Z4 at Failure, 2.9\% Story Drift. 
Due to the debonding of the mild steel, a decision was made to cycle the specimen to $6.0 \%$ story drift after the cycles at $3.5 \%$ story drift. This was because no yielding of the stainless steel bars was expected to occur due to the debonding and therefore, little additional information on the energy dissipation characteristics could be gained by cycling the specimen at story drifts of $3.5 \%, 4.0 \%, 4.5 \%$, etc. The specimen was cycled at $6.0 \%$ story drift to determine the stress in the PT steel and the ability of the connection to resist both the applied and gravity loads at this drift level.

Debonding of the bars occurred in only one beam (south beam) or on one side of the connection. Visual indications point to debonding of the bars in one beam and through the column, but debonding did not occur in the other beam. The different stages at which bond failure occurred seem to indicate that the development length of the bars, $305 \mathrm{~mm}$, was marginal.

As seen in Table 3.1, the PT steel yielded at a story drift of 5.9\%. As a result of yielding, the average stress in the PT steel at the end of the test was approximately $25 \%$ of initial stress or $0.1 \mathrm{f}_{\mathrm{pu}}$. However, sufficient clamping force was still produced by the PT steel to resist the gravity loads as no vertical slip of the beam relative to the column was noted at zero displacement. As shown in Figs. 3.8 to 3.10, the strands did not yield at 3.4\% story drift.

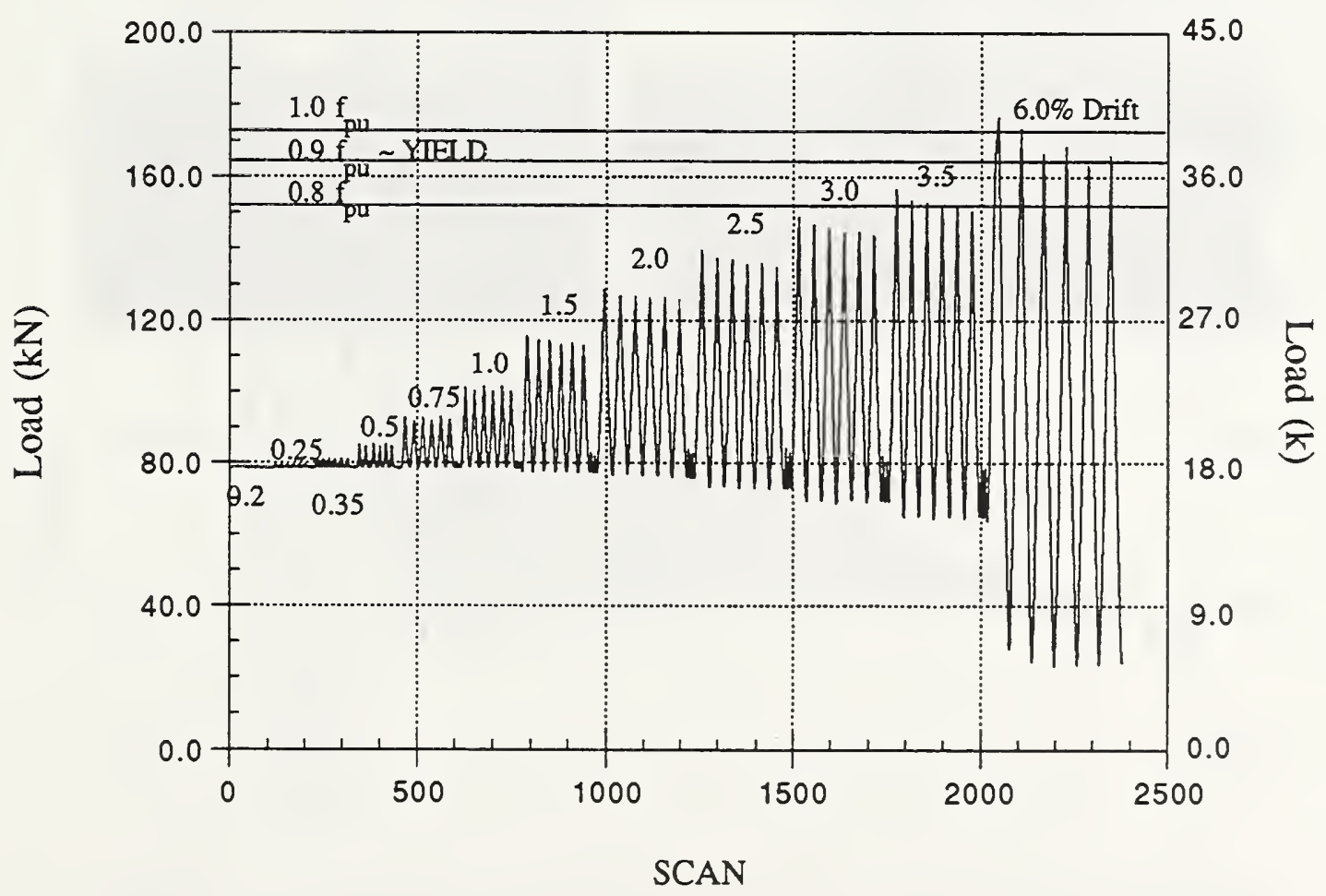

Figure 3.8. Force in Prestressing Strand 1, N-P-Z4. 


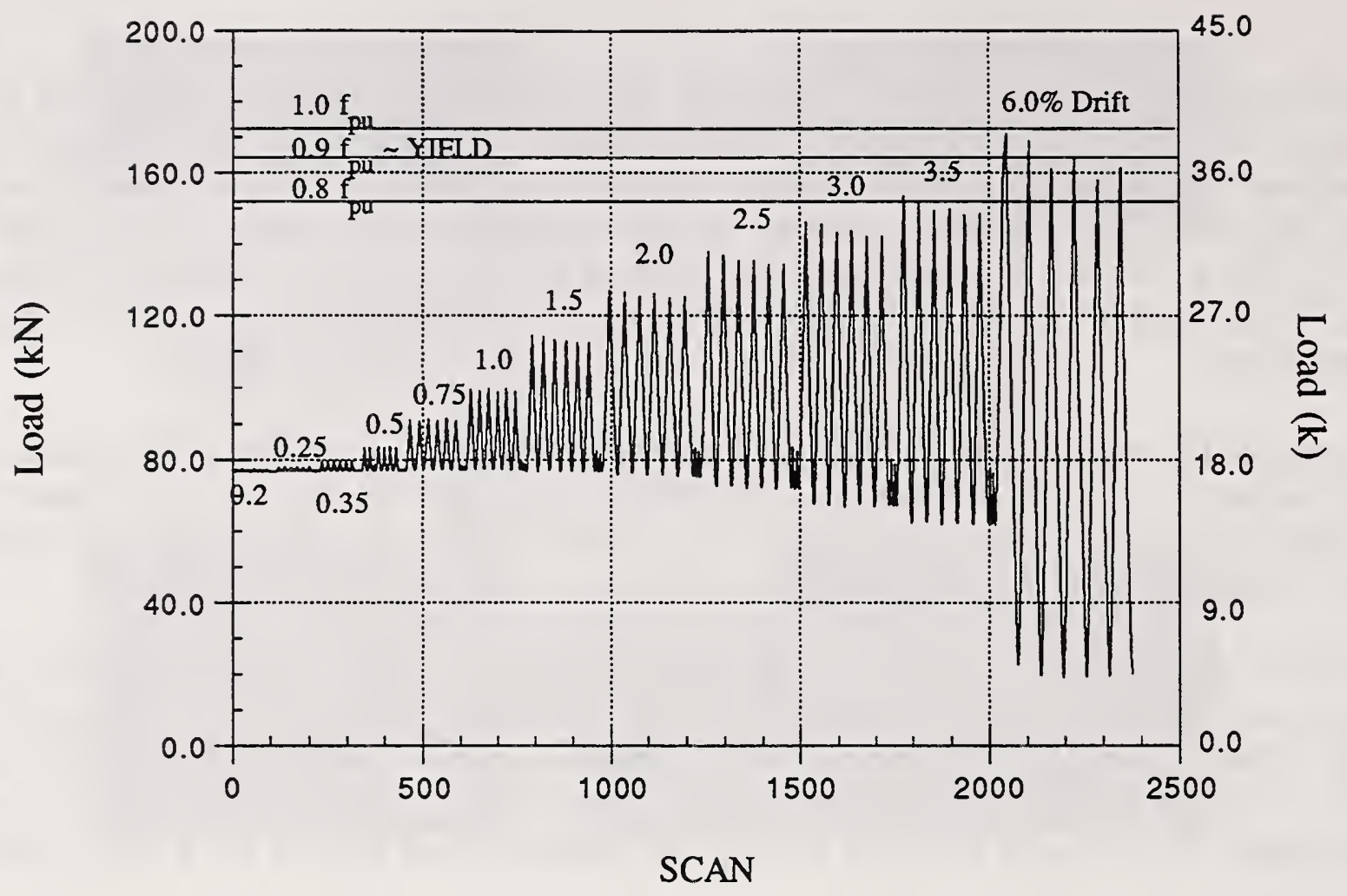

Figure 3.9. Force in Prestressing Strand 2, N-P-Z4.

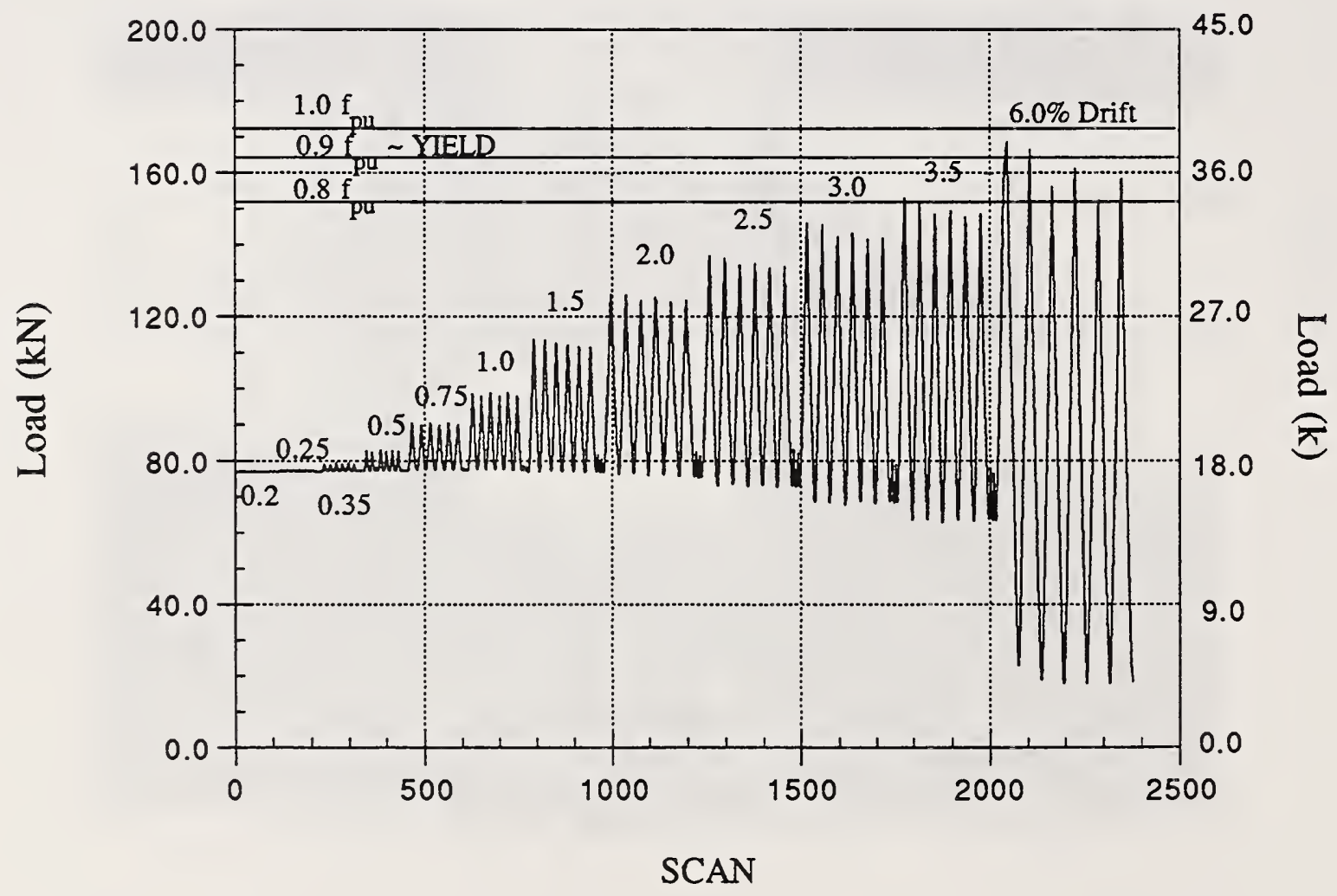

Figure 3.10. Force in Prestressing Strand 3, N-P-Z4. 


\subsubsection{Specimen O-P-Z4 (3 - \#3, Grade 60, reinforcing bar, top and bottom)}

Failure of specimen O-P-Z4 also resulted from fracture of the mild steel bars. Bar fractures occurred at story drifts of approximately $3.5 \%$ and $4.0 \%$. A total of 8 bars fractured in this specimen. The opening between the beam and column at failure was $11 \mathrm{~mm}$. Figures 3.11 and 3.12 show specimen O-P-Z4 at story drifts of $1.4 \%$ and $3.4 \%$ (failure).

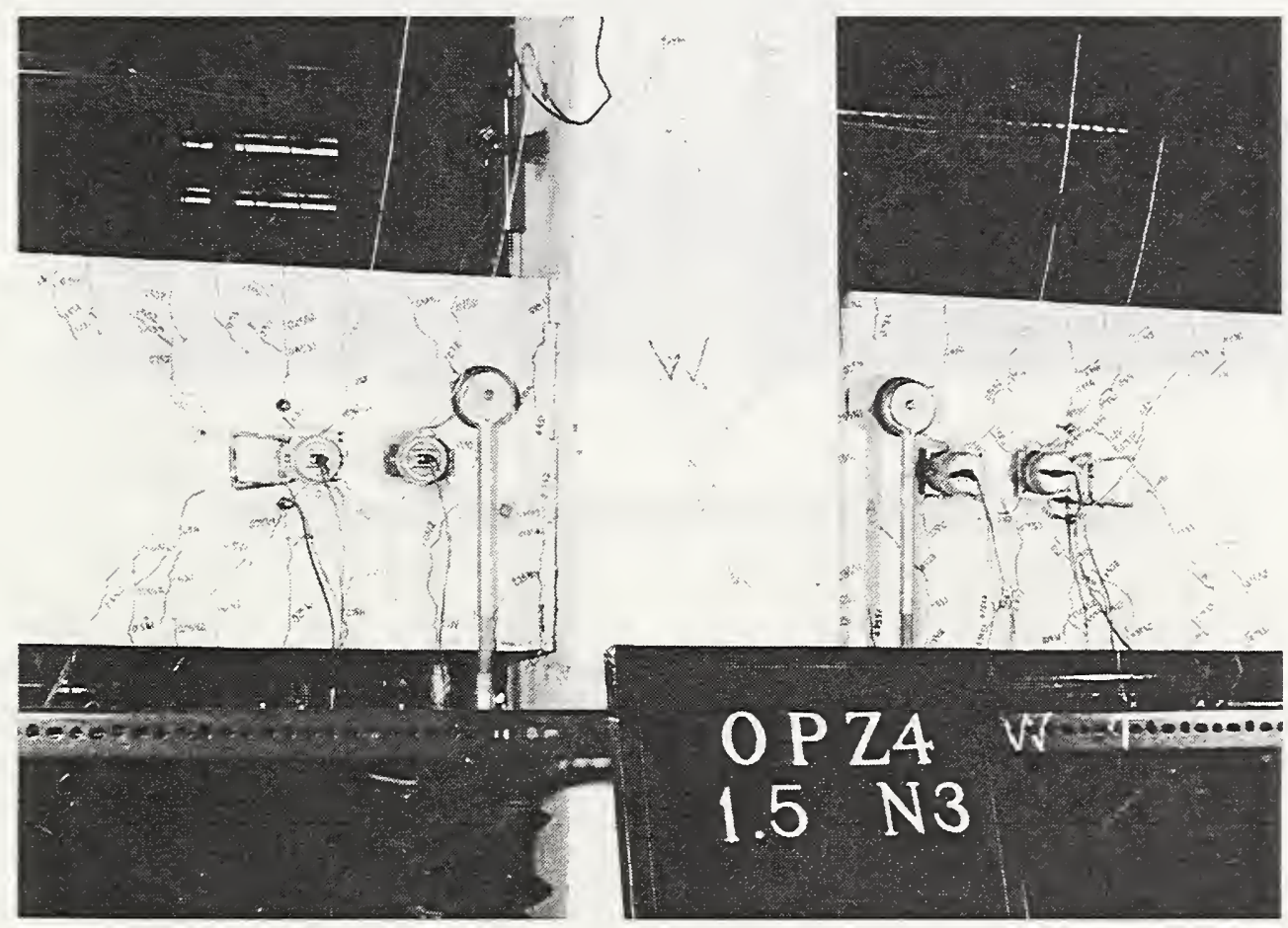

Figure 3.11. O-P-Z4 at $1.4 \%$ Story Drift. 


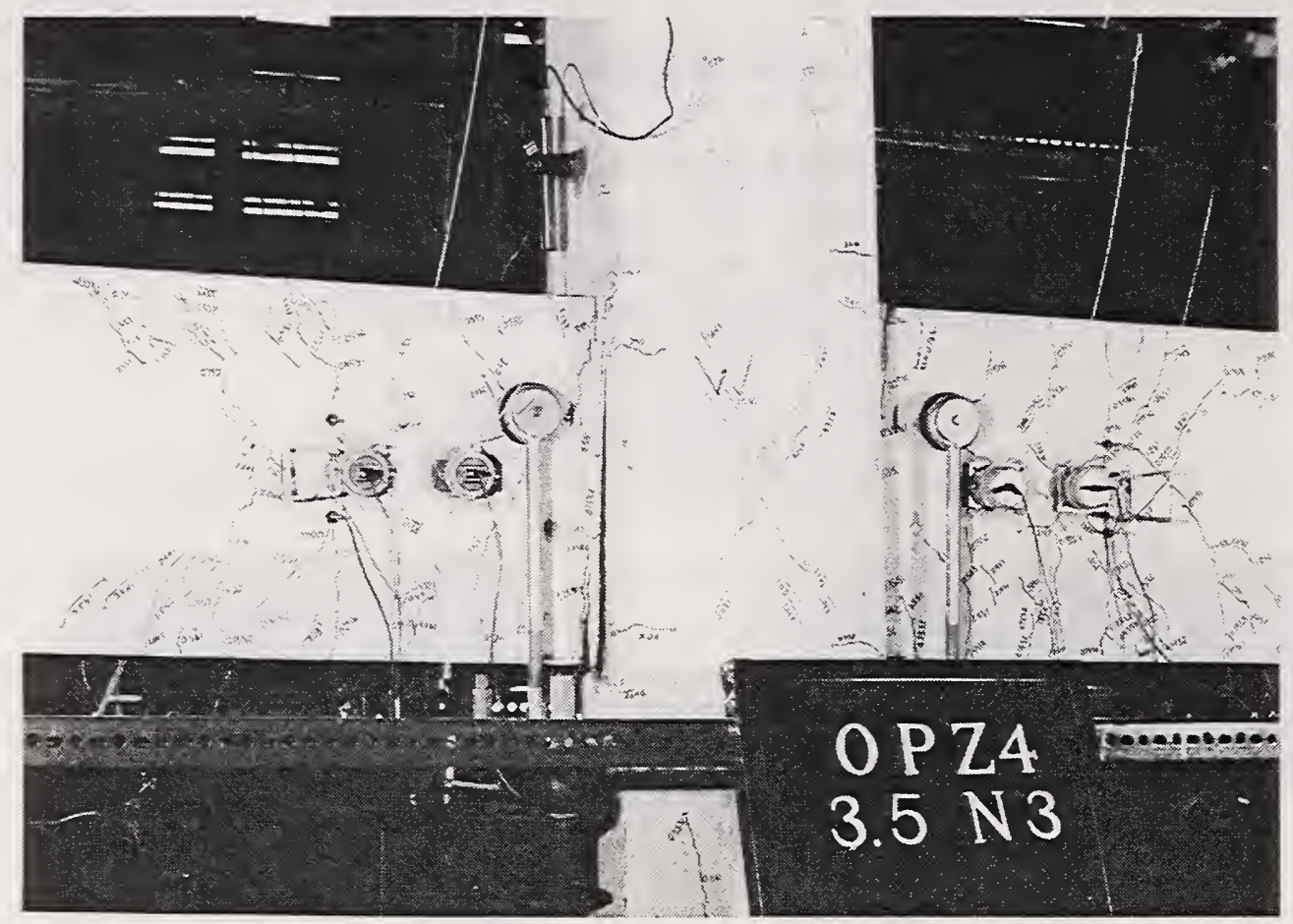

Figure 3.12. O-P-Z4 at Failure, 3.4\% Story Drift.

The PT steel in this specimen remained in the elastic range through failure with an average peak stress of $0.88 \mathrm{f}_{\mathrm{pu}}$. The total loss in prestress in the PT steel was $0.02 \mathrm{f}_{\mathrm{pu}}$. The forces in the prestressing strands are shown in Figs. 3.13 to 3.15. 


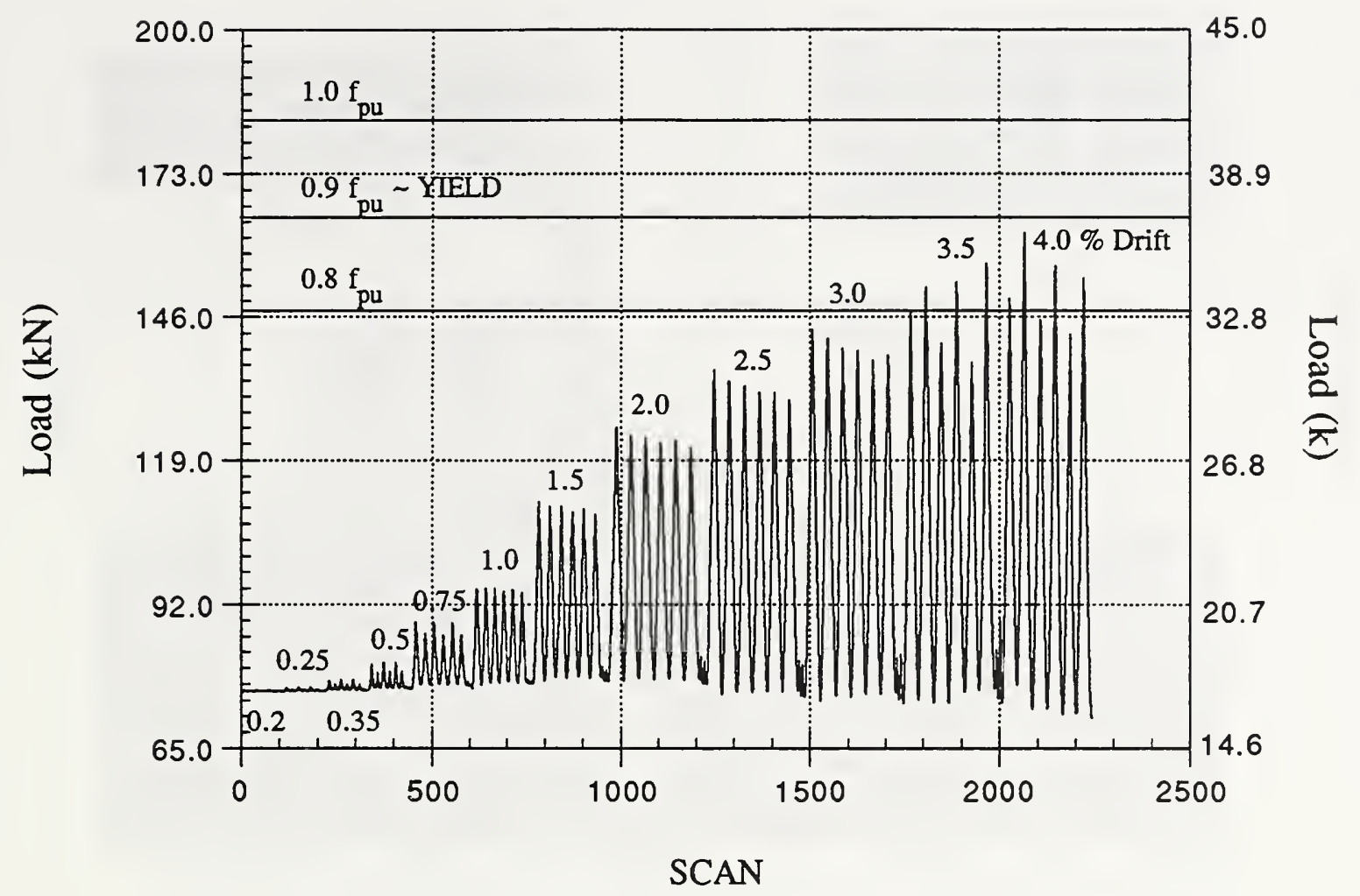

Figure 3.13. Force in Prestressing Strand 1, O-P-Z4.

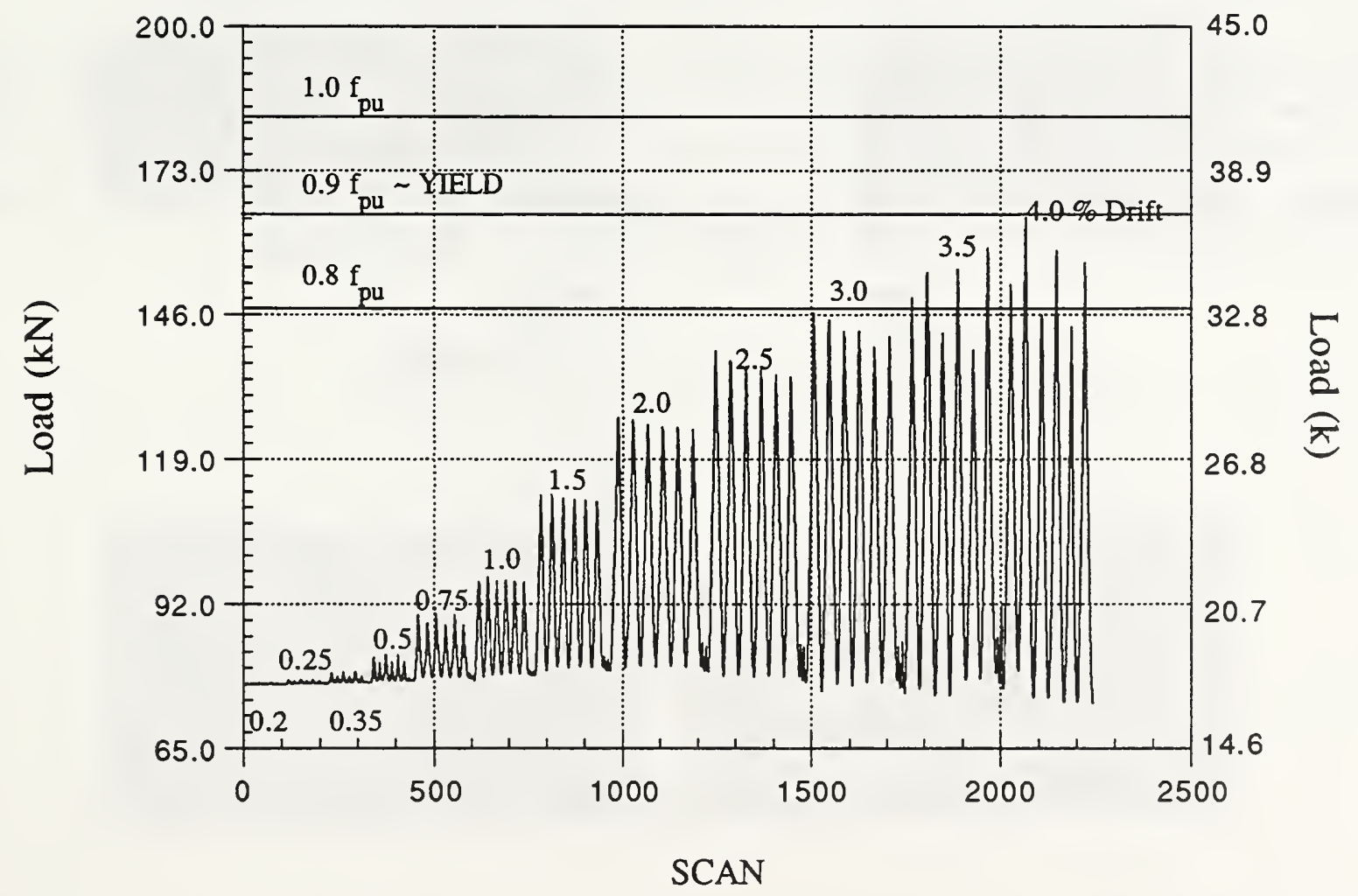

Figure 3.14. Force in Prestressing Strand 2, O-P-Z4. 


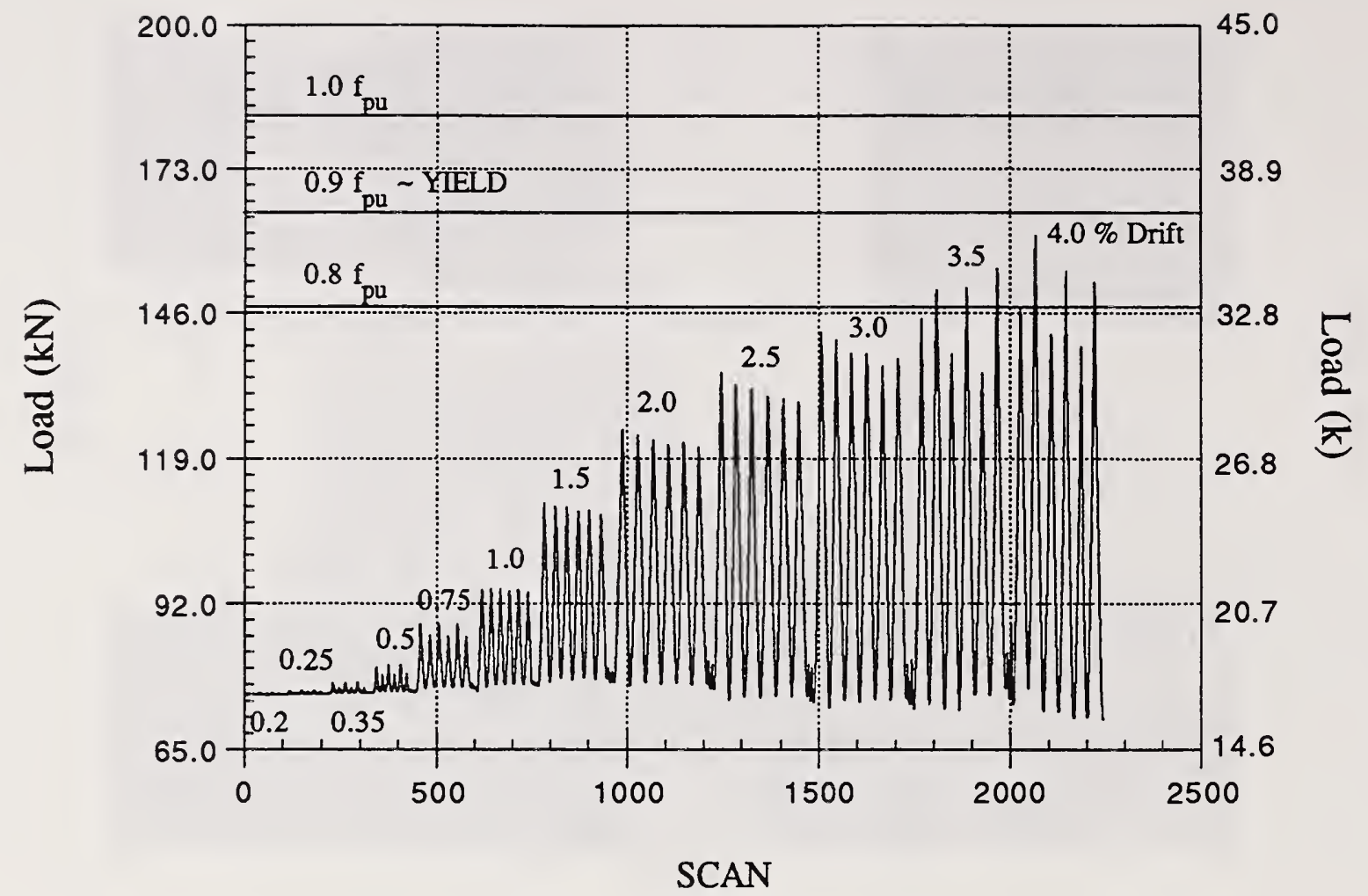

Figure 3.15. Force in Prestressing Strand 3, O-P-Z4.

\subsubsection{Specimen P-P-Z4 (3 - 9 mm $\phi, 304$ stainless steel bars, top and bottom)}

Failure of specimen P-P-Z4 resulted from fracture of the mild steel bars. Fracture of the bars may in part be due to fatigue as this specimen was subjected to a total of number of 57 cycles prior to failure. The bars fractured at story drifts of approximately $2.0 \%$ and $3.0 \%$ in the aftershock. A total of 6 stainless steel bars were suspected to have fractured. Figures 3.16 and 3.17 show specimen P-P-Z4 at $1.4 \%$ and $2.9 \%$ story drift in the aftershock. 


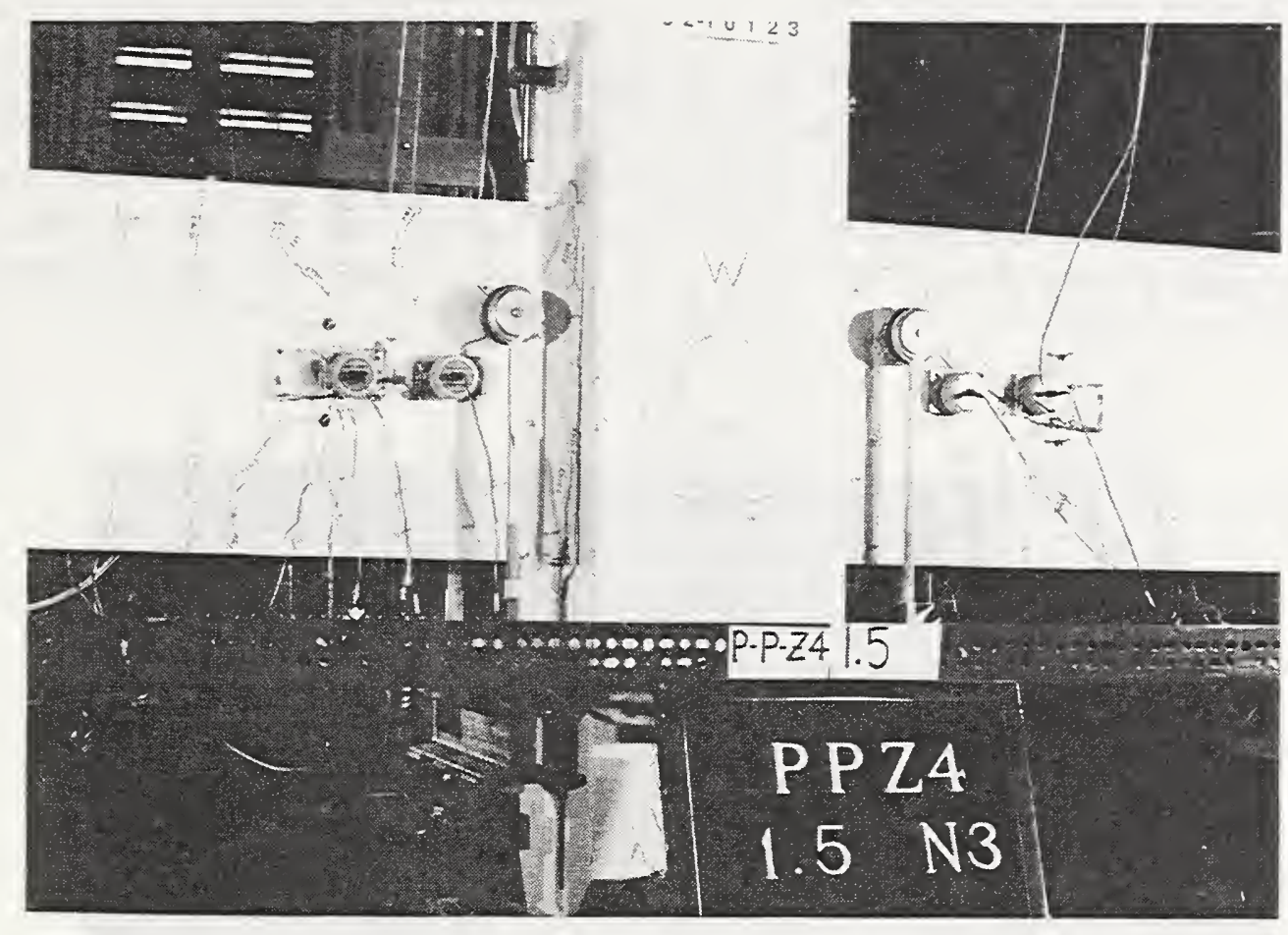

Figure 3.16. P-P-Z4 at $1.4 \%$ Story Drift.

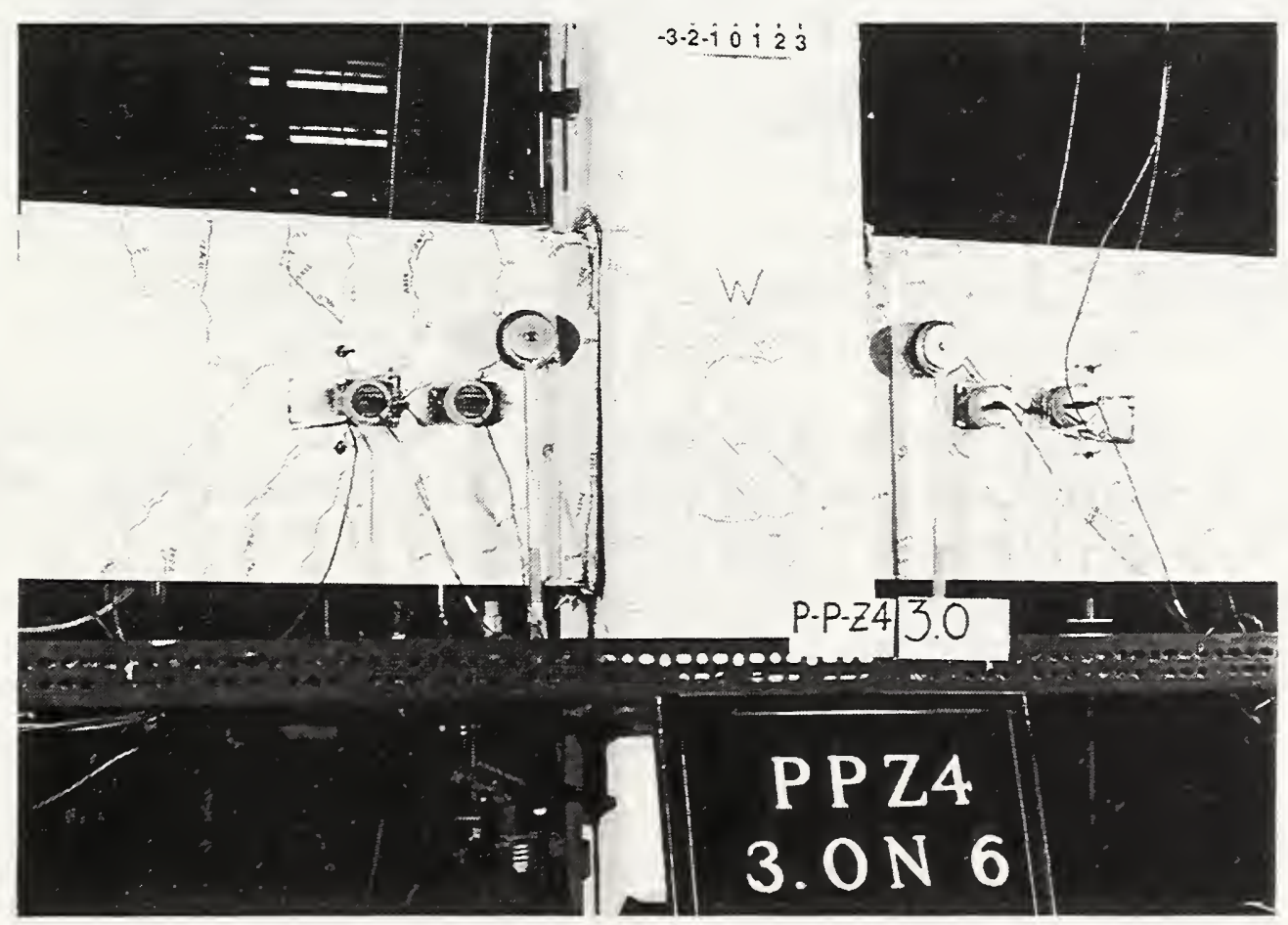

Figure 3.17. P-P-Z4 at Failure, 2.9\% Story Drift. 
Unlike the previous specimens, a large area of concrete cover (Fig. 3.18) pulled out of the column around the mild steel bars and spalled off. Similar spalling of the concrete cover around the mild steel bars occurred in the other specimens but to a lesser extent. This may have been caused by the fact that the mild steel bars in this specimen were fully grouted whereas the bars in the other specimens were debonded $25 \mathrm{~mm}$ on either side of the beam-column interface.

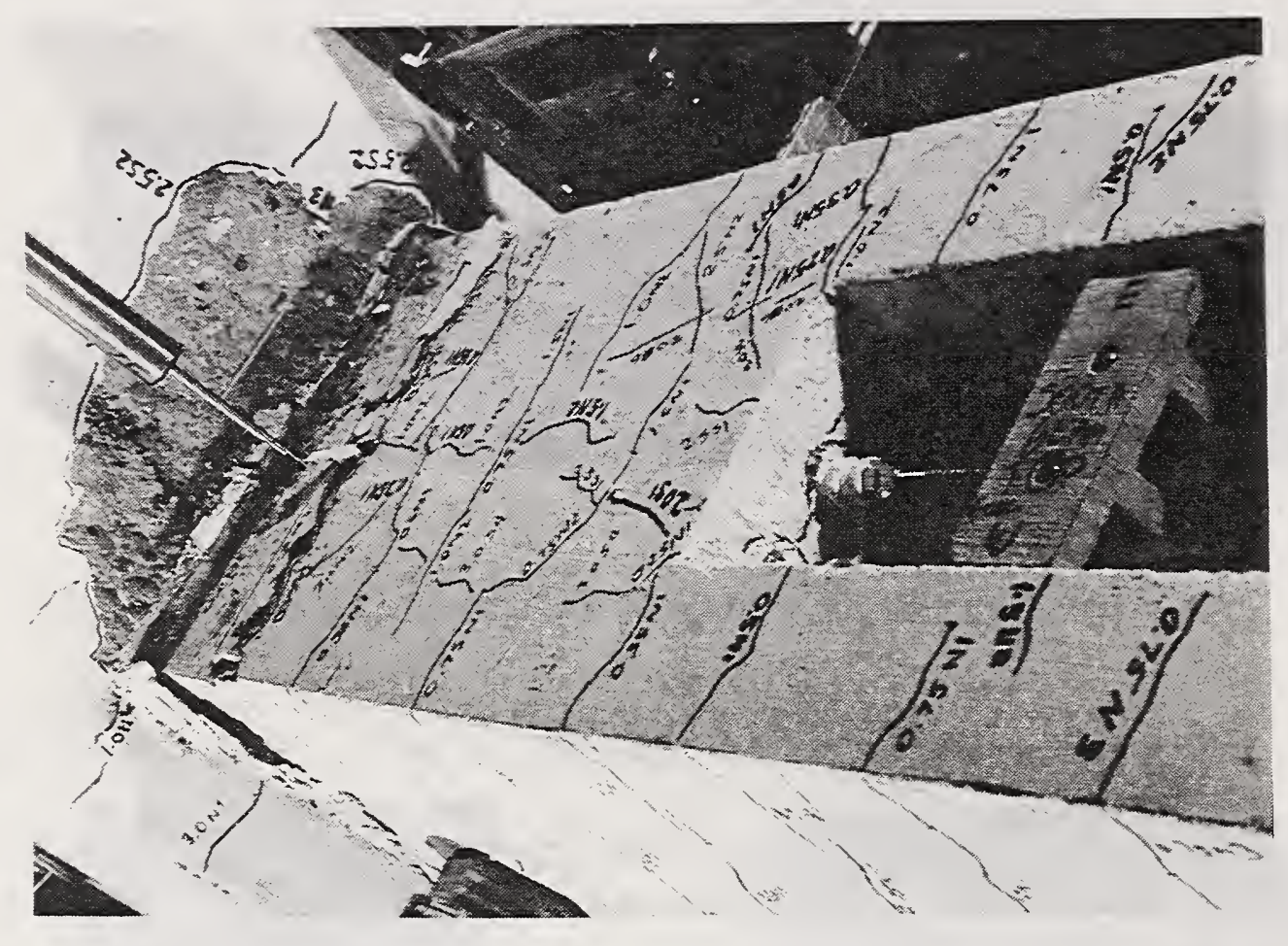

Figure 3.18. Spalling of Concrete Cover, $2.9 \%$ Story Drift, P-P-Z4.

The forces in the prestressing strands are shown in Figs. 3.19 to 3.21. As with the previous specimens, the PT steel remained in the elastic range with an average peak stress equal to 0.84 $\mathrm{f}_{\mathrm{pu}}$. As seen in Table 3.1, the stress in the PT steel at the end of the test, $0.52 \mathrm{f}_{\mathrm{pu}}$, is greater than the initial stress, $0.45 \mathrm{f}_{\mathrm{pu}}$ (Table 2.2). 


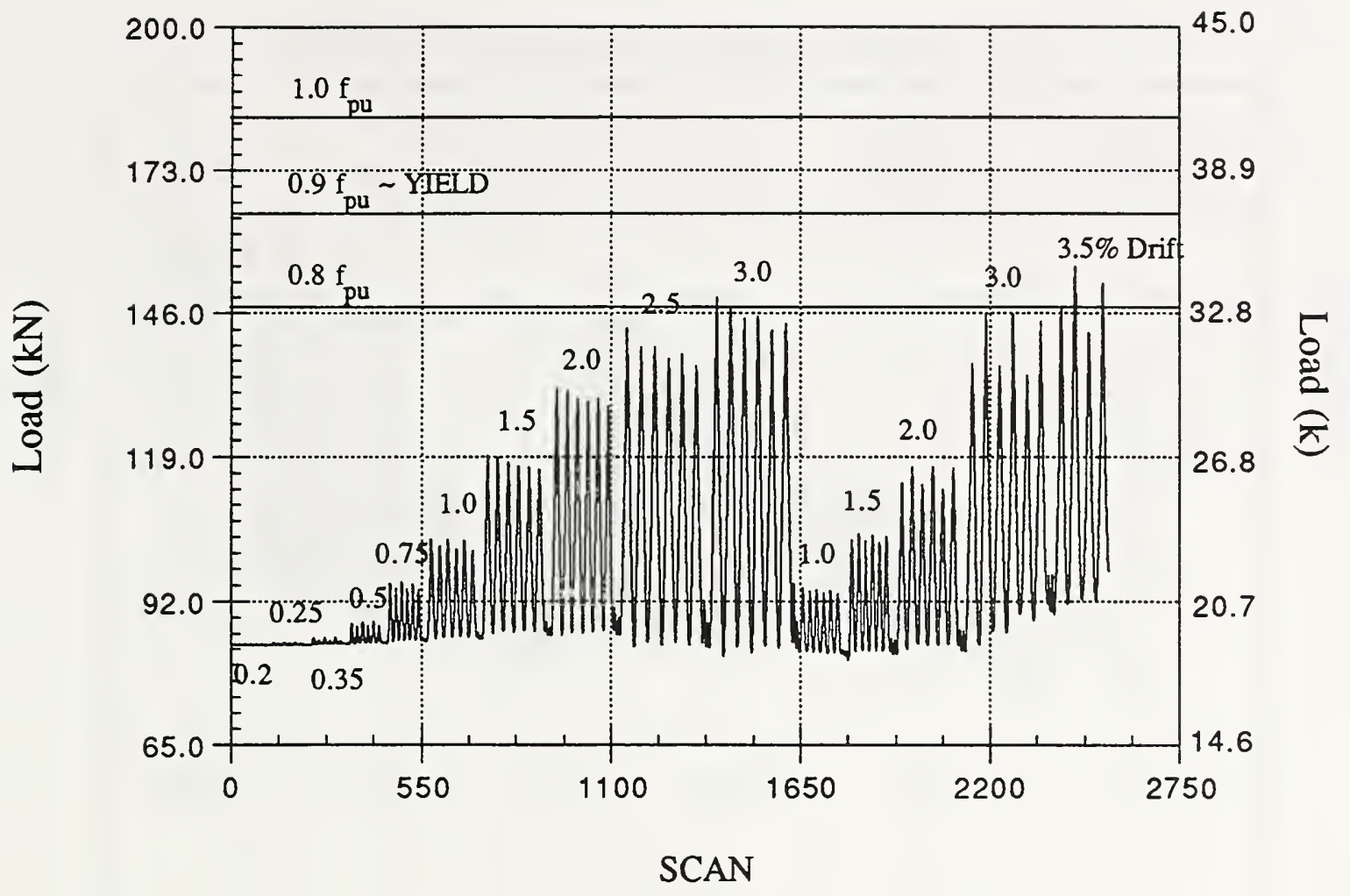

Figure 3.19. Prestressing Force in Strand 1, P-P-Z4.

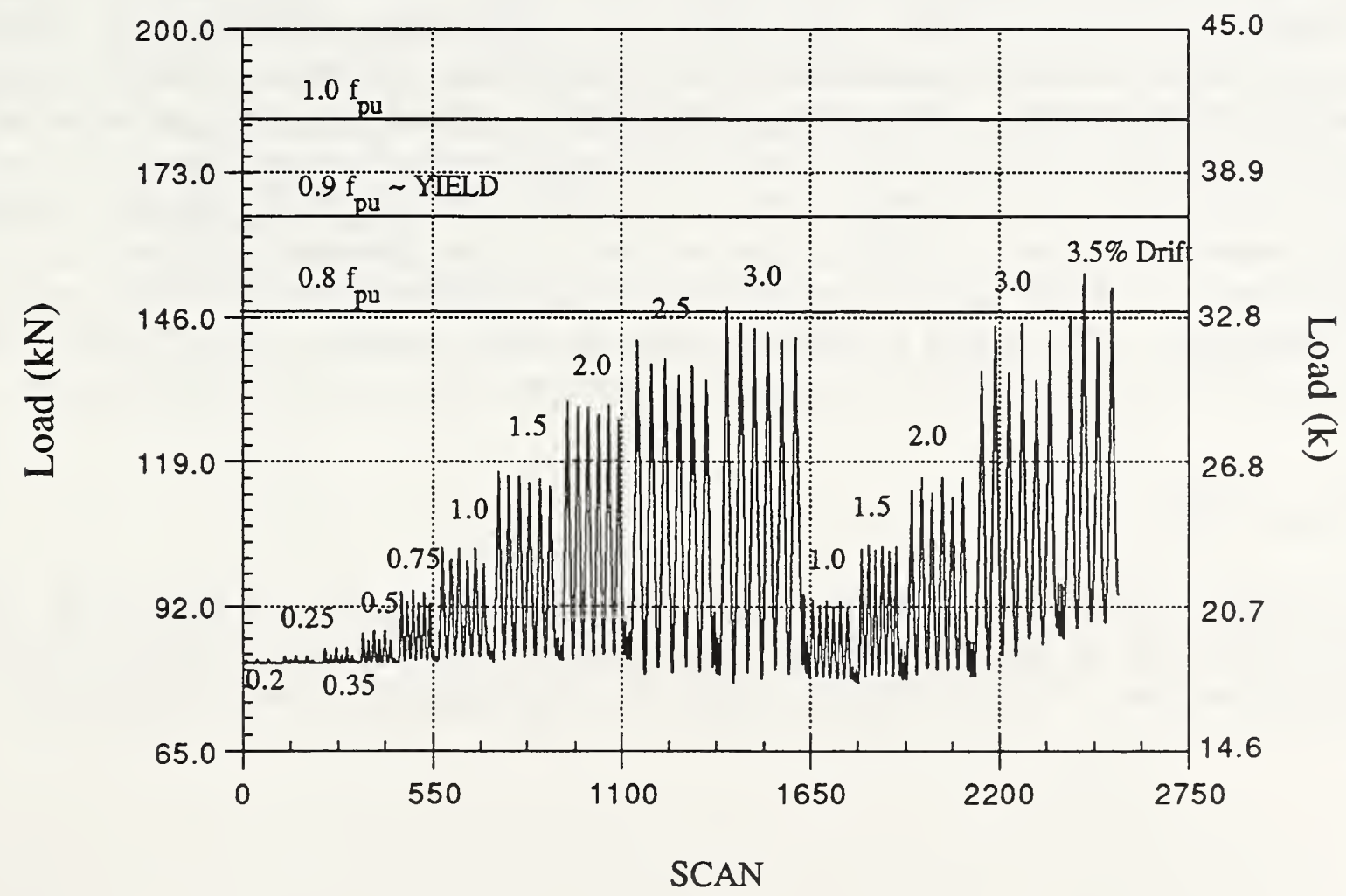

Figure 3.20. Prestressing Force in Strand 2, P-P-Z4. 


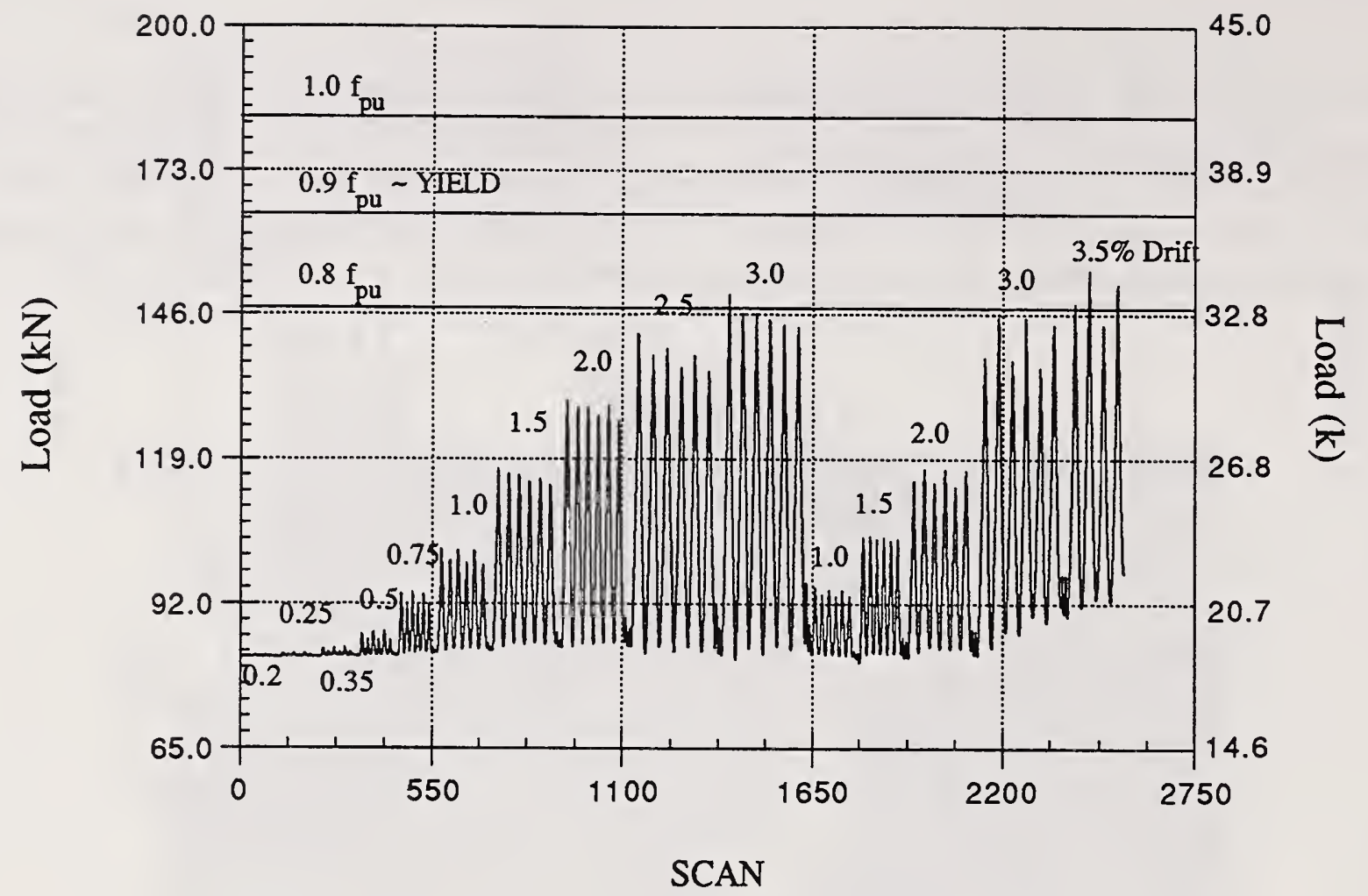

Figure 3.21. Prestressing Force in Strand 3, P-P-Z4.

Two possible reasons are offered for this increase in stress. At the end of the test, a gap of approximately $0.8 \mathrm{~mm}$ to $1.6 \mathrm{~mm}$ existed between one of the beams and the column. This gap corresponds to an increase in stress in the PT steel of $105 \mathrm{MPa}-210 \mathrm{MPa}$ based on a modulus of elasticity of $199,955 \mathrm{MPa}$. The difference in the PT steel stress from the start to the end of the test is $130 \mathrm{MPa}\left(0.07 \mathrm{f}_{\mathrm{pu}}\right)$ which is within the range stated. One possible reason for the existence of the gap is debris falling between the beam and column during the test. Another possible reason is that upon fracturing, the two pieces of the elongated mild steel bar were misaligned and as a result, kept the gap between the beam and column from closing totally at zero displacement. This reason is offered because the stress increase in the PT steel at zero displacement (see Figs. 3.19 to 3.21) began after fracture of the mild steel bars occurred.

\subsection{Story Drift}

The hysteresis plots for the Phase IV B specimens are given in Figs. 3.22 to 3.25. The hysteresis plots for the monolithic Zone 4 specimens are given in Figs. 3.26 and 3.27 for comparison purposes. The story drifts at failure for all specimens are given in Table 3.2. 
Table 3.2. Connection Strengths and Story Drifts.

\begin{tabular}{|c|c|c|c|c|}
\hline \multirow{2}{*}{ Specimen Name } & \multicolumn{2}{|c|}{ Moment $(\mathrm{kN}-\mathrm{m})$} & \multirow{2}{*}{$\begin{array}{l}\text { Experimental } \\
\text { Story Drifts } \\
\text { @ Failure (\%) }\end{array}$} & \multirow{2}{*}{$\begin{array}{l}\text { Number of } \\
\text { Loading Cycles } \\
\text { to Failure }\end{array}$} \\
\hline & Predicted & Experimental & & \\
\hline $\mathrm{A}-\mathrm{M}-\mathrm{Z} 2$ \& B-M-Z2 & 68 & $80 / 75$ & $4.4 / 4.6$ & $8 / 8$ \\
\hline $\mathrm{A}-\mathrm{P}-\mathrm{Z} 2$ \& B-P-Z2 & $49^{3}$ & $54 / 54$ & $2.5 / 2.9$ & $5 / 6$ \\
\hline $\mathrm{A}-\mathrm{M}-\mathrm{Z} 4$ \& B-M-Z4 & 132 & $148 / 153$ & $3.7 / 3.4$ & $8 / 8$ \\
\hline $\mathrm{A}-\mathrm{P}-\mathrm{Z} 4$ \& B-P-Z4 & $160^{\mathrm{a}}$ & $186 / 186$ & $3.4 / 3.8$ & $13 / 13$ \\
\hline C-P-Z4 \& D-P-Z4 & $159^{2}$ & $171 / 169$ & $6.3 / 6.2$ & $15 / 15$ \\
\hline E-P-Z4 \& F-P-Z4 & $113^{\mathrm{a}}$ & $138 / 146$ & $7.0 / 6.9$ & $16 / 15$ \\
\hline $\mathrm{G}-\mathrm{P}-\mathrm{Z} 4^{\mathrm{b}} \& \mathrm{H}-\mathrm{P}-\mathrm{Z} 4^{\mathrm{b}}$ & $111^{\mathrm{a}}$ & $123 / 132$ & $5.9 / 5.6$ & $19 / 18$ \\
\hline $\mathrm{I}-\mathrm{P}-\mathrm{Z} 4^{\mathrm{c}}$ & $133^{\mathrm{a}}$ & 138 & 2.7 & 7 \\
\hline J-P-Z4 & $153^{3}$ & 152 & 3.6 & 12 \\
\hline K-P-Z4 & $139^{a}$ & 151 & 3.1 & 7 \\
\hline $\mathrm{L}-\mathrm{P}-\mathrm{Z} 4 \mathrm{~A}^{\mathrm{b}}$ & $126^{\mathrm{a}}$ & 105 & 1.5 & 36 \\
\hline L-P-Z4 B B & $98^{\mathrm{a}}$ & 82 & 1.5 & 36 \\
\hline L-P-Z4 C & $141^{\mathrm{a}}$ & 117 & 2.0 & 38 \\
\hline M-P-Z4 & $109^{a}$ & 119 & 3.4 & 42 \\
\hline $\mathrm{N}-\mathrm{P}-\mathrm{Z} 4^{\mathrm{c}}$ & $116^{\mathrm{a}}$ & 116 & 2.9 & 38 \\
\hline $\mathrm{O}-\mathrm{P}-\mathrm{Z} 4$ & $126^{\mathrm{a}}$ & 139 & 3.4 & 43 \\
\hline P-P-Z4 & $124^{\mathrm{a}}$ & 128 & $2.9^{\circ}$ & 57 \\
\hline
\end{tabular}

a Moments obtained from an analysis program [Cheok, Stone, Lew, 1993] which calculates the moments for a section given an imposed beam rotation.

b These specimens were not tested to failure.

c Bond failure of mild steel.

Shear failure in beam.

- Failure occurred in the aftershock 

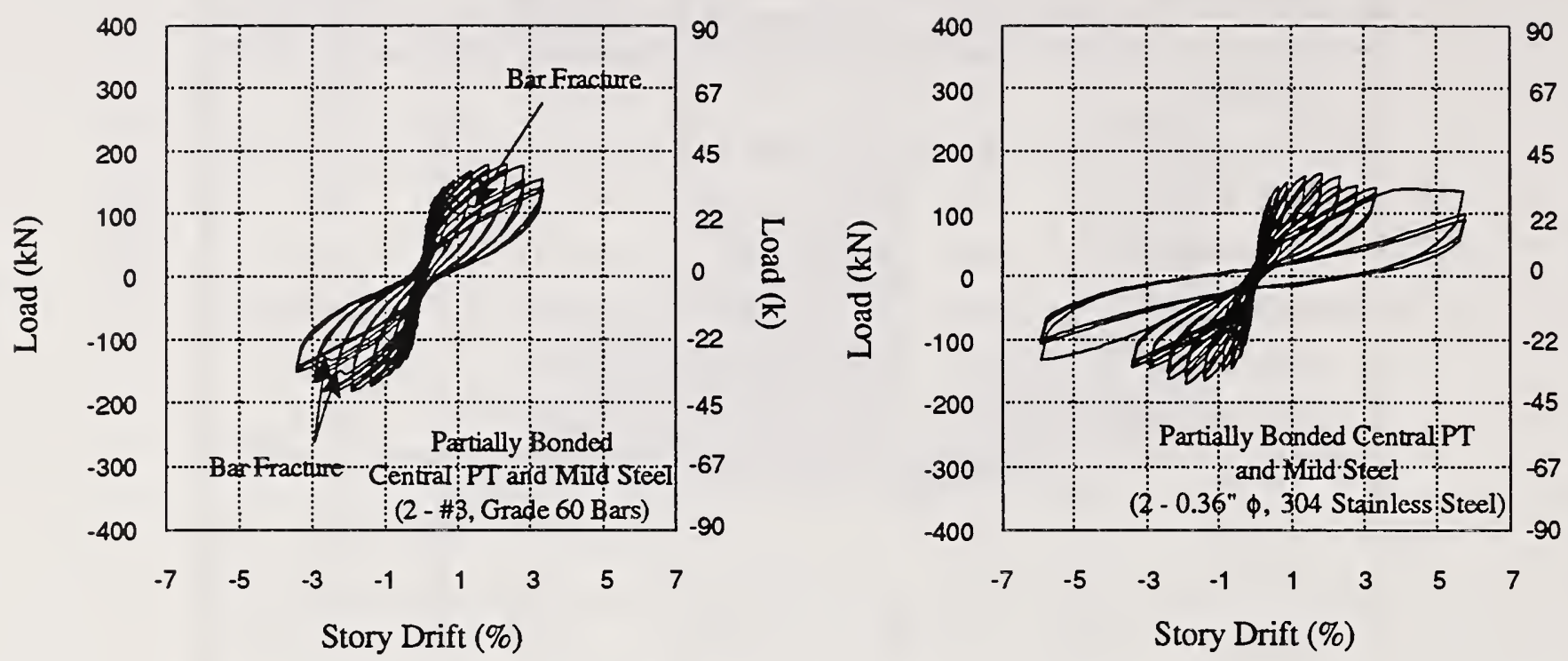

을

Figure 3.22. Hysteresis Curves for M-P-Z4. Figure 3.23. Hysteresis Curves for N-P-Z4.
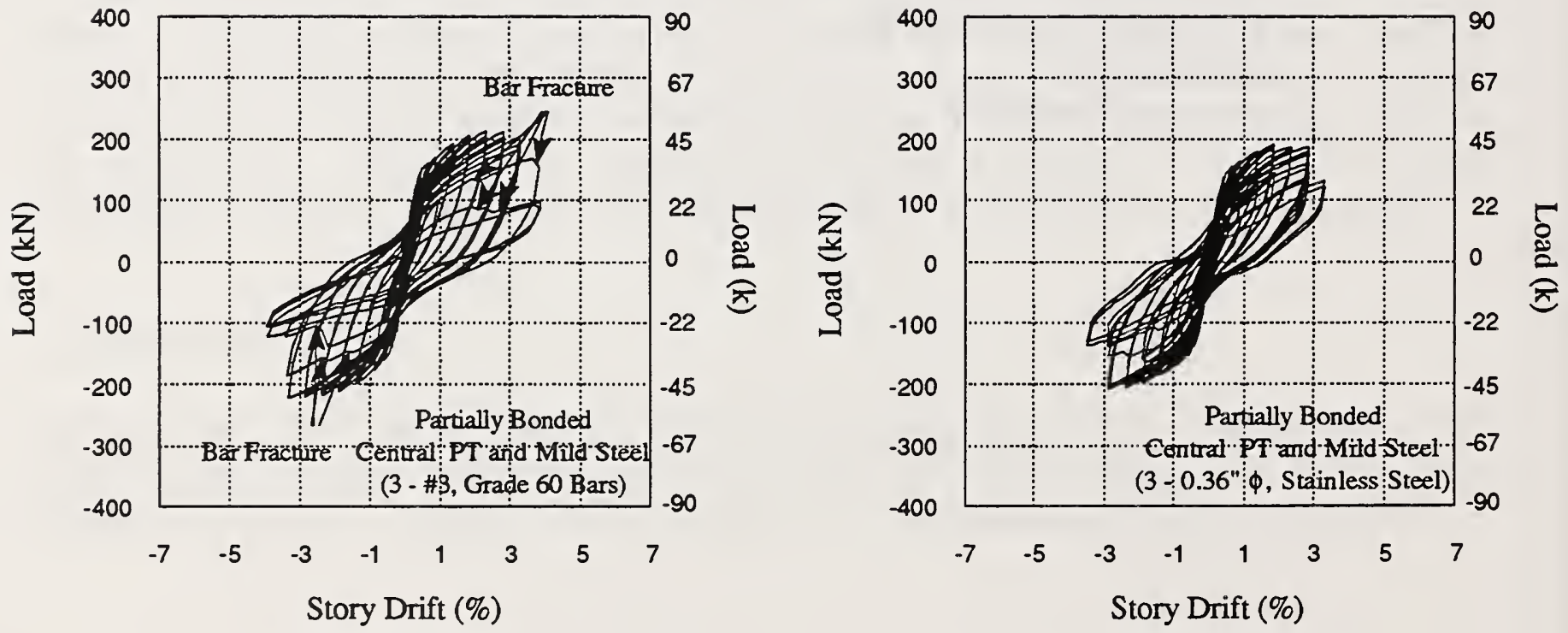

Figure 3.24. Hysteresis Curves for O-P-Z4. Figure 3.25. Hysteresis Curves for P-P-Z4. 


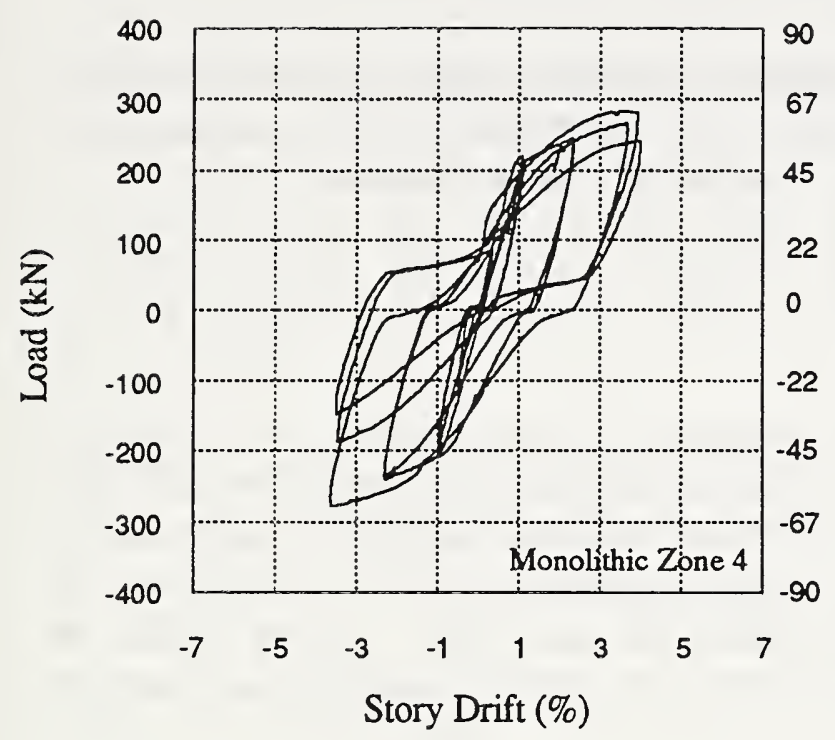

Figure 3.26. Hysteresis Curves for A-M-Z4. Figure 3.27. Hysteresis Curves for B-M-Z4.

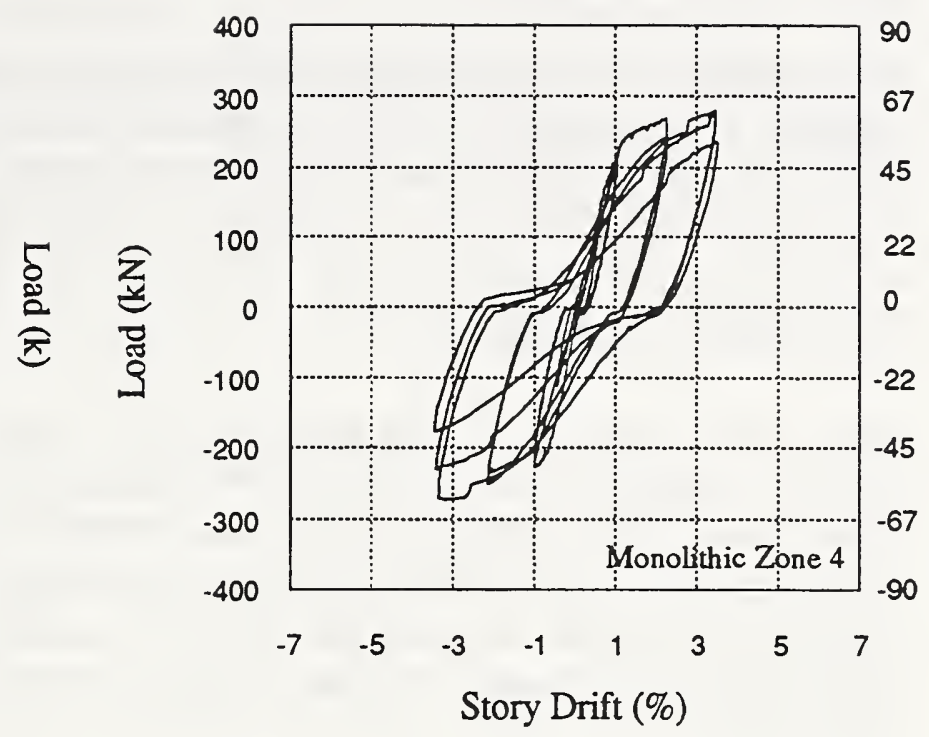

응

As seen in Table 3.2, the Phase IV B specimens had slightly lower story drifts than did the two monolithic zone 4 specimens. However, it is the opinion of the authors that the story drifts for the Phase IV B specimens would have been slightly higher than those given in Table 3.2 had these specimens been subjected to the same loading history as the monolithic specimens. The number of cycles that the Phase IV B specimens were subjected to was at least 4 times that of the monolithic Zone 4 specimens.

\subsection{Connection Strength}

The connection strengths are given in Table 3.2. The predicted moments for the monolithic specimens were calculated based on the actual yield stress of the steel with a factor of 1.25 applied to it to account for steel strain hardening, the 28-day concrete compressive strength and an ultimate concrete strain of 0.003 . The predicted moments for the precast specimens were calculated using program B6.FOR [Cheok and Stone, 1993]. In brief, steel strain hardening is accounted for in the program by using the stress-strain curve for the given steel which includes values through bar fracture. The concrete compression force was computed based on a triangular stress distribution up to steel yield and on the Whitney stress block thereafter.

From the predicted moments given in column 2 of Table 3.2, it can be seen that the predicted moments for the Phase IV B specimens are lower than those for the monolithic zone 4 specimens. As a result, the experimental moments for the Phase IV B specimens are slightly lower than those for the monolithic Zone 4 specimens. However, it can be reasoned that if the 
predicted moments for the Phase IV B specimens were similar to the monolithic Zone 4 specimens, the experimental moments for the Phase IV B specimens would be comparable to the monolithic specimens.

As seen in Table 3.2, the experimental moments obtained for the monolithic specimens were on average $14 \%$ greater than the calculated moments. For the Phase IV B specimens, the experimental moments were on average $4 \%$ higher than the predicted moments.

\subsection{Energy Dissipation}

Due to the different yield displacements and concrete strengths for the specimens, it was felt that the most practical means of comparing the energy dissipation was to plot the dimensionless cyclic energy dissipated against the story drift. The dimensionless quantity of cyclic energy dissipated was determined by dividing the energy dissipated per cycle by the product of the maximum predicted moment and the story drift (percent) for that cycle. In Fig. 3.28, the normalized cyclic energy is plotted against the story drift and a best-fit curve is drawn through these points.

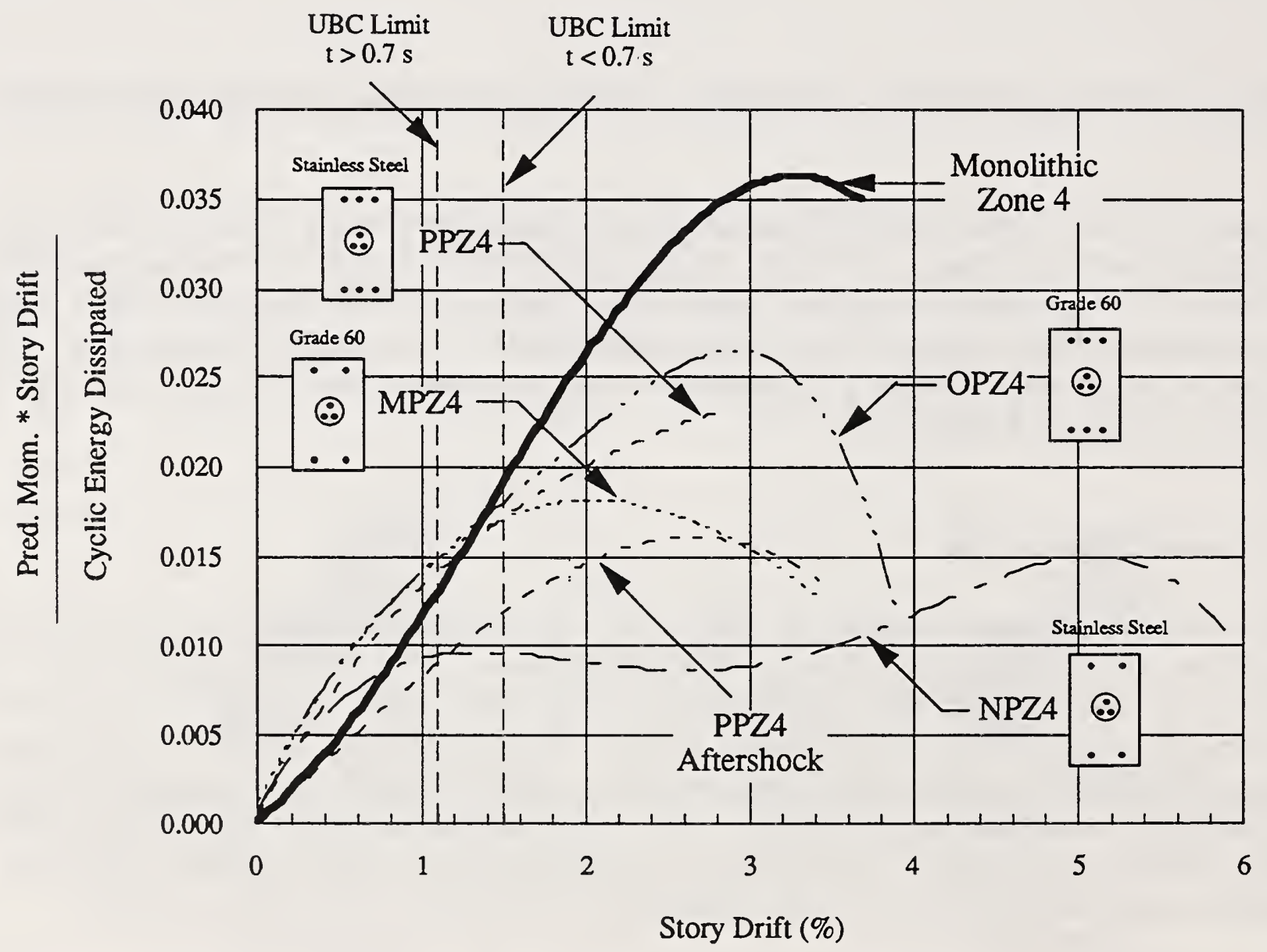

Figure 3.28. Comparison of the Normalized Cyclic Energy for Phase IV B Specimens. 
As shown in Fig. 3.28, the precast specimens (M-P-Z4, O-P-Z4 and P-P-Z4) matched the behavior of the monolithic specimen up to approximately $1.5 \%$ story drift. The code-allowed drift for the prototype structure is approximately $1.1 \%$. As seen in Fig. 3.28, the Phase IV B specimens did not perform as well as the monolithic specimen after $1.5 \%$ story drift. Two points should be made at this stage. As mentioned earlier, the monolithic specimens were subjected to a total of 8 cycles prior to failure whereas the Phase IV B specimens were subjected to more than 4 times that number of cycles. Also, recent studies [e.g. Priestley and Tao, 1993] have shown that the while some energy dissipation is necessary to control deflections, the benefits at higher drift levels is unclear. This is because the displacements of the structure are more strongly influenced by the individual characteristics of the earthquake than by the amount of energy dissipated.

The poor performance of N-P-Z4 was due to premature bond failure of the mild steel. It should be noted that in Fig. 3.28 no data points exist between 3.5 and $6.0 \%$ story drifts for N-P-Z4. The performance of O-P-Z4 which had 50\% more mild steel than M-P-Z4 was similar to that of M-P-Z4 up to $1.5 \%$ story drift. Thereafter, a distinct difference exists between the two curves (Fig. 3.28). The performance of specimen O-P-Z4 was approximately $50 \%$ better than that of M-P-Z4 beyond $1.5 \%$ story drift. The normalized energy curve for P-P-Z4 in the aftershock is approximately $75 \%$ of the original P-P-Z4 curve. This is more clearly shown in Fig. 3.29 which shows the cyclic energy dissipated for P-P-Z4.

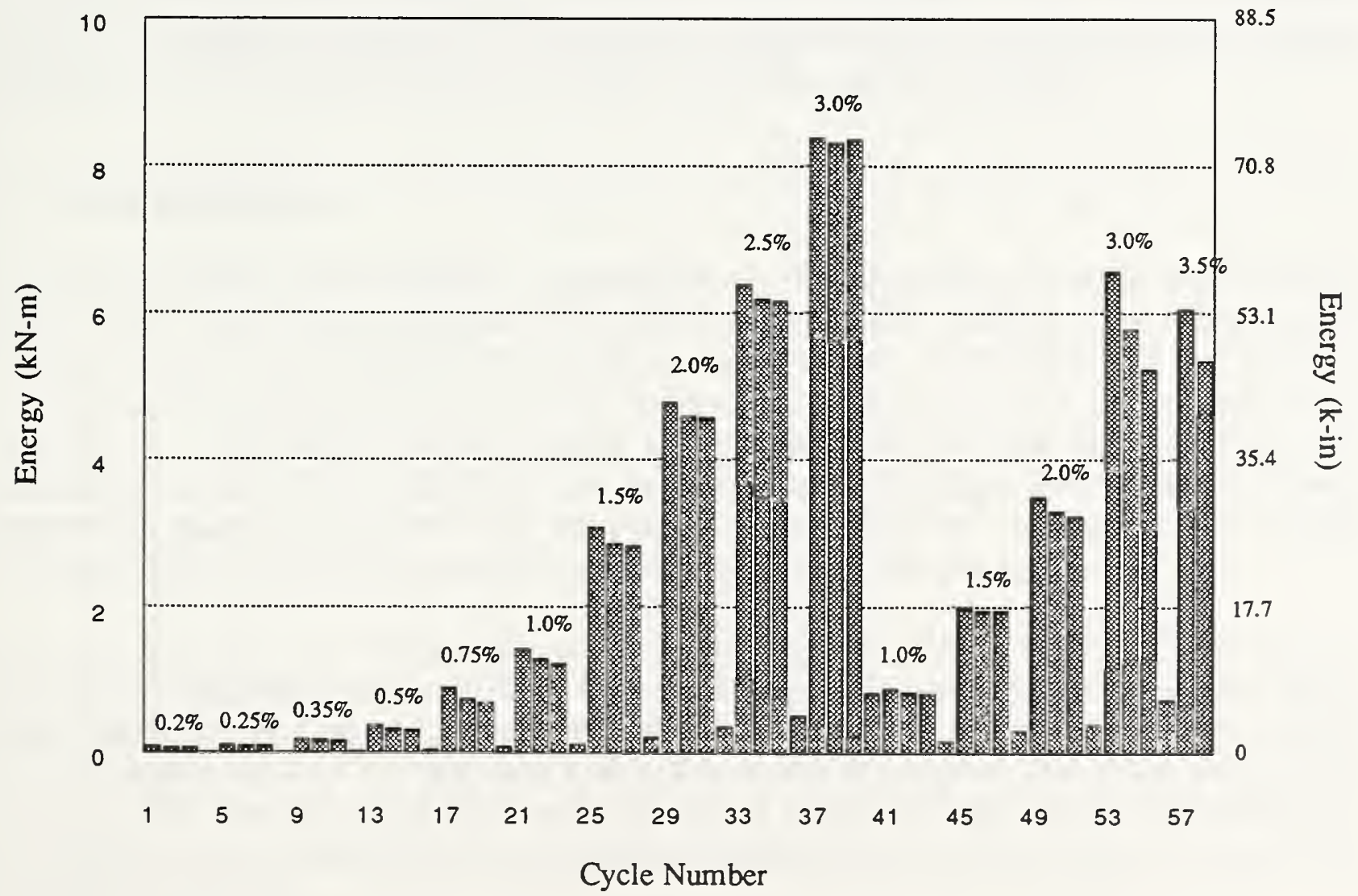

Figure 3.29. Cyclic Energy Dissipation for P-P-Z4. 
A comparison of specimens P-P-Z4 (304 stainless steel) and O-P-Z4 (Grade 60 reinforcing bar) shows no clear improvement in performance in terms of cyclic energy dissipation. It is possible that specimen P-P-Z4 (Fig. 3.27) would have attained higher drift levels with similar energy dissipation had the specimen been subjected to the same loading history as O-P-Z4. It is, however, not possible to assess the contribution towards bar fracture due to fatigue in the bars as a result of the additional 14 cycles which constituted the aftershock.

Another possible explanation for the "mediocre" performance of the 304 stainless steel was the "fabrication" of the deformations (ribs) on the bars. Tension tests of the machined stainless steel bars showed that these bars exhibited total elongation of approximately $30 \%(51 \mathrm{~mm}$ gage length) as opposed to the $55 \%$ (51 mm gage length) obtained for a 304 stainless steel bar that was not machined. Fracture of these test coupons occurred at the transition from the ribs to the reduced area as occurred in the specimen tests. Therefore, if deformed 304 stainless steel bars made in the same manner as regular reinforcing bars had been available, the performance of the connections with these bars might have been better. 


\subsection{CONCLUSIONS AND FUTURE RESEARCH}

\subsection{Summary and Conclusions}

A total of 22 concrete beam-column connection tests constituted a multi-year test program at NIST on precast concrete connections. Four of these connections were monolithically cast while the remaining 18 were post-tensioned, precast connections. The objective of the test program was to develop recommended guidelines for moment resisting precast beam-column connections. Variables included the amount and placement of the post-tensioning steel, the type of bonding of the post-tensioning steel (full, partial, none), the use of low strength steel with post-tensioning (hybrid connection), and the type and amount of low strength steel. This report summarizes the results of the hybrid connection tests.

The hybrid connections consisted of partially bonded prestressing steel located at the centroid of the beam and low strength, non-prestressed steel located at the top and bottom of the beam. The low strength steel was debonded $25 \mathrm{~mm}$ on either side of the beam-column interface to delay fracture of the bars.

The results show that a hybrid connection can be designed to match or exceed the performance of a similar monolithic connection in terms of connection strength, drift capacity, energy dissipation, residual drift, and damage to the concrete. The hybrid connection provides a means of connecting the precast members for large forces in severe seismic zones. It takes advantage of the best features of precast construction and combines them with the hysteretic damping characteristics of a conventional cast-in-place reinforced concrete structure.

\subsection{Code Implications}

Anticipated inelastic drift demand, as prescribed by UBC [Sections 2334(h)2 and 2337(b)4, ICBO, 1991], varies with the period of the structure. For office buildings employing moment resistant frames, the anticipated drift demand can be shown to be $1.5 \%$ and $1.12 \%$ for structures with first mode periods of less than $0.7 \mathrm{~s}$ and for structures with periods greater than $0.7 \mathrm{~s}$, respectively. The NIST test data clearly indicate that, even for the more rigorous drift demand level of $1.5 \%$, hybrid precast beam-column connections exceed the structural (hysteretic) damping capacity of an equivalent monolithic joint. In addition, they exhibit minimal residual drift and the precast elements sustain very little damage.

Beyond a drift level of $1.5 \%$ and up to a drift level of approximately $3.5 \%$, monolithic (cast-inplace) joints exhibited between $30 \%$ to $90 \%$ more structural damping than the precast joints, depending on the amount of dissipative steel in the precast joints. However, this extra damping was obtained at a cost of the total destruction of the monolithic beams. For drifts ranging from $1.5 \%$ to $3.5 \%$, hybrid precast joints which contained greater amounts of mild steel relative to the prestress steel produced structural damping characteristics that were closer to those of the monolithic specimens.

More importantly, destruction of the dissipative elements in the precast joint does not lead to failure of the joint (as it would in a monolithic joint). There is a "soft" failure wherein 
significantly greater drift capacity remains, since at $3.5 \%$ drift the central prestress tendons still remained elastic. In the hybrid specimen tested to $6 \%$ story drift, a strength level of approximately $55 \%$ of maximum moment capacity was maintained after 3 cycles at $6 \%$ drift. Of course, no one will design to this drift level, but the point is that the hybrid precast connection detail is inherently safer than a monolithic design in the face of unanticipated drift demand due to this redundant moment resisting mechanism.

\subsection{Future Research}

Based on the results of the NIST precast concrete connection program, it has been shown that a hybrid connection can be designed to resist seismic loading. However, the development of design guidelines will require that further studies be conducted to broaden the current database. These studies include:

- Analytical studies on the inelastic behavior of precast connections. Some studies have already been conducted by Mole [1994] and by Priestley and Tao [1993].

- Additional static tests of hybrid connections with varying amounts and types of PT and mild steels, and with varying levels of initial PT stress. The effects of different loading histories should also be investigated.

- Cyclic load tests to determine conservative development lengths for deformed energy dissipators which are grouted into precast ducts. Problems with two NIST beam-column joint specimens indicated that the development lengths for cast-inplace deformed reinforcement used in seismic zones as specified by ACI may not be conservative for deformed reinforcement grouted into pre-existing ducts.

- Shake table tests to determine the dynamic properties of the connections.

- Tests of frames incorporating hybrid connections.

As discussed earlier, hysteretic damping may play a less significant role in structural behavior than the site-dependent earthquake characteristics. Currently, inelastic, transient analysis tools employing robust hysteretic models exist to design hybrid precast buildings which will meet the strength and drift requirements of the UBC. It will, however, be some time before these tools are available to a general structural design office. As an interim solution, parametric analyses are being performed at NIST to develop equivalent $R_{w}$ factors for various classes of precast beam-column joints employed in structures of varying height founded on representative UBC soil types. These analyses will be conducted using a 7-parameter derivative of the program ICARC [Kunnath, Reinhorn, and Lobo, 1992]. The parameter identification will be carried out using the NIST in-house code NIDENT5. 


\section{ACKNOWLEDGEMENTS}

The assistance of Mr. Frank Rankin, Mr. Max Peltz, Mr. Jim Little, and Mr. Erik Anderson of the Structures Division laboratory staff is gratefully acknowledged. Special thanks are extended to Mr. Dean Stephan and Mr. Dave Seagren (both with Charles Pankow Builders, Ltd.) and Dr. John Stanton (University of Washington) for their invaluable support, advice and insight in the Phase IV tests.

The authors would also like to extend their thanks for the technical support from the following individuals: Dr. Robert Englekirk, Dr. Cathy French, Dr. S. K. Ghosh, Mr. Jacob Grossman, Dr. Grant Halverson, Mr. Dan Jenny, Mr. Paul Johal, Mr. Bob Mast, Ms. Suzanne Nakaki, Mr. Courtney Phillips, Dr. Nigel Priestley, Mr. Barry Schindler, and Mr. Norm Scott. The support and/or donations of materials from Charles Pankow Builders, Ltd., Concrete Research and Education Foundation of the American Concrete Institute, Dywidag Systems International, Mr. Hanns Baumann of BauMesh Company, Mr. Chris Campbell of R. A. Campbell Inc., Ms. Marsha Feldstein of Allied Fibers, and Mr. Bob McCulley of Master Builders are gratefully acknowledged. 



\section{REFERENCES}

American Society of Testing and Materials (1988), "Annual Book of ASTM Standards," Vol. 01.04, ASTM, Philadelphia, PA, 1988.

American Society of Testing and Materials (1992), "Annual Book of ASTM Standards," Vol. 01.01, ASTM, Philadelphia, PA, 1992.

Cheok, G. and Lew, H. S. (1990), "Performance of 1/3-Scale Model Precast Concrete Beam-Column Connections Subjected to Cyclic Inelastic Loads," NISTIR 4433, NIST, Gaithersburg, MD, October, 1990.

Cheok, G. and Lew, H. S. (1991), "Performance of 1/3-Scale Model Precast Concrete Beam-Column Connections Subjected to Cyclic Inelastic Loads - Report No. 2," NISTIR 4589, NIST, Gaithersburg, MD, June, 1991.

Cheok, G., Stone, W., and Lew, H. S. (1992), "Partially Prestressed and Debonded Precast Concrete Beam-Column Joints," Proc. of the $3^{\text {rd }}$ Meeting of the U.S. - Japan Joint Technology Coordinating Committee on Precast Seismic Structures Systems, November, 1992.

Cheok, G. and Lew, H. S. (1993), "Model Precast Concrete Beam-to-Column Connections Subject to Cyclic Loading," PCI Journal, Precast/Prestressed Concrete Institute, Chicago, IL, July/August, 1993, pp. 80-92.

Cheok, G. C., Stone W. C. and Lew, H. S (1993), "Performance of 1/3-Scale Model Precast Concrete Beam-Column Connections Subjected to Cyclic Inelastic Loads - Report No. 3," NISTIR 5246, NIST, Gaithersburg, MD, August, 1993.

International Conference of Building Officials (1985, 1988), Uniform Building Code, Whittier, CA, 1985 \& 1988.

Kunnath, S. K., Reinhorn, A. M., and Lobo, R. F. (1992), "IDARC Version 3.0: A Program for the Inelastic Damage Analysis of Reinforced Concrete Structures," Technical Report NCEER-92-0022, National Center for Earthquake Engineering Research, State University of New York at Buffalo, Buffalo, NY, August, 1992.

Mole, A., (1994), "Seismic Response of Hybrid Connections in Precast Concrete Frames," Master of Science Thesis, University of Washington, December 16, 1994.

Priestley, M. J. N. and Tao, J. R. (1993), "Seismic Response of Precast Prestressed Concrete Frames with Partially Debonded Tendons," PCI Journal, Vol. 38, No. 1, Jan/Feb, 1993, pp. $58-69$. 

APPENDIX A: SPECIMEN DRAWINGS 



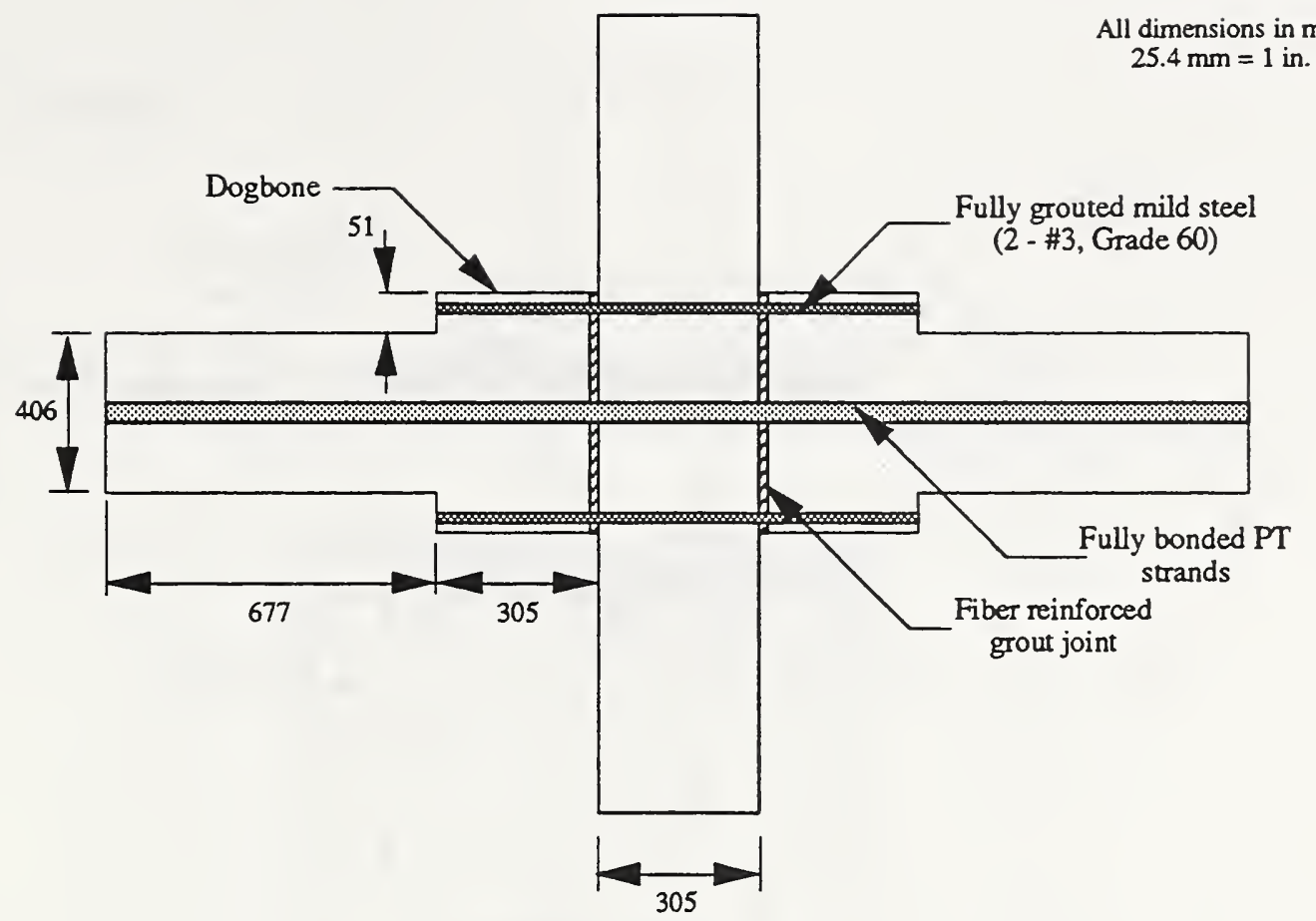

Figure A1. Basic Details for Specimens I-P-Z4 and K-P-Z4 (Phase IV A).

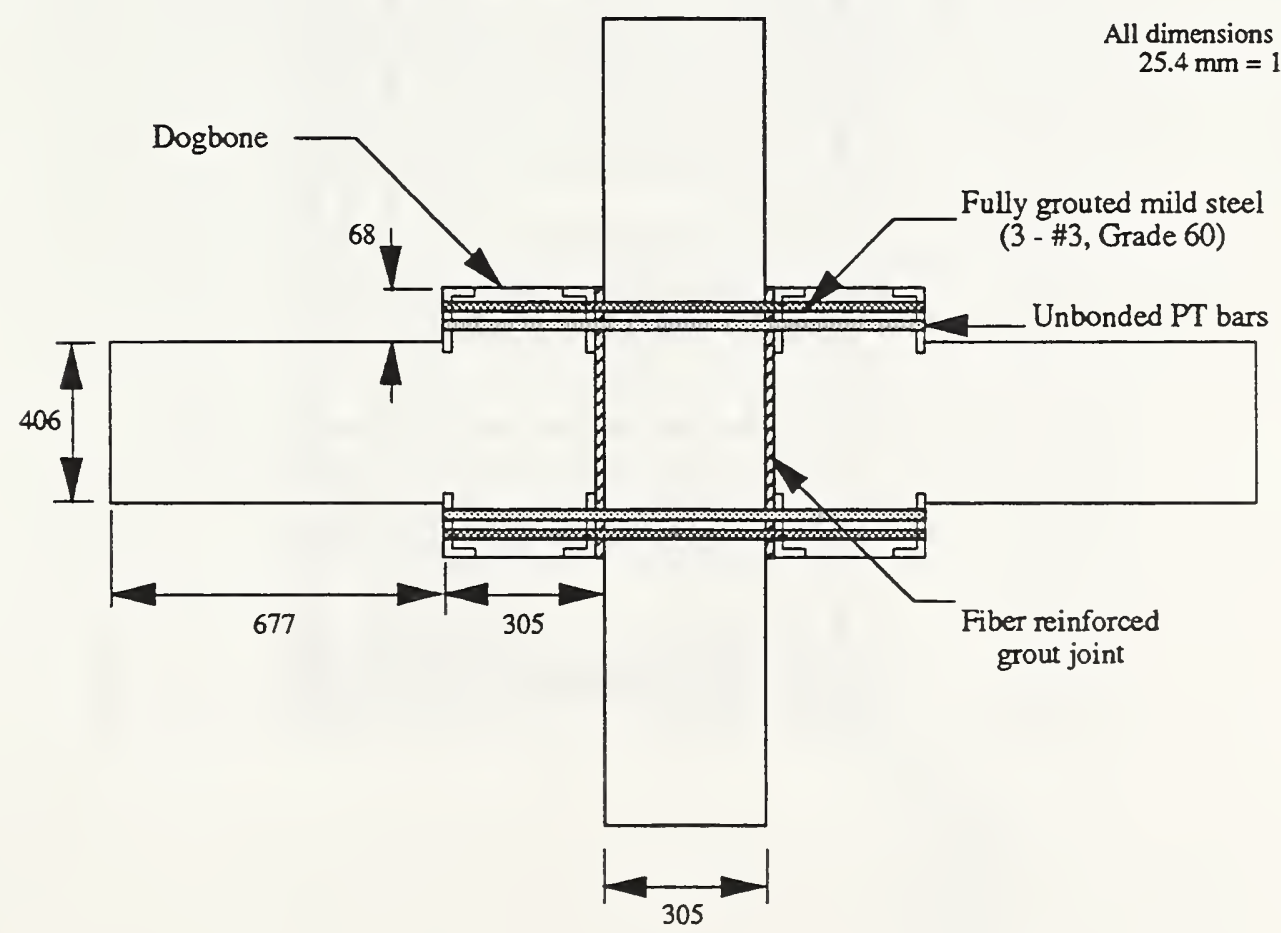

Figure A2. Basic Details for Specimen J-P-Z4 (Phase IV A). 


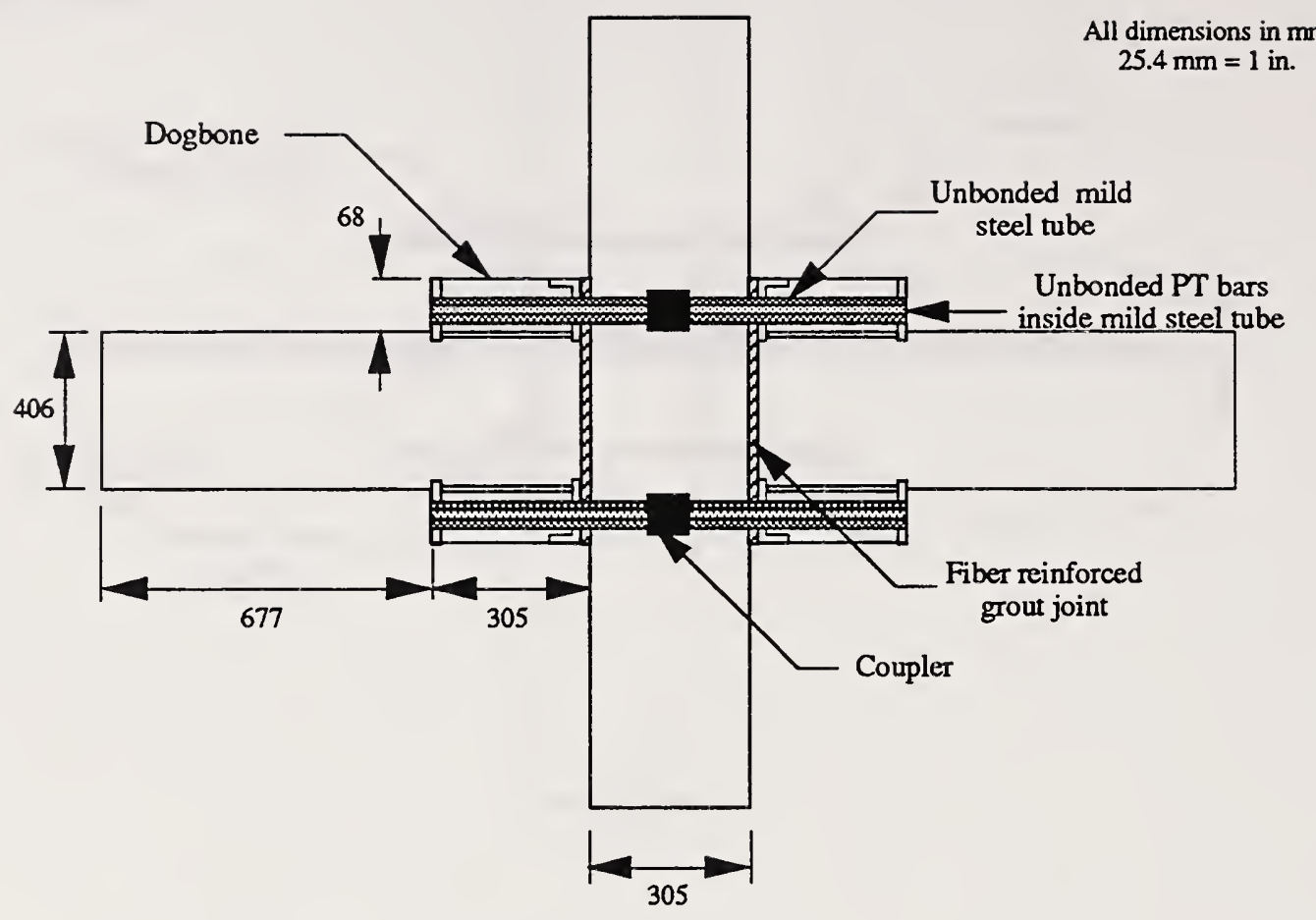

Figure A3. Basic Details for Specimen L-P-Z4 C (Phase IV A). 


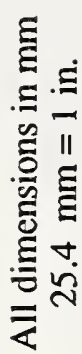

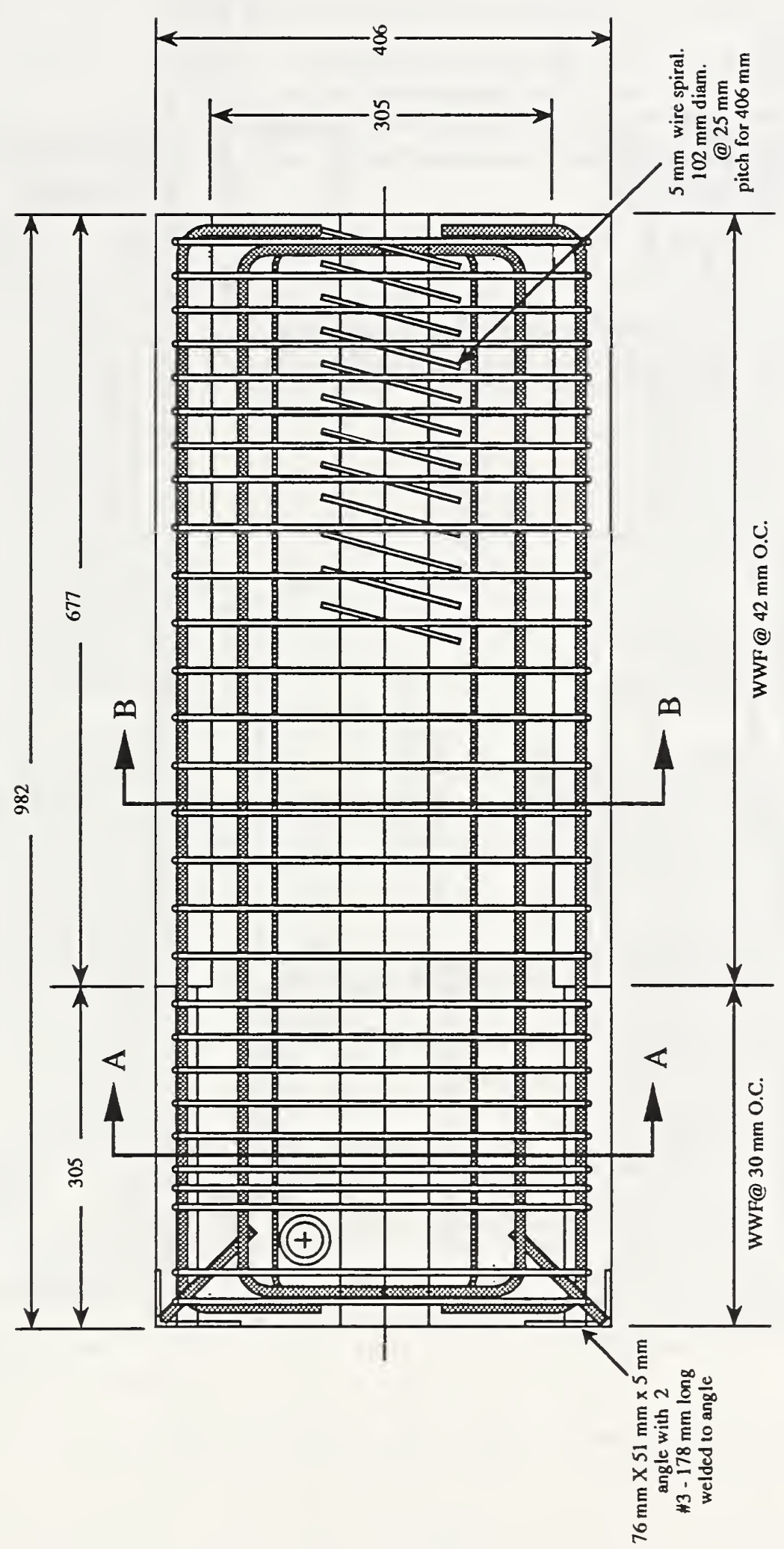

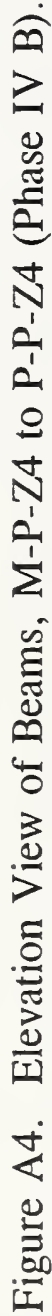




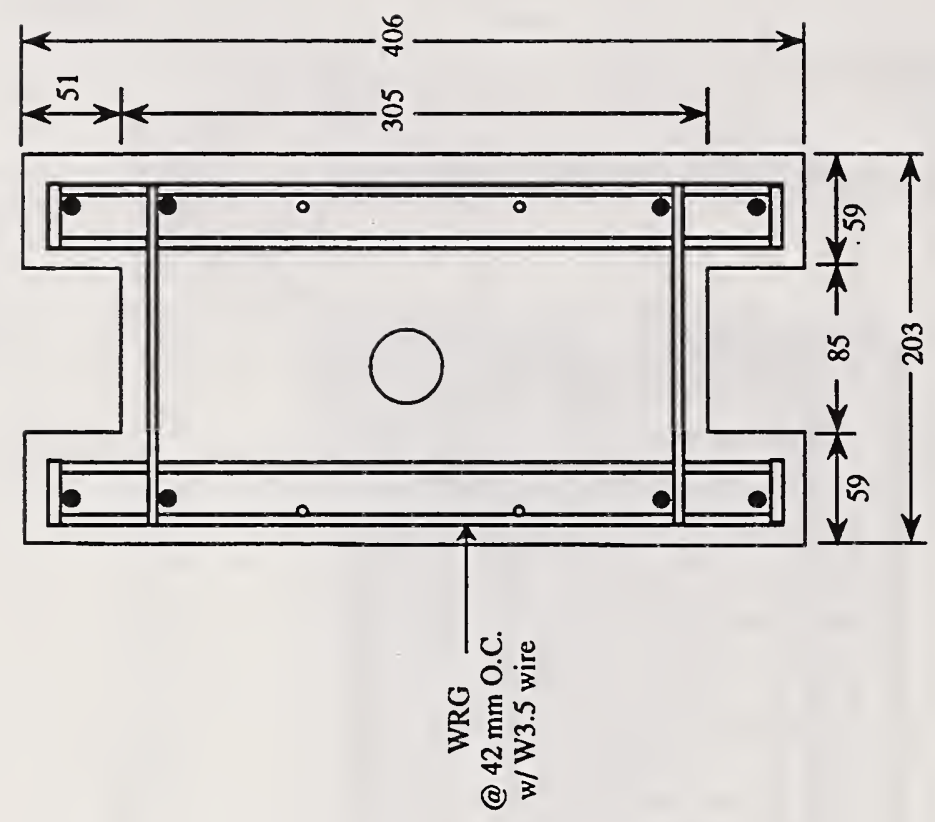

ติ

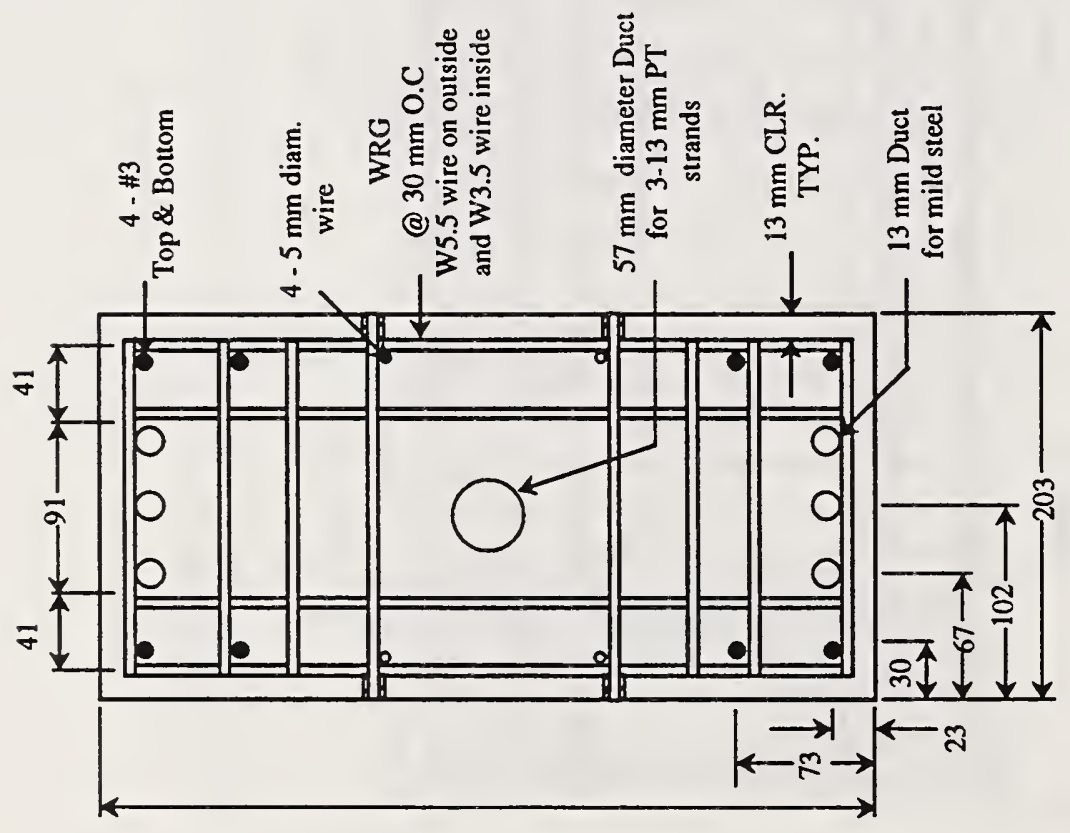

造 
运
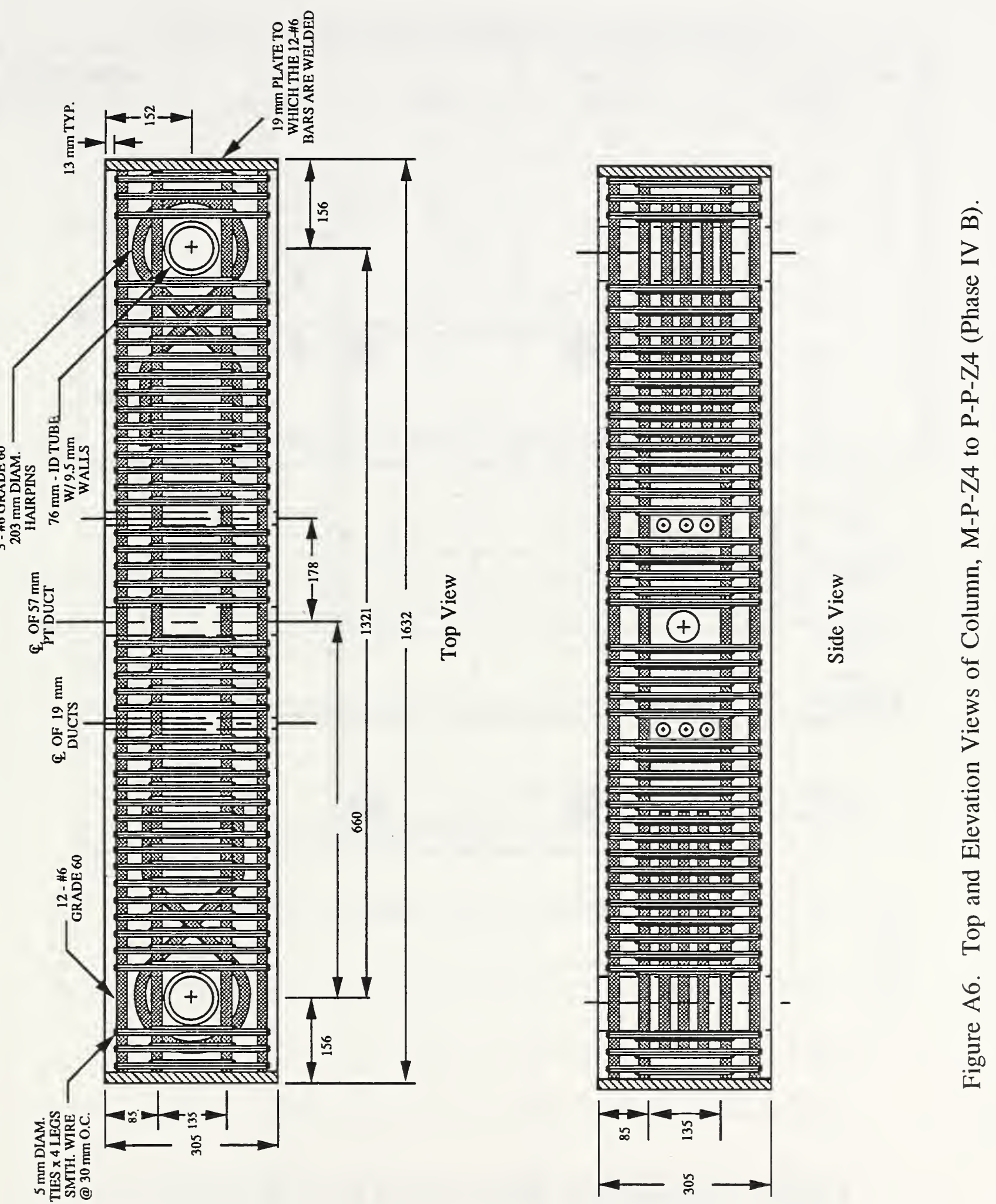
All dimensions in $\mathrm{mm}$ $25.4 \mathrm{~mm}=1 \mathrm{in}$.

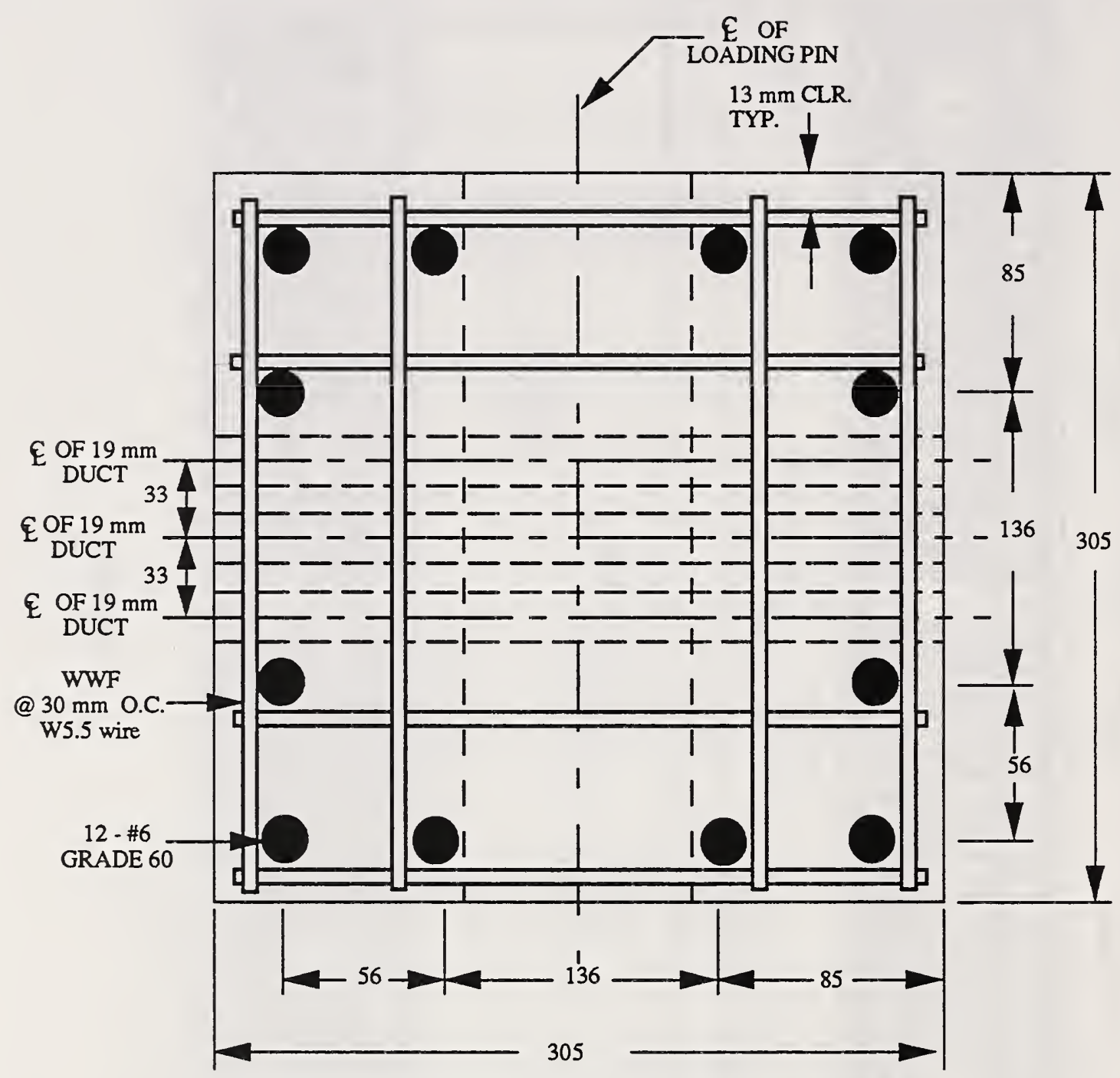

Figure A7. Column Cross Section, M-P-Z4 to P-P-Z4 (Phase IV B). 


\section{APPENDIX B: MATERIAL PROPERTIES}

Table B.1. Compressive Strengths of Concrete and Grout.

\begin{tabular}{|c|c|c|c|c|}
\hline SPECIMEN & $\begin{array}{l}\text { Age } \\
\text { (Days) }\end{array}$ & $\begin{array}{c}\mathbf{f}^{\prime} \\
\text { (MPa) }\end{array}$ & $\begin{array}{l}\text { Duct Grout } \\
\text { (MPa) }\end{array}$ & $\begin{array}{c}\text { Const. Joint Grout } \\
\text { (MPa) }\end{array}$ \\
\hline \multirow[t]{2}{*}{ M-P-Z4 } & 28 & 47 & 73 & 78 \\
\hline & Day of Test & 51 & 61 & 76 \\
\hline \multirow[t]{2}{*}{ N-P-Z4 } & 28 & 47 & 73 & $78^{\circ}$ \\
\hline & Day of Test & 53 & 66 & 80 \\
\hline \multirow[t]{2}{*}{ O-P-Z4 } & 28 & 47 & 73 & 78 \\
\hline & Day of Test & 53 & 80 & 85 \\
\hline \multirow[t]{2}{*}{ P-P-Z4 } & 28 & 47 & 77 & 75 \\
\hline & Day of Test & 53 & 71 & 76 \\
\hline
\end{tabular}

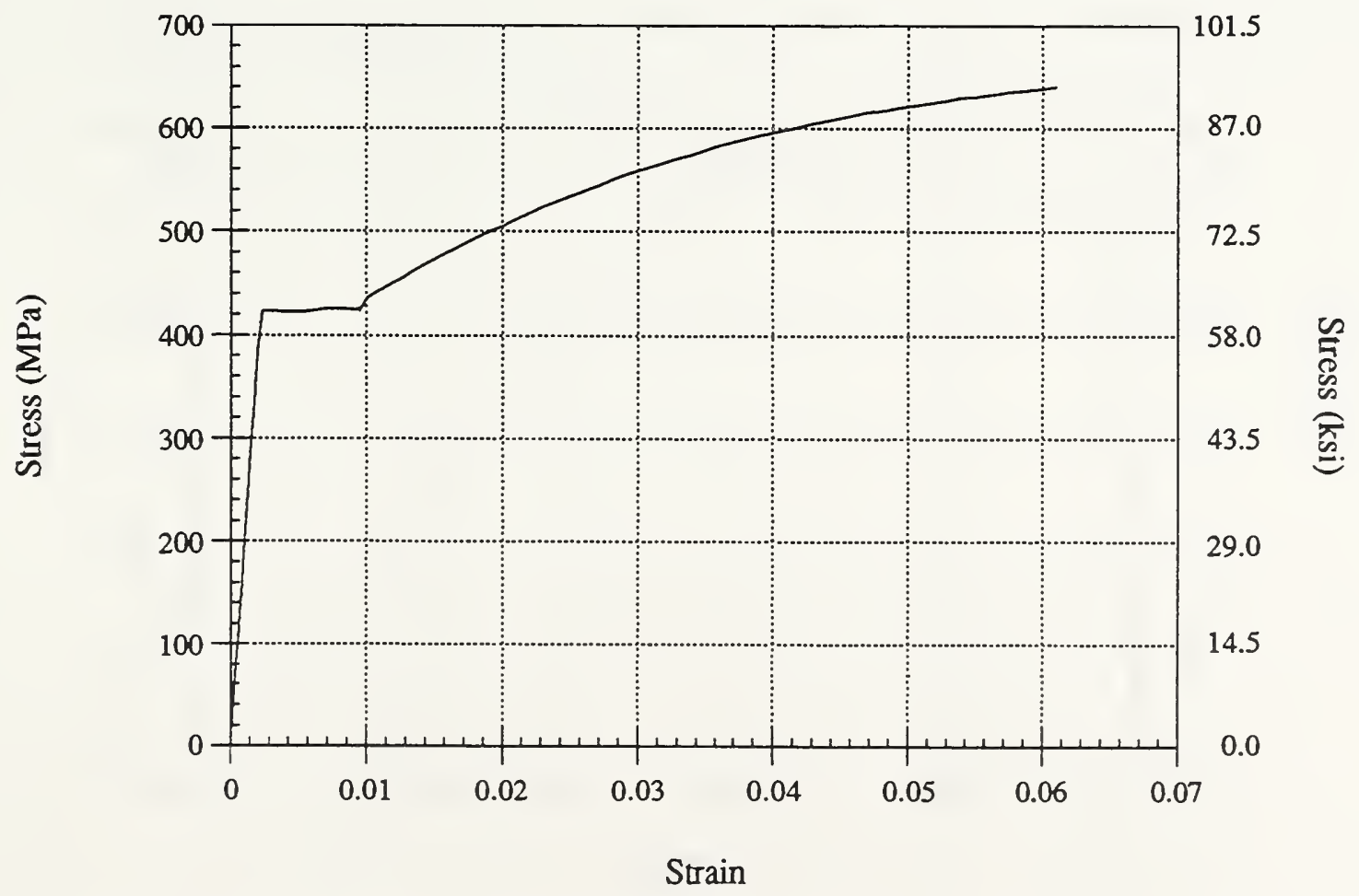

Figure B1. \#3, Grade 60, Reinforcing Bar Used as Mild Steel in M-P-Z4. 


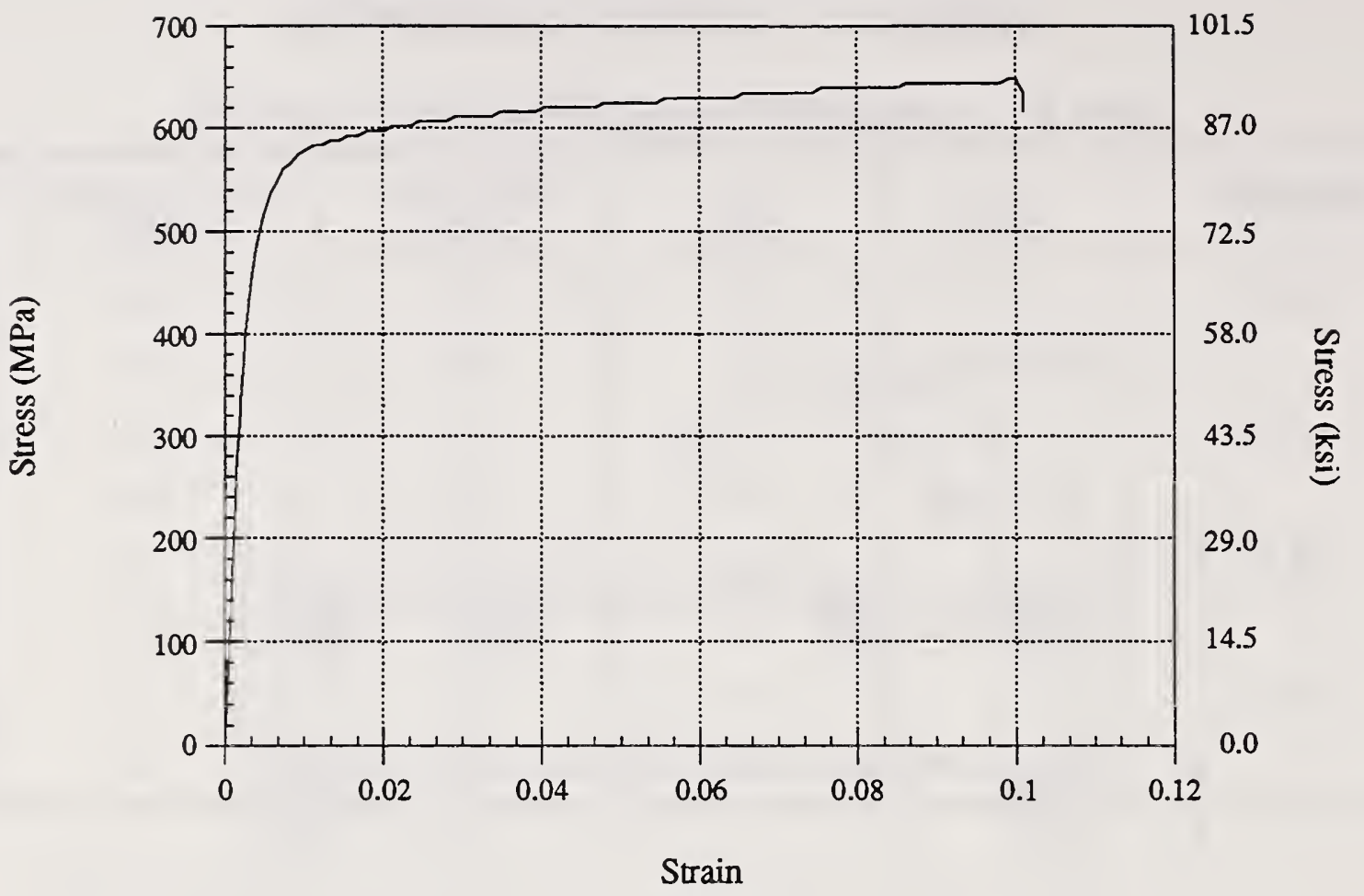

Figure B2. 304 Stainless Steel Bar Used as Mild Steel in N-P-Z4.

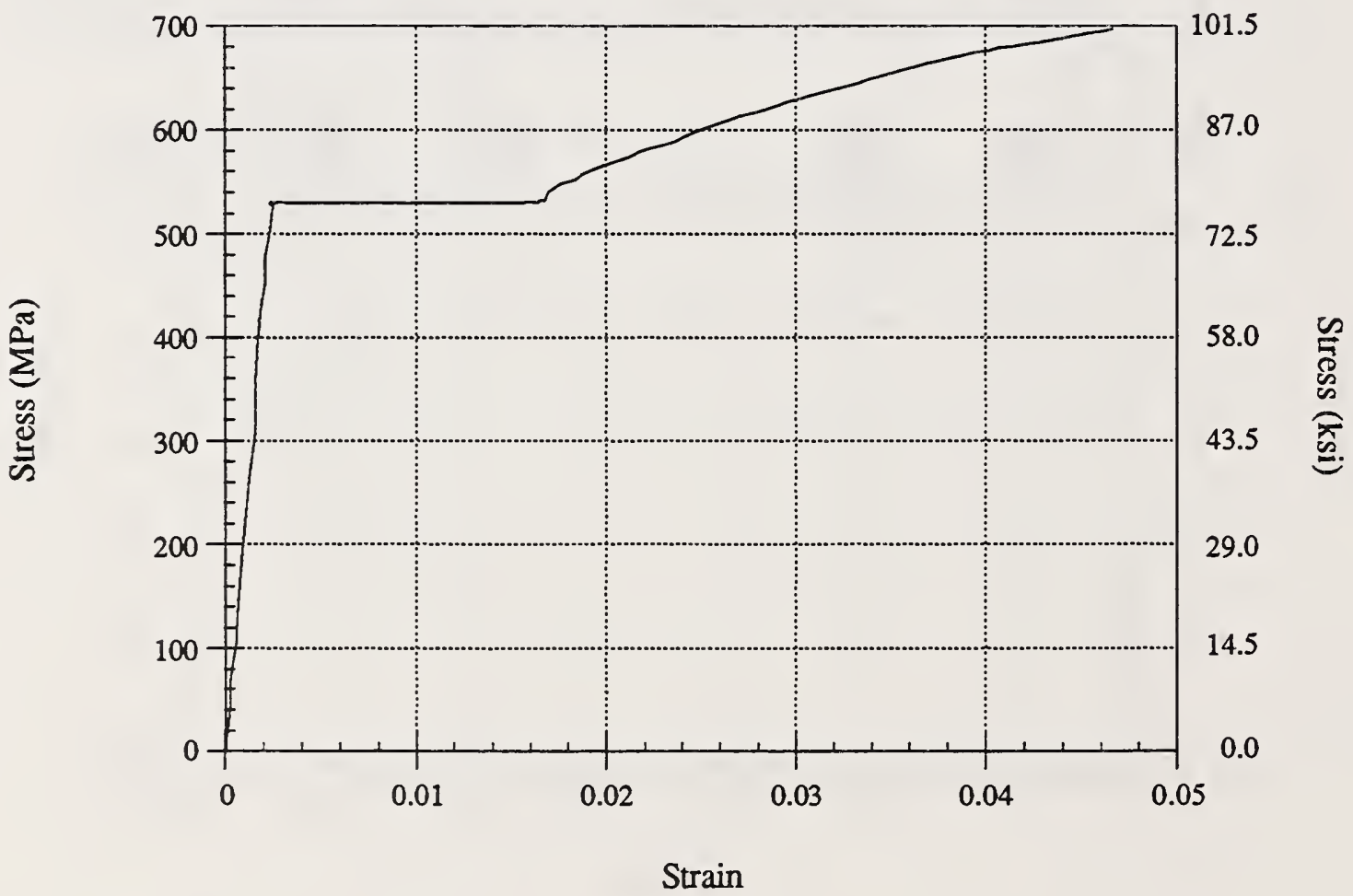

Figure B3. \#3, Grade 60, Reinforcing Bar Used as Mild Steel in O-P-Z4. 


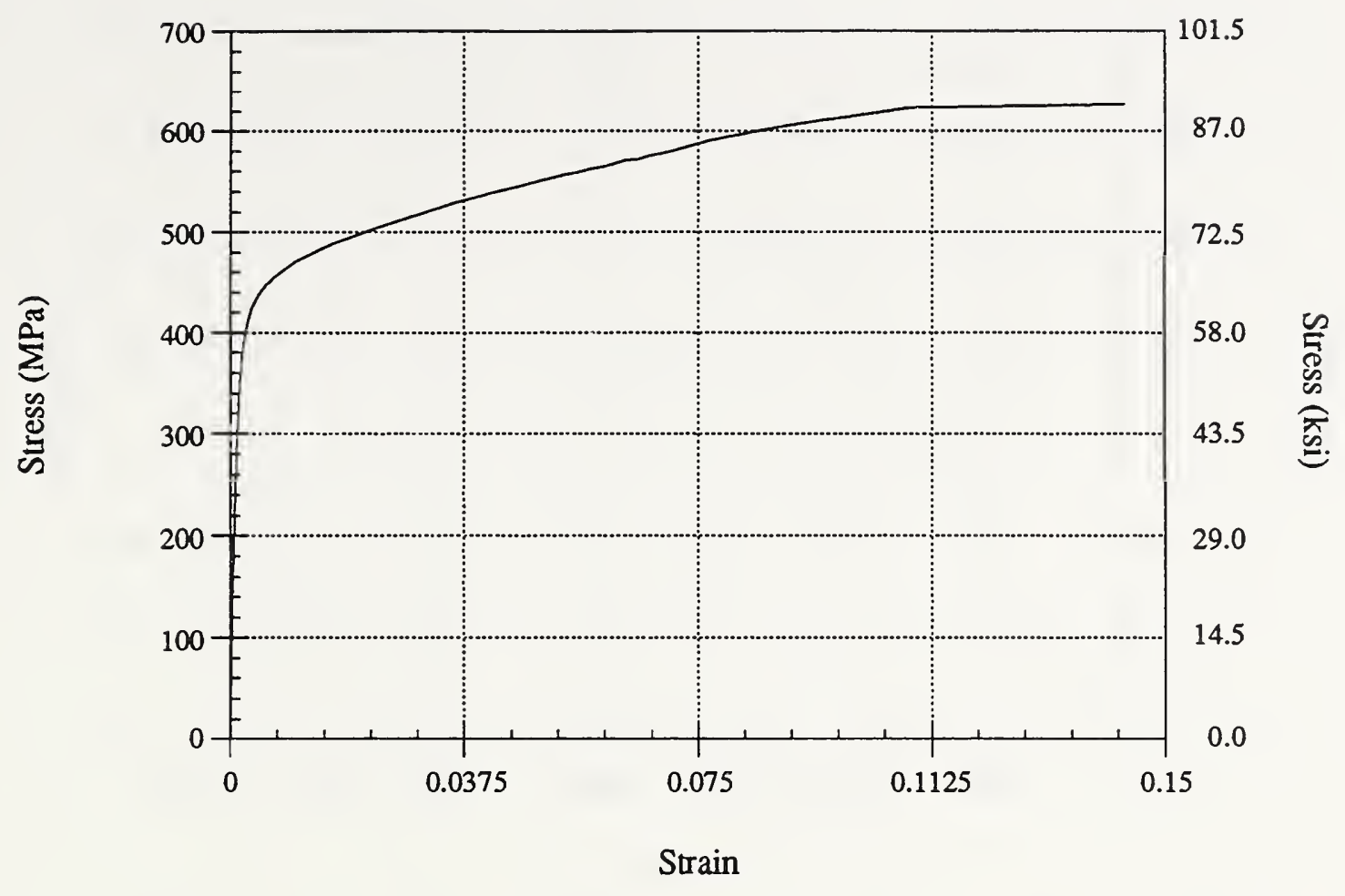

Figure B4. 304 Stainless Steel Bar Used as Mild Steel in P-P-Z4.

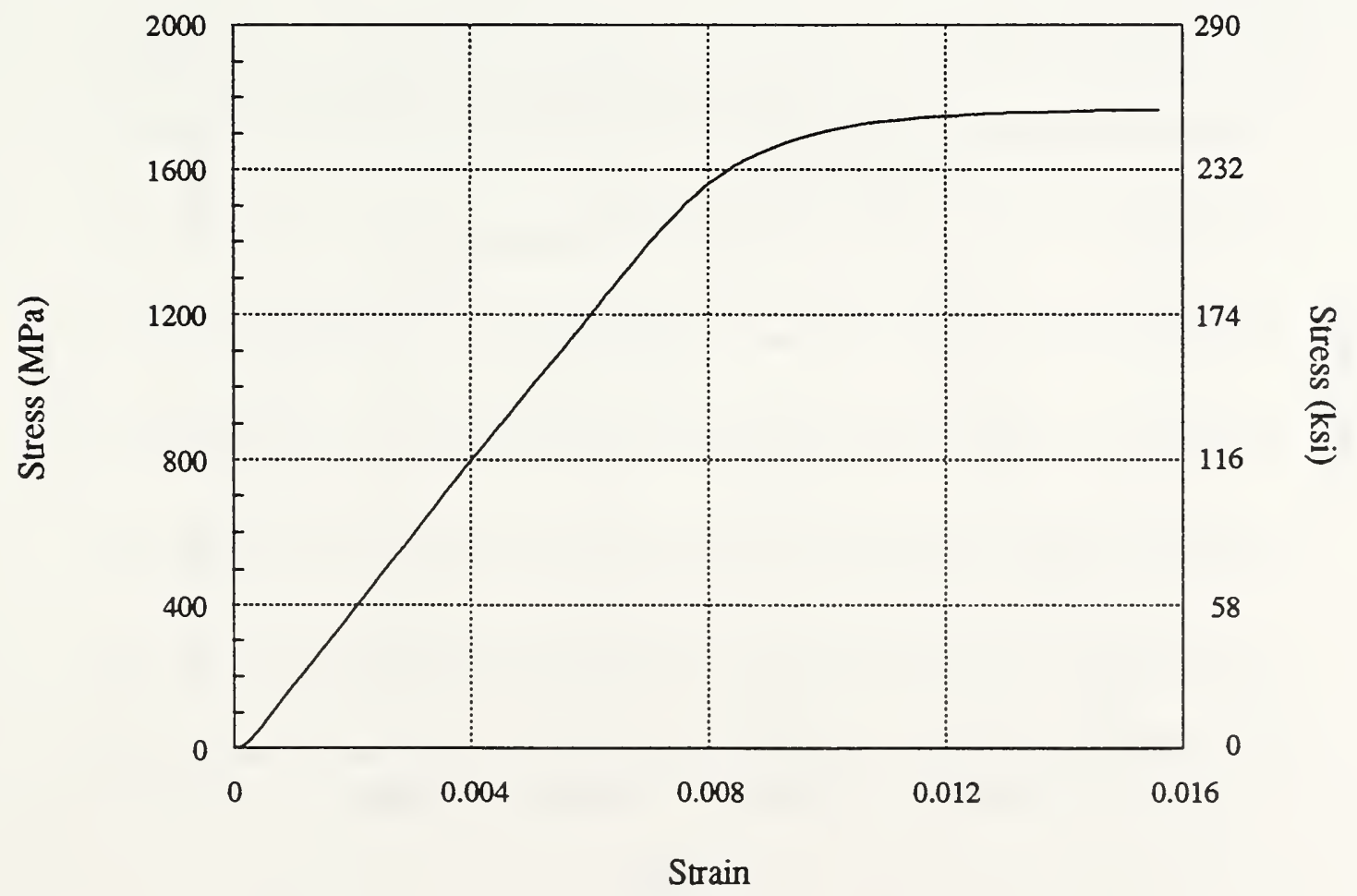

Figure B5. Prestressing Tendon, $13 \mathrm{~mm} \phi$, Grade 270. 


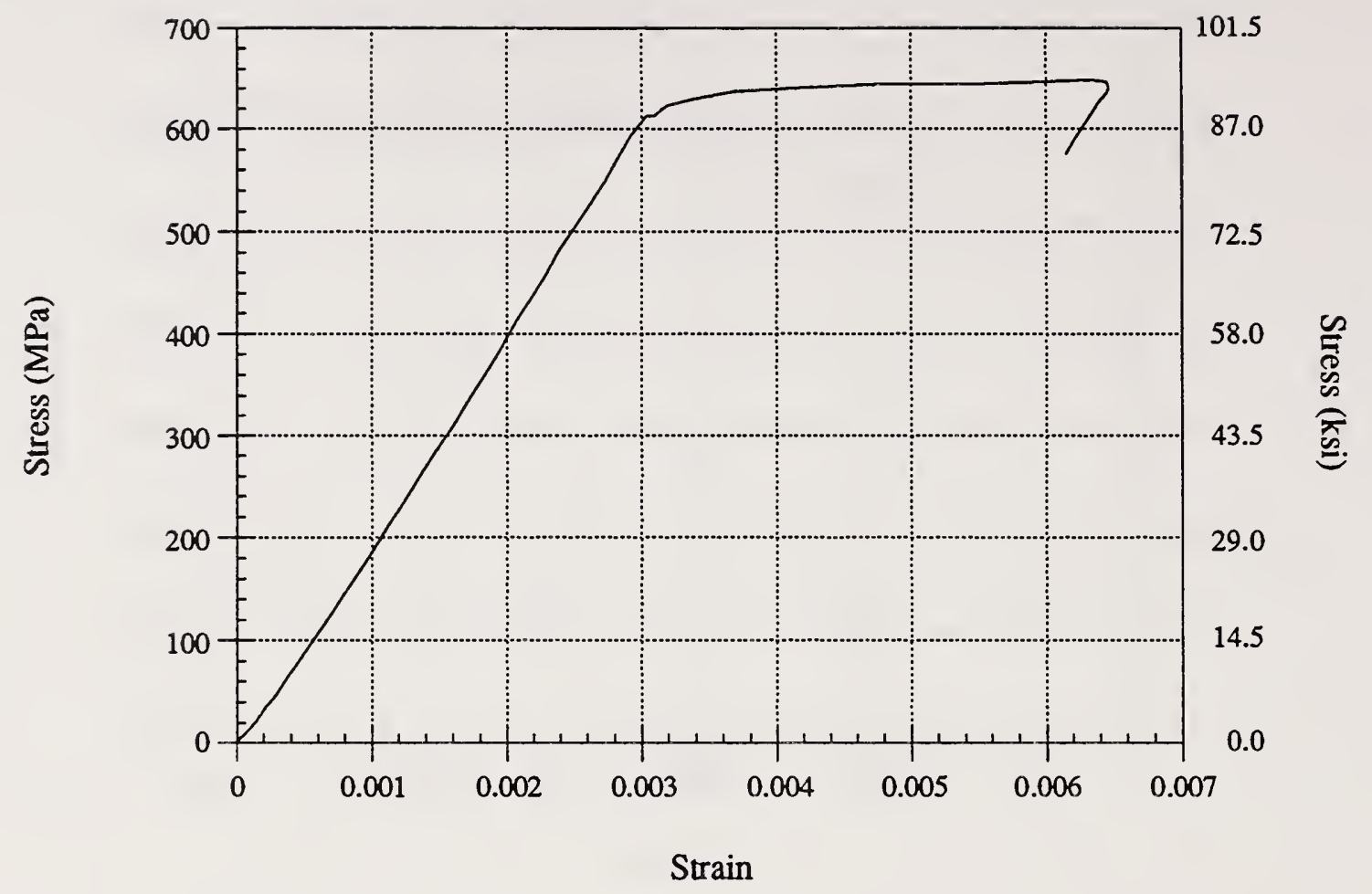

Figure B6. Wire, $5 \mathrm{~mm} \phi$, used in WRG.

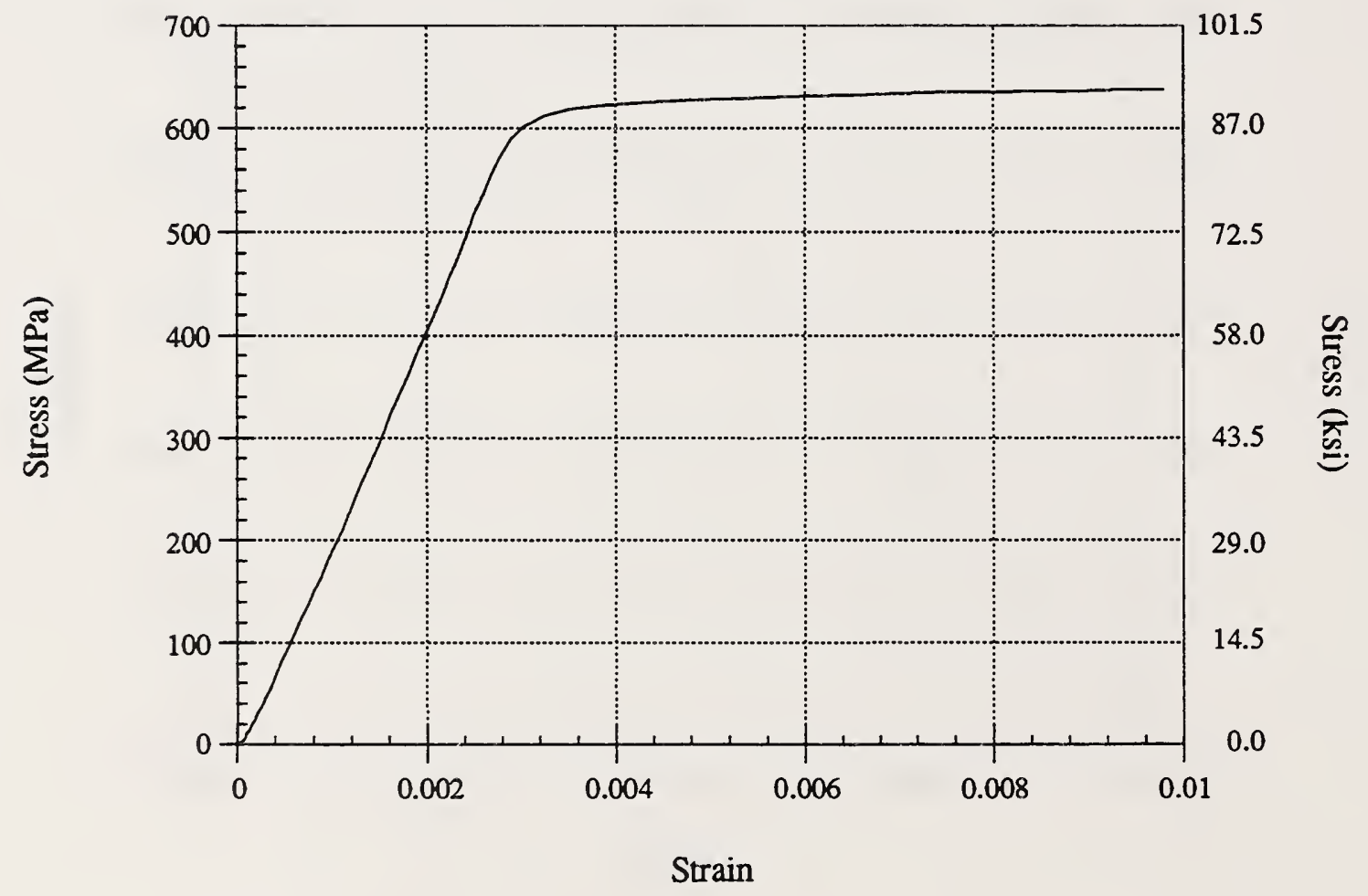

Figure B7. Wire, $7 \mathrm{~mm} \phi$, used in WRG. 


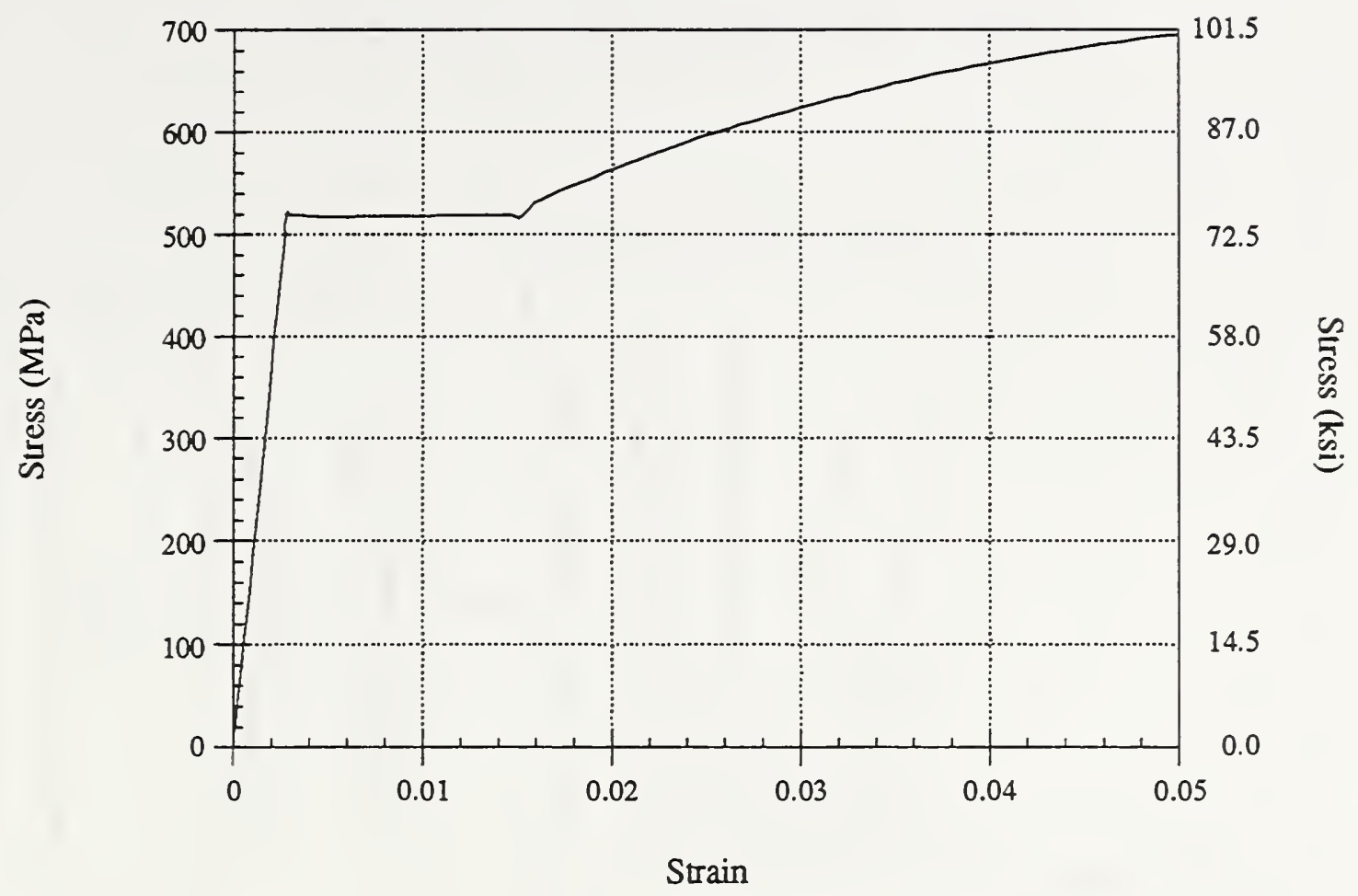

Figure B8. \#3, Grade 60, Reinforcing Bars Used in Beams, M-P-Z4 to P-P-Z4.

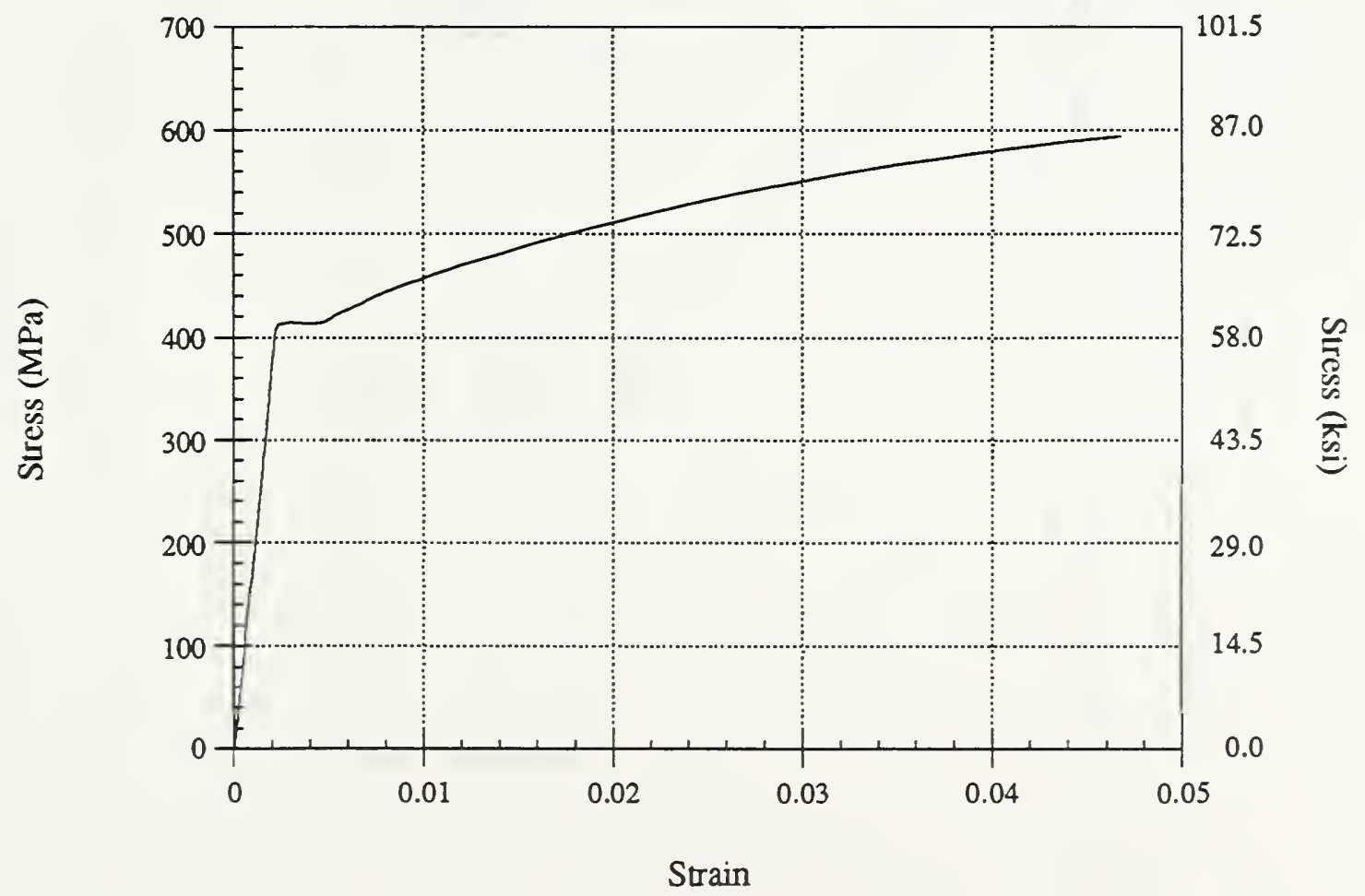

Figure B9. \#6, Grade 60, Reinforcing Bars Used in Columns, M-P-Z4 to P-P-Z4. 



\section{APPENDIX C: ORGANIZATIONAL CHART}

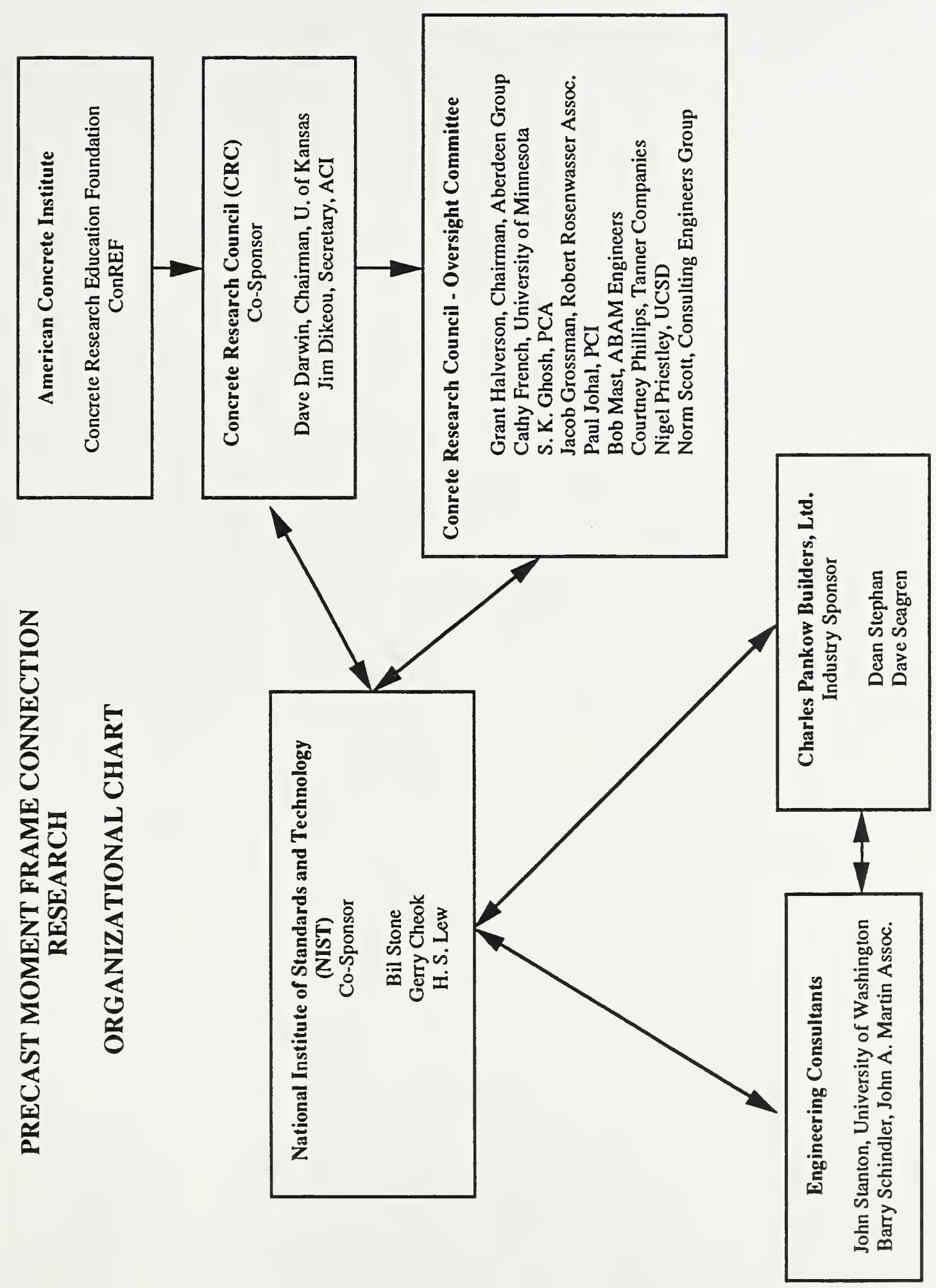




